\title{
Development of Ultrasound Measurement System for Characterizing Viscoelastic Materials Using Ultrasound Reflectance Method
}

By

\author{
Zhen Qu, B. Eng
}

\begin{abstract}
A thesis submitted to
The Faculty of Graduate Studies and Research

in partial fulfillment of the requirements for the degree of

Master of Applied Science in Biomedical Engineering
\end{abstract}

Ottawa-Carleton Institute of Biomedical Engineering (OCIBME)

Department of Systems and Computer Engineering

\author{
Carleton University \\ Ottawa Ontario, K1S 5B6 \\ Canada
}

September 2010

Copyright $(C$

Zhen Qu, 2010 


$\begin{array}{ll}\begin{array}{l}\text { Library and Archives } \\ \text { Canada }\end{array} & \begin{array}{l}\text { Bibliothèque et } \\ \text { Archives Canada }\end{array} \\ \begin{array}{l}\text { Published Heritage } \\ \text { Branch }\end{array} & \begin{array}{l}\text { Direction du } \\ \text { Patrimoine de l'édition }\end{array} \\ \begin{array}{l}\text { 395 Wellington Street } \\ \text { Ottawa ON K1A ON4 } \\ \text { Canada }\end{array} & \begin{array}{l}\text { 395, rue Wellington } \\ \text { Ottawa ON K1A ON4 } \\ \text { Canada }\end{array}\end{array}$

Your file Votre référence

ISBN: 978-0-494-71564-2

Our file Notre référence

ISBN: 978-0-494-71564-2

NOTICE:

The author has granted a nonexclusive license allowing Library and Archives Canada to reproduce, publish, archive, preserve, conserve, communicate to the public by telecommunication or on the Internet, loan, distribute and sell theses worldwide, for commercial or noncommercial purposes, in microform, paper, electronic and/or any other formats.

The author retains copyright ownership and moral rights in this thesis. Neither the thesis nor substantial extracts from it may be printed or otherwise reproduced without the author's permission.
AVIS:

L'auteur a accordé une licence non exclusive permettant à la Bibliothèque et Archives Canada de reproduire, publier, archiver, sauvegarder, conserver, transmettre au public par télécommunication ou par l'Internet, prêter, distribuer et vendre des thèses partout dans le monde, à des fins commerciales ou autres, sur support microforme, papier, électronique et/ou autres formats.

L'auteur conserve la propriété du droit d'auteur et des droits moraux qui protège cette thèse. $\mathrm{Ni}$ la thèse ni des extraits substantiels de celle-ci ne doivent être imprimés ou autrement reproduits sans son autorisation.
In compliance with the Canadian Privacy Act some supporting forms may have been removed from this thesis.

While these forms may be included in the document page count, their removal does not represent any loss of content from the thesis.
Conformément à la loi canadienne sur la protection de la vie privée, quelques formulaires secondaires ont été enlevés de cette thèse.

Bien que ces formulaires aient inclus dans la pagination, il n'y aura aucun contenu manquant.

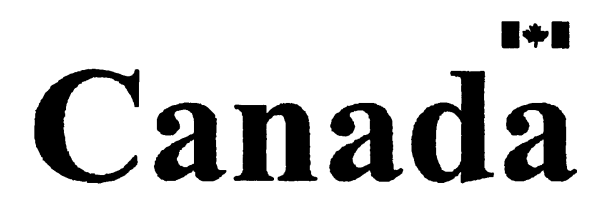


The undersigned recommend to

The Faculty of Graduate Studies and Research

acceptance of the thesis

\title{
Development of Ultrasound Measurement System for Characterizing Viscoelastic Materials Using Ultrasound Reflectance Method
}

\author{
submitted by Zhen Qu, B. Eng
}

in partial fulfillment of the requirements for the degree of

Master of Applied Science in Biomedical Engineering

Howard Schwartz

Chair, Department of System and Computer Engineering

\author{
Yuu Ono, Thesis Supervisor
}

Carleton University

September 2010 


\begin{abstract}
This thesis presents the development of an ultrasonic measurement system which aims to characterize viscoelastic properties of tissue or tissue-like materials. The system is consisted of several components, such as an ultrasound probe, a mechanical stage, a temperature control system, a data acquisition system, and data analysis programs.
\end{abstract}

The ultrasound probe design and measurement system stability test are mainly focused in this thesis. Through theoretical and experimental investigations, a probe with polymer buffer rod substrate such as polyimide or Plexiglas has better measurement sensitivity than the substrate with metallic materials such as aluminum. One of the factors affecting the measurement accuracy is the temperature stability of the measurement environment. A temperature compensation method is proposed to reduce the measurement error due to temperature fluctuation during the measurements and to improve measurement accuracy.

In future research, a more sensitive ultrasound probe will be developed to implement the experiment with higher precision. In addition, the environment temperature will be controlled to be more constant in order to reduce error. 


\section{Acknowledgements}

I would like to express my sincerest gratitude to my supervisor Dr. Yuu Ono. This thesis work could not be accomplished without his professional guidance and encouragement. I would also like to express my appreciation to Dr. C. K. Jen at Industrial Materials Institute (IMI) of National Research Council Canada (NRC), who has kindly provided us with ultrasound probes, substrates and valuable data.

I also would like to acknowledge the Natural Sciences and Engineering Research Council of Canada (NSERC) for their financial support of this research and the Carleton University for the entrance scholarship.

Thanks to my colleagues Rachel Morehouse, Huanran Wang, Bea Xu and Wen Dou for their kind help and assistance throughout my research of this thesis. They have always shared their experience and knowledge with me generously.

Finally, I would like to give my special thanks to my family and my girlfriend for their support, enthusiasm and encouragement all the time. 


\section{Contents}

Abstract $\cdots \cdots \cdots$

Acknowledgements

Contents

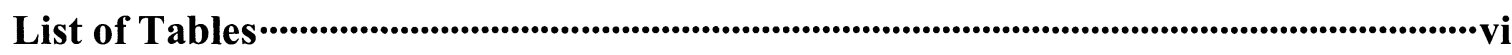

List of Figures

List of Abbreviations

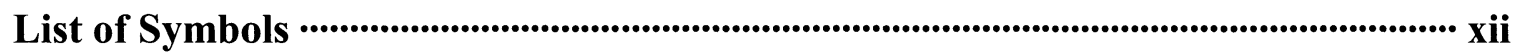

Chapter 1: Introduction

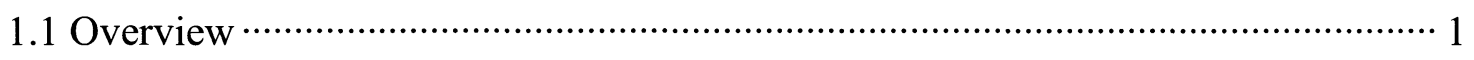

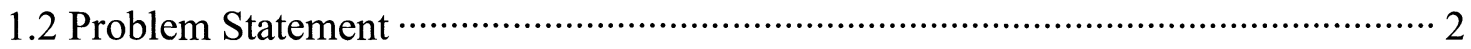

1.3 Objectives

1.4 Thesis Contributions

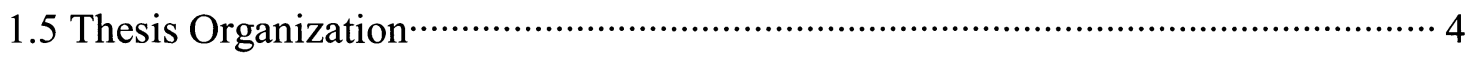

Chapter 2: Background Review

2.1 Basics of Ultrasound and Viscoelasticity …................................................... 5

2.1.1 Basics of Ultrasound ………………….............................................. 5 
2.1.3 Shear Reflectance Method …….................................................................. 9

2.1.4 Viscosity Measurement by Other Methods …............................................ 9

2.2 Shear and Longitudinal Reflectance Method …............................................... 11

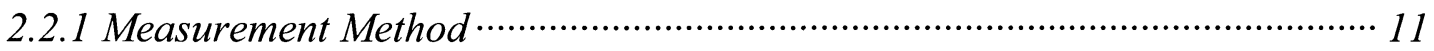

2.2.2 Mathematical Model of a Viscoelastic Material

2.2.3 Theory of Parameters Estimation ……………....................................... 17

Chapter 3: Development of Ultrasound Measurement System …...................................21

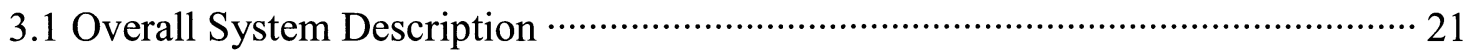

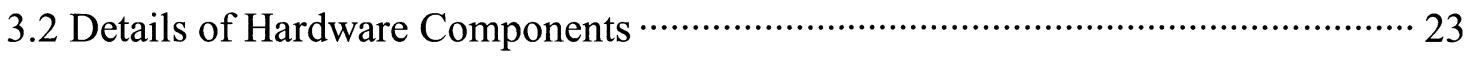

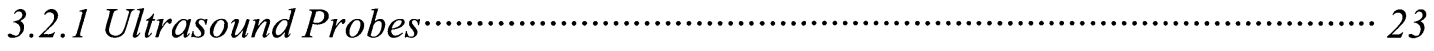

3.2.1.1 Theoretical Calculation for Ultrasound Probe Design ……….................. 23

3.2.1.2 Diagram of the Ultrasound Probe Design ….................................... 29

3.2.1.3 Available Ultrasound Probes for Current Research ……........................ 30

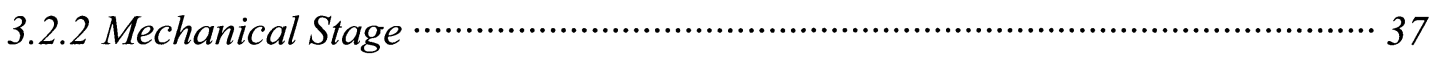

3.2.3 Temperature Measurement Device ………........................................... 38

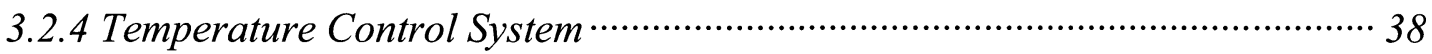

3.2.5 Electronics

3.2.6 Ultrasound Data Acquisition System ……............................................. 41

3.3 Calibration of the Temperature Sensors ……............................................. 43

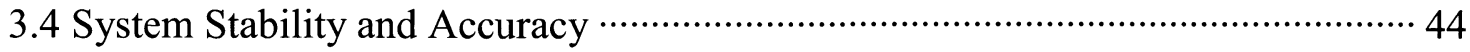

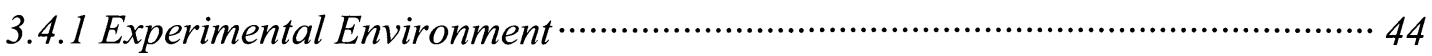

3.4.2 Data Acquisition Device ………………................................................. 46 
Chapter 4: Temperature Compensation Method …….......................................................50

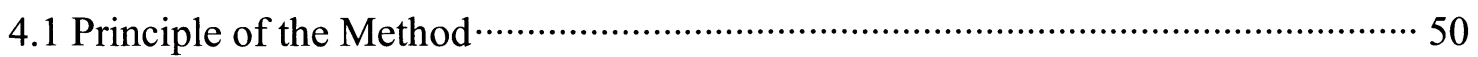

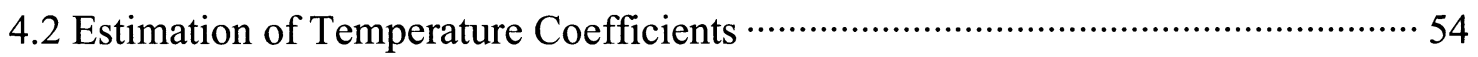

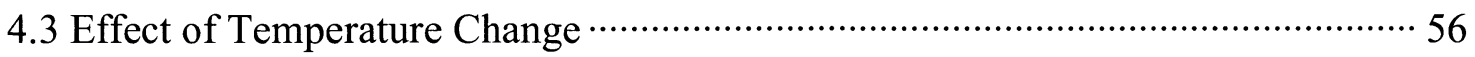

Chapter 5: Experiments, Results and Discussions ….....................................................559

5.1 Samples

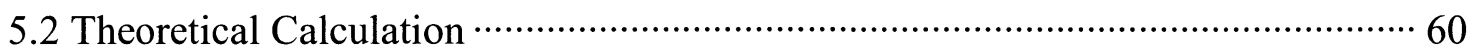

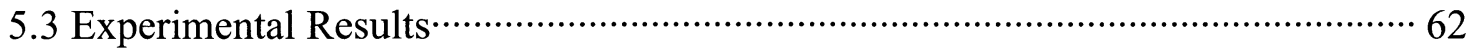

5.3.1 Results of the Experiment with Probe $\# 1$ …….............................................. 62

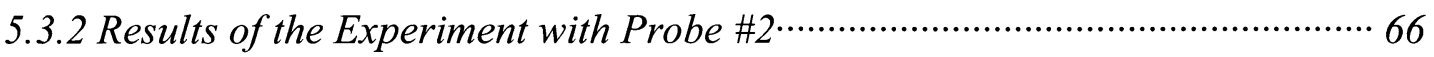

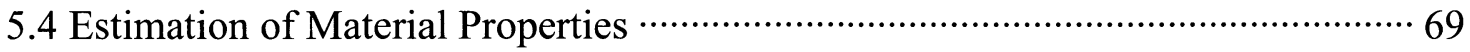

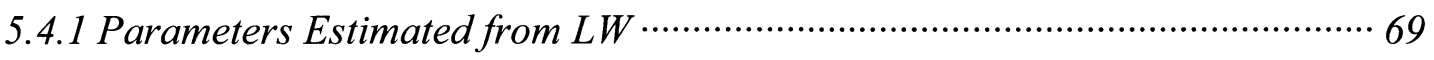

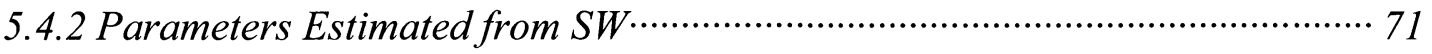

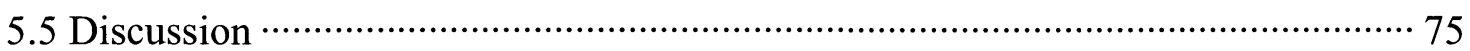

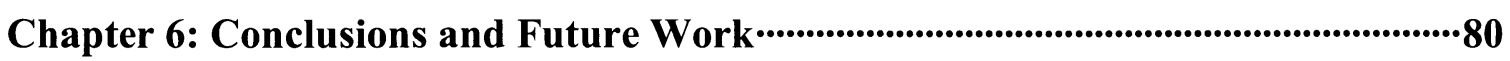

6.1 Overall Conclusions

6.2 Evaluation of the Measurement System and Experimental Results …................. 81

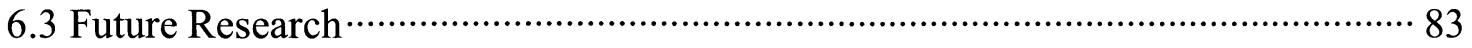

Appendix

References 


\section{List of Tables}

Table. 3.1 - Amplitude ratio $r$ and phase shift $\Delta \phi$ with $\eta=1000 \mathrm{cP}, \rho_{S}=974 \mathrm{~kg} / \mathrm{m}^{3}$, and frequency is $5 \mathrm{MHz}$.

Table. 4.1 - Temperature coefficients. 56

Table. 5.1 - Experimental sample - engine oil. 59

Table. 5.2 - Experimental sample - pure silicone fluid. 60

Table. 5.3 - Specific theoretical calculation for $r_{S}$ and $\Delta \phi_{S}$ with both probes. 61

Table. 5.4 - Amplitude and phase values for the experiment with probe \#1.

Table. 5.5 - Amplitude and phase values for the experiment with probe $\# 2$.

Table. 5.6 - Parameters for LW of the sample as gear oil SAE 140 at $12.7 \mathrm{MHz}$ for the experiment with probe \#1: (a) Known parameters, (b) Measured parameters, (c) Estimated parameters.

Table. 5.7 - Shear properties of the sample as gear oil SAE 140 for the experiment with probe \#1 operating at $12.7 \mathrm{MHz}$ : (a) Known parameters, (b) Measured parameters (c) Estimated parameters.

Table. 5.8 - Parameter estimation for different frequency components with probe $\# 1 . \cdots 72$

Table. 5.9 - Shear properties of the sample as silicone fluid RT 1,000 for the experiment with probe \#2 operating at $1.465 \mathrm{MHz}$ : (a) Known parameters, (b) Measured parameters, (c) Estimated parameters. 
Table. 5.10 - Comparison between the theoretical and experimental SW Results of $r_{S}$, $\Delta \phi_{S}$, and $\eta$. 


\section{List of Figures}

Figure. 2.1 - Longitudinal wave and shear wave. ……............................................. 5

Figure. 2.2 - Longitudinal wave transform into shear wave in a substrate. …….............. 7

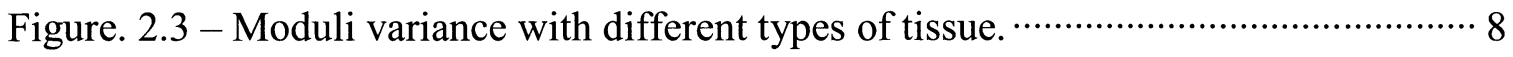

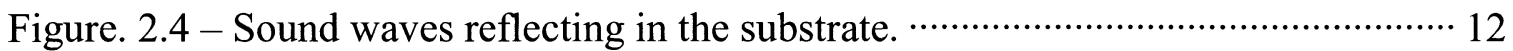

Figure. 2.5 - The two steps of ultrasound measurement: (a) exploring to air, (b) attaching with sample.

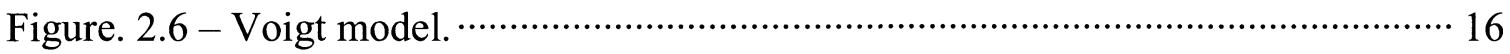

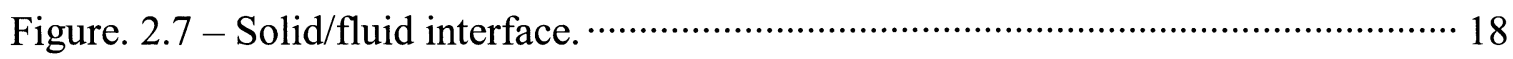

Figure. 3.1 - Diagram of the measurement system design. ………….......................... 22

Figure. 3.2 $-r_{S}$ and $\Delta \phi_{S}$ with different pulse frequency: (a) Amplitude ratios $-r$, (b)

Phase shifts $-\Delta \phi$.

Figure. $3.3-r$ and $\Delta \phi$ with different $Z_{\text {sub }}$ : (a) Amplitude ratios - $r$, (b) Phase shifts - $\Delta \phi$.

Figure. 3.4 $-r$ and $\Delta \phi$ with different $\eta$ : (a) Amplitude ratios $-r$, (b) Phase shifts $-\Delta \phi \cdot 26$

Figure. 3.5 - Diagram of the ultrasound probe design.

Figure. 3.6 - Probe \#1: (a) wave propagation path in probe \#1, (b) probe product.…..... 30

Figure. 3.7 - Waveform of the $1^{\text {st }}$ echo for both LW and SW in probe $\# 1$. 
Figure. 3.8 - The magnitude spectrums for probe \#1: (a) LW spectrum, (b) SW spectrum.

Figure. 3.9 - The phase spectrums for probe \#1: (a) LW spectrum, (b) SW spectrum. $\cdots 33$ Figure. 3.10 - Probe \#2: (a) design, (b) buffer rod substrate, (c) probe (Plexiglas substrate and LW UT, V1111). 34

Figure. 3.11 - Waveform of $1^{\text {st }}$ echo for SW in probe \#2. 35

Figure. 3.12 - The magnitude spectrum for SW of probe \#2. 35

Figure. 3.13 - The phase spectrums for SW of probe \#2. 36

Figure. 3.14 - Mechanical stage and Slides Controllers. 37

Figure. 3.15 - Temperature DAQ device. 38

Figure. 3.16 - Refrigerated bath, RTE-7 D+115/60. 39

Figure. 3.17 - Electronic devices connection. 40

Figure. 3.18 - Electronic devices: (a) signal generator, (b) ultrasound pulser /receiver. 40

Figure. 3.19 - PCI digitizer, ATS 460. 41

Figure. 3.20 - DAQ program by LabVIEW. 42

Figure. 3.21 - Temperature detected for sensor \#1 and \#2. 43

Figure. 3.22 - Temperature detected after calibration for sensor \#1 and \#2. 43

Figure. 3.23 - Temperature fluctuation of the ultrasound probe. 45

Figure. 3.24 - Measurement resolutions: (a) amplitude resolution for LW, (b) amplitude resolution for SW, (c) phase resolution for $\mathrm{LW}$, (d) phase resolution for SW.

Figure. 3.25 - Measurement resolutions after 100 points moving average: (a) amplitude resolution for $\mathrm{LW}$, (b) amplitude resolution for $\mathrm{SW}$, (c) phase resolution for $\mathrm{LW}$, (d) phase resolution for $\mathrm{SW}$. 
Figure. 4.1 - Amplitude and phase changes with temperature: (a) for amplitude, (b) for phase.

Figure. 4.2 - Detailed view of amplitude and phase changes with temperature: (a) for LW amplitude, (b) for LW phase, (c) for SW amplitude, (d) for SW phase.

Figure. 5.1 - Amplitude and phase shifts for LW and SW with probe \#1: (a) Amplitude shift, (b) Phase shift.

Figure. 5.2 - The amplitude and phase shifts for the experiment with probe \#1: (a) Amplitude for LW, (b) Phase for LW, (c) Amplitude for SW, (d) Phase for SW. $\cdots 64$

Figure 5.3 - Phase change of the experiment with probe \#1 after temperature compensation.

Figure. 5.4 - Sample measurement with probe \#2: immersed at an angle. 66

Figure. 5.5 - Amplitude and phase shifts for the experiment with probe \#2: (a) Amplitude shift, (b) Phase shift. 68

Figure. 5.6 - All estimated data with frequency for shear properties: (a) Amplitude ratio, (b) Phase shift, (c) Viscosity of the sample, (d) Shear elastic modulus of the sample, (e) Shear attenuation of the sample, (f) Shear velocity of the sample.

Figure. 5.7 - Comparison between the theoretical and experimental SW Results: (a)

Amplitude ratio $-r_{S}$, (b) Phase shift $-\Delta \phi_{S}$, (c) Viscosity $-\eta$. 75

Figure. 6.1 - Basic temperature-controlled bath design. 83

Figure. 6.2 - Plexiglas substrate with two angles shaped design. 84 


\section{List of Abbreviations}

$\begin{array}{ll}\text { NRC } & \text { National Research Council } \\ \text { UT } & \text { Ultrasound Transducer } \\ \text { LW } & \text { Shear Wave } \\ \text { SW } & \text { Aluminum } \\ \text { Al } & \text { Stainless Steel } \\ \text { SS } & \text { Data Acquisition } \\ \text { DAQ } & \text { Pulse Repetition } \\ \text { PR } & \text { Arbitrary unit (the unit of amplitude from the frequency spectrum) } \\ \text { arb } & \text { Radian (the unit of phase) } \\ \end{array}$




\section{List of Symbols}

\section{Symbols}

$u_{x}$

$\mu$

$V_{i}$

$V_{r_{-} \text {ref }}$

$V_{r}$

$R$

$--R^{*}$

$--R_{L}$

--- $R_{S}$ *

$A$

$---A_{i}$

--- $A_{\text {r_ref }}$

$--A_{r}$

--- $d A$

--- $A_{m}$

$---A_{m s}$
Description

Units

particle displacement

amplitude attenuation factor

incident wave

reference reflected wave

reflected wave

reflection coefficient

complex reflection coefficient

longitudinal reflection coefficient

complex shear reflection coefficient

amplitude

amplitude of the incident wave

amplitude of the reference reflected wave

amplitude of the reflected wave

amplitude due to the temperature change

measured amplitude without sample attaching

measured amplitude with sample attaching nepers/m

(Subscripts "L_" represents “longitudinal" and "S_" represents "shear") 


\begin{tabular}{|c|c|c|c|}
\hline$r_{S}$ & & shear amplitude ratio & $\%$ \\
\hline$\alpha_{L}$ & & longitudinal temperature coefficient of amplitude & $\operatorname{arb} /{ }^{\circ} \mathrm{C}$ \\
\hline$\alpha_{S}$ & & shear temperature coefficient of amplitude & $\operatorname{arb} /{ }^{\circ} \mathrm{C}$ \\
\hline$\phi$ & & phase & radian \\
\hline & $---\phi_{i}$ & phase of the incident wave & radian \\
\hline & $--\phi_{r_{-} r e f}$ & phase of the reference reflected wave & radian \\
\hline & $---\phi_{r}$ & phase of the reflected wave & radian \\
\hline & $--\Delta \phi$ & phase shift due to the viscosity & radian \\
\hline & $--d \phi$ & phase shift due to the temperature change & radian \\
\hline & $---\phi_{m}$ & measured phase without sample attaching & radian \\
\hline & $---\phi_{m s}$ & measured phase with sample attaching & radian \\
\hline$\Delta \phi_{S}$ & & shear phase shift & radian \\
\hline$\beta_{L}$ & & longitudinal temperature coefficient of phase & $\mathrm{rad} /{ }^{\circ} \mathrm{C}$ \\
\hline$\beta_{S}$ & & shear temperature coefficient of phase & $\mathrm{rad} /{ }^{\circ} \mathrm{C}$ \\
\hline$\rho_{\text {sub }}$ & & density of the substrate & $\mathrm{Kg} / \mathrm{m}^{3}$ \\
\hline$K_{s u b}$ & & bulk modulus of the substrate & $\mathrm{Pa}$ \\
\hline$G_{s u b}$ & & shear modulus of the substrate & $\mathrm{Pa}$ \\
\hline$Z_{L_{-} s u b}$ & & longitudinal acoustic impedance of the substrate & $\mathrm{kg} / \mathrm{m}^{2} \mathrm{~s}$ \\
\hline$Z_{S_{-} s u b}$ & & shear acoustic impedance of the substrate & $\mathrm{kg} / \mathrm{m}^{2} \mathrm{~s}$ \\
\hline$v_{L \_} s u b$ & & longitudinal velocity of the substrate & $\mathrm{m} / \mathrm{s}$ \\
\hline$v_{S_{-} s u b}$ & & shear velocity of the substrate & $\mathrm{m} / \mathrm{s}$ \\
\hline$\rho_{s p}$ & & density of the sample & $\mathrm{Kg} / \mathrm{m}^{3}$ \\
\hline$k^{*}$ & & complex wave number & \\
\hline
\end{tabular}




\begin{tabular}{|c|c|c|c|}
\hline$K_{s p}$ & & bulk modulus of the sample & $\mathrm{Pa}$ \\
\hline$G_{s p}^{*}$ & & complex shear modulus of the sample & \\
\hline & --- $G^{\prime}$ & shear elastic modulus of the sample & $\mathrm{Pa}$ \\
\hline & $--G^{\prime \prime}$ & loss modulus of the sample & $\mathrm{Pa}$ \\
\hline$\eta$ & & viscosity of the sample & $\mathrm{cP}$ \\
\hline$Z_{L_{-} s p}$ & & longitudinal acoustic impedance of the sample & $\mathrm{kg} / \mathrm{m}^{2} \mathrm{~s}$ \\
\hline$Z_{S_{-} s p} *$ & & complex shear acoustic impedance of the sample & \\
\hline & $---R_{S}$ & shear resistance of the sample & $\mathrm{kg} / \mathrm{m}^{2} \mathrm{~s}$ \\
\hline & $---X_{S}$ & shear reactance of the sample & $\mathrm{kg} / \mathrm{m}^{2} \mathrm{~s}$ \\
\hline$v_{L_{-} s p}$ & & longitudinal velocity of the sample & $\mathrm{m} / \mathrm{s}$ \\
\hline$v_{S_{-} s p}$ & & shear velocity of the sample & $\mathrm{m} / \mathrm{s}$ \\
\hline$\alpha$ & & shear attenuation & $\mathrm{m}^{-1}$ \\
\hline
\end{tabular}




\section{Chapter 1: Introduction}

The following chapter is an introduction, which creates an overview of the entire thesis. In addition, the objective and contribution of the research will be presented.

\subsection{Overview}

Tissue can be characterized by using their viscoelasticity. Throughout this thesis, "tissue" means a biological tissue consisting of cell and intercellular substance, and "tissue-like material" means a material consisting of the abiotic components used to simulate the biological tissue. Tissue viscoelasticity research is meaningful for medical studies especially in pathology since tissue viscoelasticity properties often change due to diseases. One of the methods to determine the materials' viscoelasticity is to measure the ultrasound wave reflectance from a sample.

Reflection coefficient, measured by the ultrasound wave reflectance is determined by the properties of the measuring probe, such as the acoustic impedance of the substrate and those of the test sample, such as the acoustic impedance and viscoelasticity. What can be measured form the experiment are the amplitude and the phase of the reflection coefficient. 
In this thesis, a method to measure the reflection coefficient of both longitudinal wave (LW) and shear wave (SW) simultaneously and to obtain the properties from LW and SW of a sample are investigated. In addition, methods to increase the measurement accuracy and to reduce measurement errors are discussed.

\subsection{Problem Statement}

The long term objective of the research is to use an ultrasonic method to characterize the viscoelasticity of tissue or tissue-like materials. A new ultrasound probe was designed, which can generate LW and SW simultaneously to obtain and analyze the tissue properties such as elasticity and viscosity at same time.

The viscoelasticity properties of tissue or tissue-like material generally depend on the temperature $[1,2]$. Therefore, tissue viscoelastic characterization, which is implemented by measuring the amplitude and phase shifts of the reflection coefficient of SW and LW, is affected by the temperature instability of the measurement environment. Therefore, a temperature compensation method, which can reduce such a factor, is proposed using a LW and SW ultrasound probe in this thesis. The details about the method will be introduced in Chapter 4.

Several factors can affect the measurement accuracy. An investigation to optimize the measurement sensitivity of the ultrasound probe has been made, and the discussion is provided in this thesis as well.

The advantage to use the LW and SW probe is that the properties of both LW and SW can be estimated at the same time [3]. In addition the temperature compensation method is implementable by using this probe. 


\subsection{Objectives}

The main goal of present work is to develop the ultrasound measurement platform for tissue viscoelasticity characterization, and to test and improve the performance of this system. In addition, the viscosity measurement sensitivity of the ultrasound probe is investigated in this thesis.

Toward thesis goals, theoretical calculation is conducted as a first step for investigating the measurement sensitivity of the ultrasound probe employed in the measurement system. In the next step, an ultrasound measurement platform is designed and constructed, with a mechanical stage, electronic devices, and a data acquisition system. In addition, a temperature compensation method is proposed to reduce the effect of temperature fluctuation on the amplitude and phase shift measurements.

\subsection{Thesis Contributions}

The following are the main research contributions demonstrated in this thesis:

1. An ultrasound measurement system for tissue or tissue-like materials viscoelastic characterization has been constructed and the system stability has been evaluated.

2. A data acquisition program was created, which allows signal acquisition from a PCI digitizer. The acquisition program was modified using LabVIEW.

3. A temperature compensation method to remove errors due to the environmental temperature fluctuation has been proposed. This method improves the accuracy of amplitude and phase shifts measurements. 
4. The measurement sensitivity of the ultrasound probe substrate has been investigated. In addition, a new probe with high measurement sensitivity has been designed.

\subsection{Thesis Organization}

Chapter 1 introduces the long term objectives of the research. The main problem and goals for this thesis are presented.

Chapter 2 provides background knowledge and information on ultrasound technique and tissue viscoelasticity. The method and theory to solve the problem are introduced in this chapter as well.

Chapter 3 presents the development of the measurement system. A probe with high measurement sensitivity is designed. In addition, the system stability and experimental conditions are discussed.

Chapter 4 proposes a temperature compensation method which can reduce the error due to the temperature instability.

Chapter 5 presents the theoretical calculation results corresponding to the parameters of the probes used in this thesis. Experimental results with two probes are analyzed and discussed with the theoretical results.

Chapter 6 concludes the current research for this thesis. The evaluation is conducted for the measurement system and research results. Improvement suggestions and future research are discussed. 


\section{Chapter 2: Background Review}

This chapter introduces the basics about the ultrasound technique and the principle for material viscoelastic characterization. The contents of this chapter are fundamental to this thesis.

\subsection{Basics of Ultrasound and Viscoelasticity}

\subsubsection{Basics of Ultrasound}

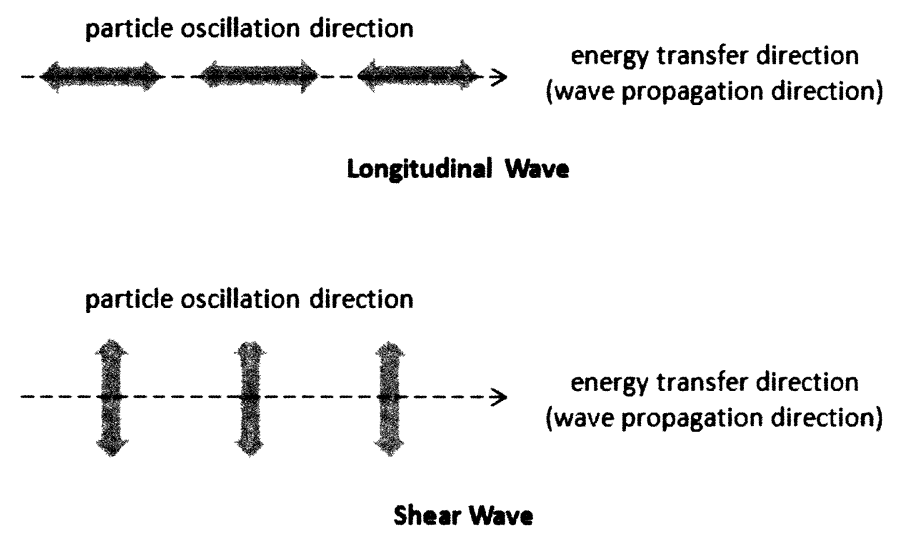

Figure. 2.1 - Longitudinal wave and shear wave.

Ultrasound is sound with a frequency greater than the upper limit of human hearing, typically $20 \mathrm{kHz}$. There are two main wave types: LW and SW [4, 5, 6]. The oscillation forms of two types of wave are shown in Figure 2.1. LW is the wave that has the same direction of oscillation or vibration as its direction of travel. SW, also called transverse 
wave, is a moving wave that consists of oscillations occurring perpendicular to the direction of energy transfer [4]. The shear sound wave equation is given by:

$$
\frac{\partial^{2} u_{x}}{\partial z^{2}}=\frac{1}{v^{2}} \frac{\partial^{2} u_{x}}{\partial t^{2}}
$$

where $u_{x}$ is the particle displacement along the $\mathrm{x}$ axis, $v$ is the wave propagation velocity, $z$ and $t$ represent the distance and time of the wave propagates through, respectively [4]. When wave propagates in materials, the particle displacement can be described as:

$$
\begin{aligned}
& u_{x}=A_{0} e^{-\mu z} e^{j(\omega t-k z)} \\
& \alpha=20\left(\log _{10} e\right) \mu
\end{aligned}
$$

where $\mu$ is amplitude attenuation factor and $\alpha$ is the attenuation coefficient, $k$ is the wave number and it will be used for this thesis latter in Chapter 2, Section 2.2.3.

An ultrasound probe used in this thesis consists of an ultrasound transducer (UT) and a coupling substrate [3]. The substrate, which is directly connected to the examining material, is called a buffer rod substrate $[4,7,8]$. Measurement sensitivity for tissue viscoelasticity depends on the material of the substrate and the ultrasonic frequency of the probe $[9,10]$.

With a specific incident angle $[3,11,12]$, LW may transform into SW after the reflection as shown in Figure 2.2. The specific incident angle is determined by the material which the sound wave propagates through. 


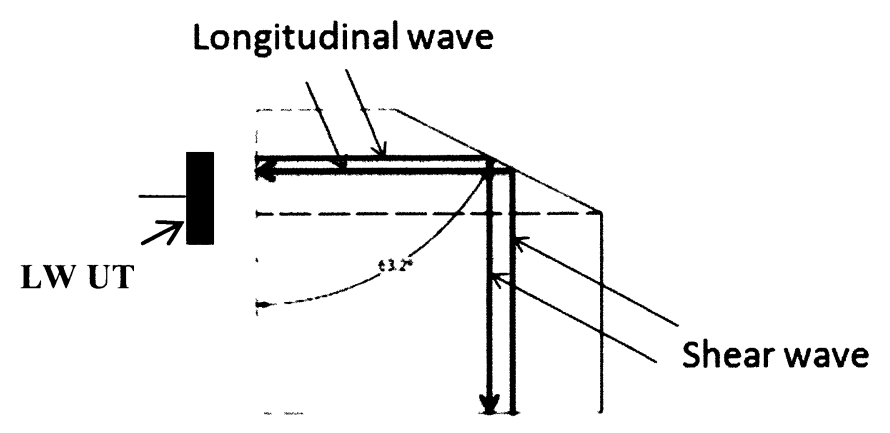

Figure. 2.2 - Longitudinal wave transform into shear wave in a substrate.

\subsubsection{Viscoelasticity of Materials}

Materials which we are interested in can be classified into two major groups, solids and fluids [5]. In this research, tissue or tissue-like materials (soft tissue in particular), can be treated as fluid-like solids, which means these kinds of materials have characteristics of both solids and fluids [5]. A way to characterize such material is the analysis of their viscoelastic properties, which consists of elasticity and viscosity.

Elasticity is a physical property which describes the ability of a material to return to its original shape after stress is removed [13]. Viscosity describes the ability of a fluid or a fluid-like material to resist deformation due to shear stress or tensile stress [13]. A material with only elasticity can be called a purely elastic material, and a material with only viscosity can be called a Newtonian fluid $[14,15]$. A soft tissue or tissue-like material is in between these two kinds of materials, therefore it is called a viscoelastic material [16]. Purely elastic material does not lose its energy during loading. However, viscoelastic material in the same condition loses energy due to its viscosity [13].

For a solid material, the bulk modulus $(\mathrm{K})$ and the shear modulus $(\mathrm{G})$, which are both real quantities, are used to describe the material's elastic properties [5, 13]. However, 
for a viscoelastic material such as a soft tissue, the shear modulus becomes a complex quantity and is called complex shear modulus $\left(\mathrm{G}^{*}\right)$. It can be expressed as:

$$
G^{*}=G^{\prime}+j G^{\prime \prime}
$$

where $G^{\prime}$ is the shear elastic modulus and the $G^{\prime \prime}$ is the loss modulus which is caused by viscosity $[17,18,19]$. Therefore, to characterize viscoelastic materials such as tissue or tissue-like materials, bulk modulus, shear elastic modulus and loss modulus are all necessary and need to be considered [5]. In this thesis, the measurement system including the ultrasound probe is designed and improved for a better viscosity measurement sensitivity and accuracy.

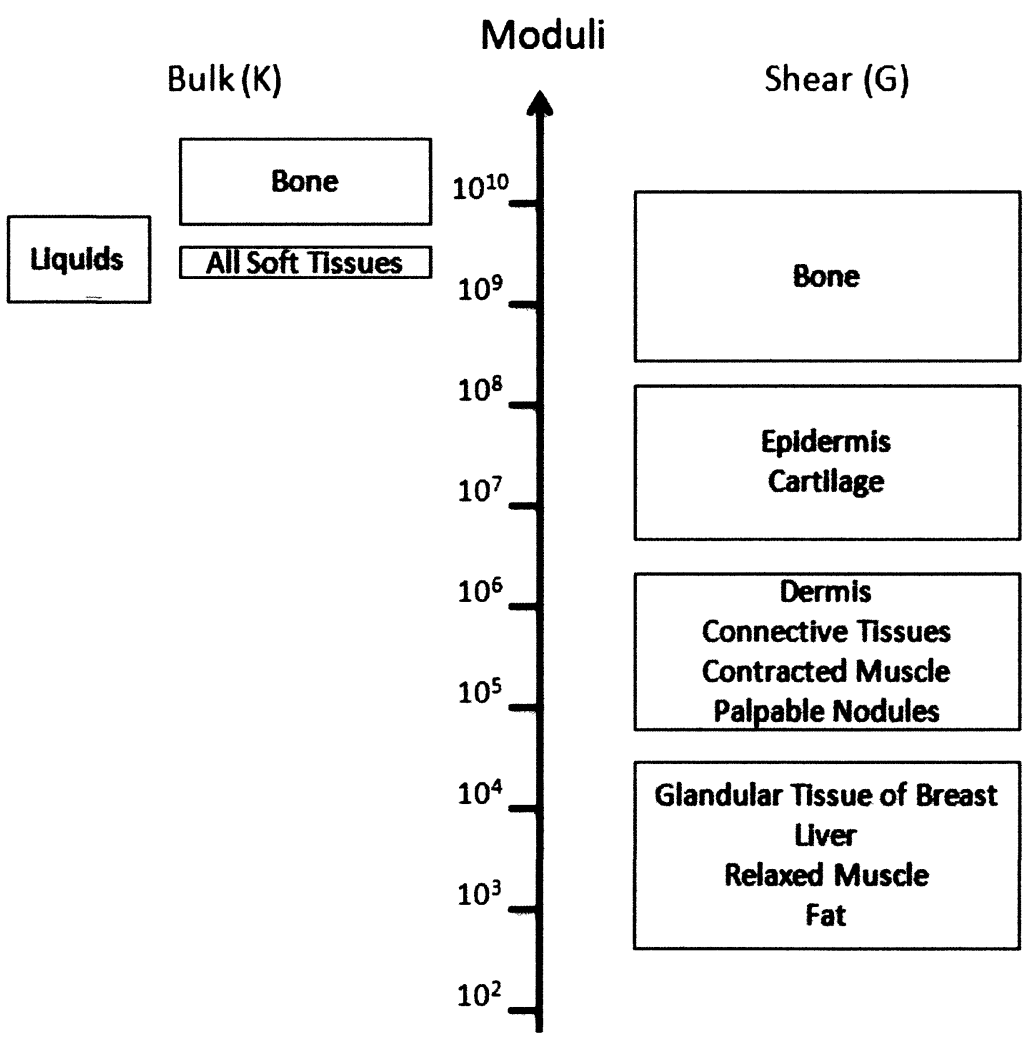

Figure. 2.3 - Moduli variance with different types of tissue (reproduced from [5]).

From Figure 2.3 it can be seen that different types of normal (healthy) tissue can be differentiated through investigating the moduli of the sample materials. 


\subsubsection{Shear Reflectance Method}

Mason's group studied shear elastic and viscous properties of a material in 1948 with an ultrasonic reflectance method [20]. A designed torsional quartz crystal was used to generate shear waves higher than $500 \mathrm{KHz}$ to measure the different polymer liquids with temperature controlled. Through the investigation of the magnitude and phase of the measured reflection coefficient, the shear elasticity and viscosity of the fluids was estimated [20]. Nowadays, this method is widely used for the research on viscoelasticity of tissue using ultrasound measurement.

With the principle of this ultrasonic measurement technique, moduli mentioned in the previous section can be obtained through analyzing the measured data. The bulk modulus can be estimated through the LW measurement and the complex shear modulus can be estimated through the SW measurement. Details of the principles will be introduced in the next section.

For this thesis, the unit of shear elastic modulus, loss modulus, shear modulus and bulk modulus is Pascal (Pa). The unit of viscosity used in this thesis is centipoise (cP), where $1 \mathrm{cP}$ equals 0.001 Pascal second (Pas) [15].

\subsubsection{Viscosity Measurement by Other Methods}

Instrument based on the ultrasonic technique can measure the viscoelasticity continuously in real time and requires a minimal volume sample $[1,14]$. The ultrasound probe which is designed for this research can measure viscosity and elasticity simultaneously [3]. Therefore, there are many research groups using the ultrasonic technique to investigate tissue viscoelastic properties [22-29]. 
There are several other types of methods and instruments called viscometers which can measure the viscosity of materials as summarized below according to [14]:

1. Capillary viscometers.

This type of viscometers is widely used to measure the viscosity of Newtonian liquids. The principle of it is to calculate the viscosity from the flow rate of the liquid inside of the capillary tube. Since the different liquids have different viscosity, the flow rates when it is dropping due to the gravity are different. However, this kind of viscometer needs to be calibrated with a known viscosity liquid firstly before measuring other liquid with unknown viscosity.

2. Orifice viscometers.

Orifice viscometer is widely used in the oil industry. It is a capillary viscometer, in which the tube length does not exceed 10 times the diameter of the orifice, and this viscometer allows the test fluid discharge into a separate reservoir. However, this type of viscometer is not as accurate as capillary viscometer.

3. High-temperature high-shear rate viscometers.

The non-Newtonian fluid with viscosity higher than 1000 poise can be measured by this type of viscometers. It is a capillary viscometer which can control the testing temperature and working in a high temperature (up to $150{ }^{\circ} \mathrm{C}$ ).

4. Rotational viscometers.

The principle of rotational viscometer is measuring the rate of rotation of a fluid with a known torque and angular velocity. This type of viscometers has less 
accurate for Newtonian fluid comparing with the capillary viscometer but good to measure the non-Newtonian fluid.

5. Falling ball viscometers.

A solid body is allowed to fall through a viscous fluid under the gravity in this viscometer. Since the viscous resistance of the fluid finally may balance the gravitational force, the solid body will attain a uniform terminal velocity after the initial acceleration. To measure this velocity can finally estimate the viscosity of the fluid.

6. Vibrational viscometers.

This viscometer is measuring an oscillating resonator which immersed in a fluid. The higher the viscosity, the larger the resonator will be applied. It has high sensitivity and requires small volume of test sample with wide range of viscosity, and it is widely used in the petrochemical industry.

\subsection{Shear and Longitudinal Reflectance Method}

This section introduces the principles of how to estimate the longitudinal and shear properties of a material. One thing to be noted is that the ultrasound wave reflections which are mentioned in this chapter are all referring to reflection by vertical incidence.

\subsubsection{Measurement Method}

The material's viscosity, shear velocity and shear attenuation can be all estimated by measuring the reflection coefficient of the SW from the ultrasound probe [30, 31]. The 
bulk modulus and longitudinal velocity of the material can be estimated through the reflection coefficient from the LW of the ultrasound probe [4].

Reflection coefficient $(\mathrm{R})$ is the ratio of the reflected wave signal $V_{r}$, divided by the incident wave signal $V_{i}$, shown as Figure 2.4:

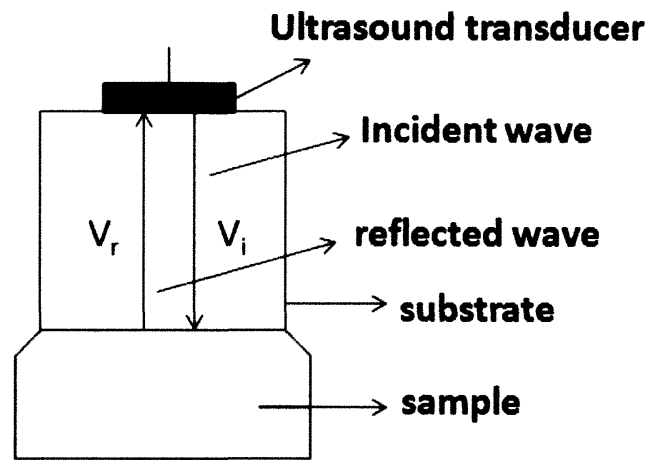

Figure. 2.4 - Sound waves reflecting in the substrate.

The definition of reflection coefficient $(\mathrm{R})$ is:

$$
R=\frac{Z_{s p}-Z_{s u b}}{z_{s p}+Z_{s u b}}=\frac{V_{r}}{V_{i}}
$$

where $Z_{s p}$ is the acoustic impedance of the sample, and $Z_{s u b}$ is the acoustic impedance of the substrate $[4,18]$.

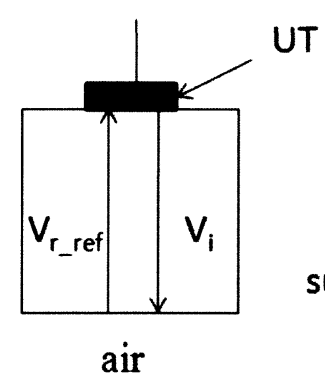

(a)

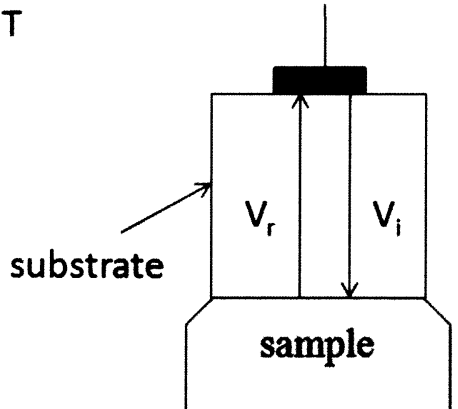

(b)

Figure. 2.5 - The two steps of ultrasound measurement: (a) exploring to air, (b) attaching with sample. 
As equation (5) shows, both $V_{r}$ and $V_{i}$ are required to obtain R. However, for real experiments, since a signal receiver cannot estimate the incident signal directly, a twostep method is a prerequisite to obtain R. Figure 2.5 shows the two measurement steps to obtain $\mathrm{R}$ for an ultrasound reflection. Firstly a reference reflection is implemented and the reference reflected signal, $V_{r_{-} r e f}$, reflecting at the substrate/air interface is acquired without a sample as shown in Figure 2.5 (a). Then, the signal, $V_{r}$, reflected at the substrate/sample interface is acquired as shown in Figure 2.5 (b). Each signal can be described with amplitude and phase [2]:

$$
\begin{aligned}
& V_{i}=A_{i} e^{j\left(\phi_{i}\right)} \\
& V_{r_{-} r e f}=A_{r_{-} r e f} e^{j\left(\phi_{r_{-} r e f}\right)} \\
& V_{r}=A_{r} e^{j\left(\phi_{r}\right)},
\end{aligned}
$$

where $A$ is the amplitude and $\phi$ is the phase of the ultrasound wave. Subscript $i, r \_r e f$ and $r$ represent the incident signal, reference reflected signal (at Figure 2.5 a) and reflected signal (at Figure $2.5 \mathrm{~b}$ ), respectively.

The acoustic impedance of a material is defined as the product of its density and its sound velocity. At $20{ }^{\circ} \mathrm{C}$, the air has the density of about $1.2 \mathrm{~kg} / \mathrm{m}^{3}$ and the longitudinal velocity of $343 \mathrm{~m} / \mathrm{s}$ [6], thus the longitudinal acoustic impedance of air is $411.6 \mathrm{~kg} / \mathrm{m}^{2} \mathrm{~s}$, which is much smaller than that of aluminum $\left(8.379 \times 10^{6} \mathrm{~kg} / \mathrm{m}^{2} \mathrm{~s}\right)$ and it is negligible. In addition, shear wave is difficult to propagate through the air because the air cannot afford the shear stress. Therefore, the shear velocity of the air can be considered as 0 and thereafter the shear acoustic impedance can be ignored. 
When the incident signal $V_{l}$ reflects at the solid/air interface, due to the acoustic impedance of the air is negligible, this reference reflection becomes a total reflection [2], and the reference reflection coefficient $\left(\mathrm{R}_{\mathrm{ref}}\right)$ equals -1 , which means the $V_{r_{-} r e f}$ has a $180^{\circ}$ phase shift to the $V_{l}$ and amplitude stays the same. This can be expressed as equation (9) and (10):

$$
\begin{gathered}
V_{r_{-} r e f}=A_{i} e^{j\left(\phi_{l}-180^{\circ}\right)} \\
R_{\text {ref }}=\frac{V_{r_{r} e f}}{V_{\iota}}=-1 .
\end{gathered}
$$

Therefore, the incident signal of the probe is opposite to the reference reflected signal which can be measured by the system, as $V_{l}=-V_{r_{-} \text {ref. }}$. Now it can be derived that:

$$
\begin{aligned}
& R=\frac{V_{r}}{-V_{r_{-} r e f}}=-\frac{A_{r}}{A_{r_{-} r e f}} e^{j\left(\phi_{r}-\phi_{r_{-} r e f}\right)} \\
& r=\frac{A_{r}}{A_{r_{-} r e f}} \\
& \Delta \phi=\phi_{r}-\phi_{r_{-} r e f},
\end{aligned}
$$

where $r$ and $\Delta \phi$ represent the amplitude ratio and phase shift, respectively. These values can be obtained directly through the experiments $[12,31,32,33]$.

For the LW, the longitudinal velocity and longitudinal acoustic impedance in the solid (i.e. the substrate of ultrasound probe in this thesis), can be expressed as:

$$
\begin{aligned}
& v_{L_{-} s u b}=\sqrt{\frac{K_{\text {sub }}+4 / 3 G_{\text {sub }}}{\rho_{\text {sub }}}} \\
& Z_{L_{-} \text {sub }}=\rho_{\text {sub }} \times v_{L_{-} \text {sub }},
\end{aligned}
$$


where the $v_{L_{-} s u b}$ is the longitudinal velocity in the probe's substrate. $K_{\text {sub }}, G_{\text {sub }}$ and $\rho_{\text {sub }}$ represents the bulk modulus, shear modulus and density, respectively, of the probe's substrate. $Z_{L_{-} \text {sub }}$ is the longitudinal acoustic impedance of the substrate [4].

For the SW, the shear velocity and shear acoustic impedance in the substrate can be expressed as:

$$
\begin{aligned}
& v_{S_{-} \text {sub }}=\sqrt{\frac{G_{\text {sub }}}{\rho_{\text {sub }}}} \\
& Z_{S_{-} \text {sub }}=\rho_{\text {sub }} \times v_{S_{-} \text {sub }},
\end{aligned}
$$

where the $v_{S_{-} s u b}$ is the shear velocity in the probe's substrate and $Z_{S_{-} s u b}$ is the shear acoustic impedance of the substrate $[9,34]$.

The velocity and acoustic impedance of the probe substrate for both LW and SW can be measured since parameters $K_{\text {sub }}, G_{\text {sub }}$ and $\rho_{\text {sub }}$ are known from the references (will be shown in the Chapter 5). In addition, the amplitude and phase for both LW and SW can be obtained through the measurement devices. Therefore, from equation (5), the parameters, acoustic impedance of the sample for both LW and SW, can be estimated. The viscoelasticity can be obtained by investigating these acoustic impedances. Therefore, one main object of this ultrasound reflectance method to investigate the sample's viscoelasticity is to estimate the acoustic impedances of the sample for both LW and SW [9]. 


\subsubsection{Mathematical Model of a Viscoelastic Material}

A Voigt Model (as shown in Figure 2.6) $[9,18,34,35]$ is chosen to be the mathematical model for all calculations in this thesis. It is represented by a purely viscous damper connected in parallel to a purely elastic spring.

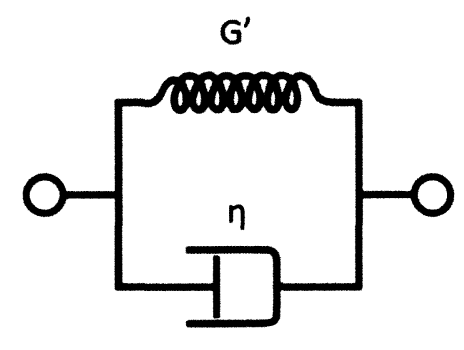

Figure. 2.6 - Voigt model.

By using the Voigt Model, equation (4) can be recast as:

$$
G_{s p}^{*}=G^{\prime}+j \omega \eta
$$

where $G_{s p}$ * is the complex shear modulus of the viscoelastic sample, $\eta$ is the viscosity of the viscoelastic sample and $\omega$ is the angular ultrasonic frequency which is associated with the ultrasonic frequency [19]. Here in equation (18), $\omega \eta$ is the loss modulus of a viscoelastic material due to viscosity $[19,34]$.

The longitudinal acoustic impedance of viscoelastic sample $Z_{L_{-} s p}$ can be defined as the product of the sample density $\left(\rho_{s p}\right)$, and longitudinal velocity $\left(v_{L_{-} s p}\right)[4]$ which is a real quantity, expressed as:

$$
Z_{L_{-} s p}=\rho_{s p} \times v_{L_{-} s p}
$$


The shear acoustic impedance of viscoelastic sample $Z_{S_{-} p}$ can be expressed as [4, 19]:

$$
Z_{S_{-} s p}{ }^{*}=\sqrt{\rho_{s p} G_{s p}{ }^{*}} .
$$

The $G_{s p}{ }^{*}$ is a complex quantity, therefore the shear acoustic impedance of the sample is complex $[18,19]$. From equation (18) and (20), $Z_{S_{-} s p}{ }^{*}$ can be derived as:

$$
Z_{S_{-} s p}{ }^{*}=\sqrt{\rho_{s p}\left(G^{\prime}+j \omega \eta\right)}
$$

Therefore, with Voigt model, the parameters $Z_{L_{-} s p}$ and $Z_{S_{-} s p} *$ which can describe the viscoelastic properties are expressed by these mathematical equations.

\subsubsection{Theory of Parameters Estimation}

Since $Z_{L_{-} s p}$ is real, it can be assumed that there is no phase shift ( $\Delta \phi$ is 0 for $\left.L W\right)$ after the two-step measurement with the LW. Therefore from (11) and (12), the longitudinal reflection coefficient can be expressed as a negative amplitude ratio:

$$
R_{L}=-r_{L}
$$

where $R_{L}$ is the longitudinal reflection coefficient and $r_{L}$ is the amplitude ratio for LW.

From the equation (5), (19) and (22), the longitudinal velocity $v_{L_{-} s p}$ can be derived:

$$
v_{L_{-} s p}=\frac{\left(1-r_{L}\right) Z_{L_{-} s u b}}{\left(1+r_{L}\right) \rho_{s p}}
$$

In addition, the longitudinal velocity in the viscoelastic material can be defined with the bulk modulus of the sample $\left(K_{s p}\right)[4,6]$ : 


$$
v_{L_{-} s p}=\sqrt{\frac{K_{s p}}{\rho_{s p}}}
$$

therefore,

$$
K_{s p}=\rho_{s p} \times v_{L_{-} s p}{ }^{2}
$$

The bulk modulus of the sample can be estimated through these equations and it is one of the most important parameters used to investigate the material's viscoelasticity [6].

As introduced above, the shear acoustic impedance of the sample $Z_{S_{-} s p}{ }^{*}$ is a complex quantity, therefore, the reflection coefficient of SW $\left(R_{S}^{*}\right)$ is complex.

Figure 2.7 shows the SW incident at the interface between the substrate and the viscoelastic sample.

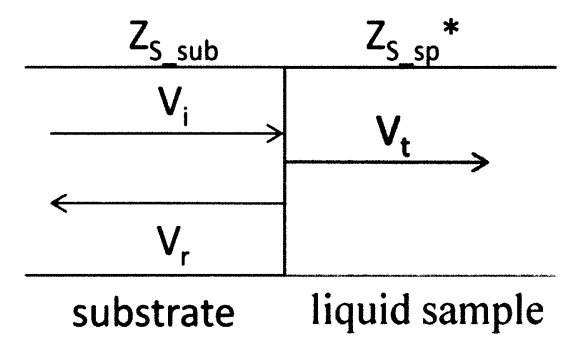

Figure. 2.7 - Solid/fluid interface.

From equation (11), (12) and (13), the expression of $R_{S}{ }^{*}$ is expressed as:

$$
R_{S}^{*}=\frac{Z_{S_{-} s p^{*}-Z_{S_{-} s u b}}}{Z_{S_{-} s p^{*}+Z_{S_{-} s u b}}}=-r_{S} e^{j\left(\Delta \phi_{S}\right)}
$$

where $r_{S}$ is the amplitude ratio of SW, and $\Delta \phi_{S}$ is the phase shift of SW. These two parameters are measurable through the experiment [12]. In addition, as mentioned in 
Section 2.2.1, $Z_{S_{-} s u b}$ can be measured as well. Therefore, the shear acoustic impedance of the sample can be expressed with measurable parameters as:

$$
Z_{S_{-} s p}{ }^{*}=\frac{\left[1-r_{S} e^{j\left(\Delta \phi_{S}\right)}\right] Z_{S_{S} s u b}}{1+r_{S} e^{j\left(\Delta \phi_{S}\right)}}
$$

Since the $Z_{S_{-} s p} *$ is complex, it can be expressed with a resistance $R_{S}$ and a reactance $X_{S}$ of the sample [18]:

$$
Z_{S_{-} s p}{ }^{*}=\sqrt{\rho_{s p}\left(G^{\prime}+j \omega \eta\right)}=R_{S}+j X_{S}
$$

Therefore, shear elastic modulus $G$ ' and viscosity $\eta$ now can be expressed as:

$$
\begin{aligned}
& G^{\prime}=\frac{R_{S}^{2}-X_{S}^{2}}{\rho_{s p}} \\
& \eta=\frac{2 R_{S} X_{S}}{\rho_{s p} \omega} .
\end{aligned}
$$

Parameter $k^{*}$, which is called the wave number, is defined as $[18,30]$ :

$$
k^{* 2}=\frac{\rho_{s p} \omega^{2}}{G_{s p}{ }^{*}}
$$

The wave number is a complex quantity. The shear velocity of the sample $\left(v_{S_{s} s p}\right)$ and shear attenuation $(\alpha)$ can be estimated through this complex wave number:

$$
\begin{aligned}
& v_{S_{-} s p}=\frac{\omega}{\operatorname{Real}\left(k^{*}\right)}=\frac{R_{S}^{2}+X_{S}{ }^{2}}{\rho_{s p} R_{S}} \\
& \alpha=\operatorname{Imag}\left(k^{*}\right)=\frac{\omega \rho_{s p} X_{S}}{R_{S}{ }^{2}+X_{S}{ }^{2}},
\end{aligned}
$$

where Real $\left(k^{*}\right)$ means the real part of the complex wave number $k^{*}$, and the imaginary part of the $k^{*}$ is $\operatorname{Imag}\left(k^{*}\right)[18,30]$. 
The parameters which are used in this research are now all listed mathematically. It is known that to investigate the properties of viscosity, SW measurement is required. For the investigation of viscoelasticity, both LW and SW measurements are required. All calculations used in this thesis are based upon these equations. 


\section{Chapter 3: Development of Ultrasound Measurement}

\section{System}

The following chapter presents the main work of this thesis. It introduces the experimental system developed and used for this thesis. It includes hardware, such as ultrasound probes, electronic devices, a mechanical stage and a data acquisition (DAQ) system, with a PCI digitizer. Data acquisition and analysis programs are also developed using LabVIEW and MATLAB, respectively. Test samples are introduced as well. At the end of this chapter, the investigation of the system's stability will be presented.

\subsection{Overall System Description}

This system is originally designed for long-term research of the viscoelastic characterization of tissue or tissue-like materials. In this thesis, the main objective is the development of the system. The measurement system can complete all procedures of the experiment, which includes signal generation, sample measurement, data acquisition, and signal processing. 


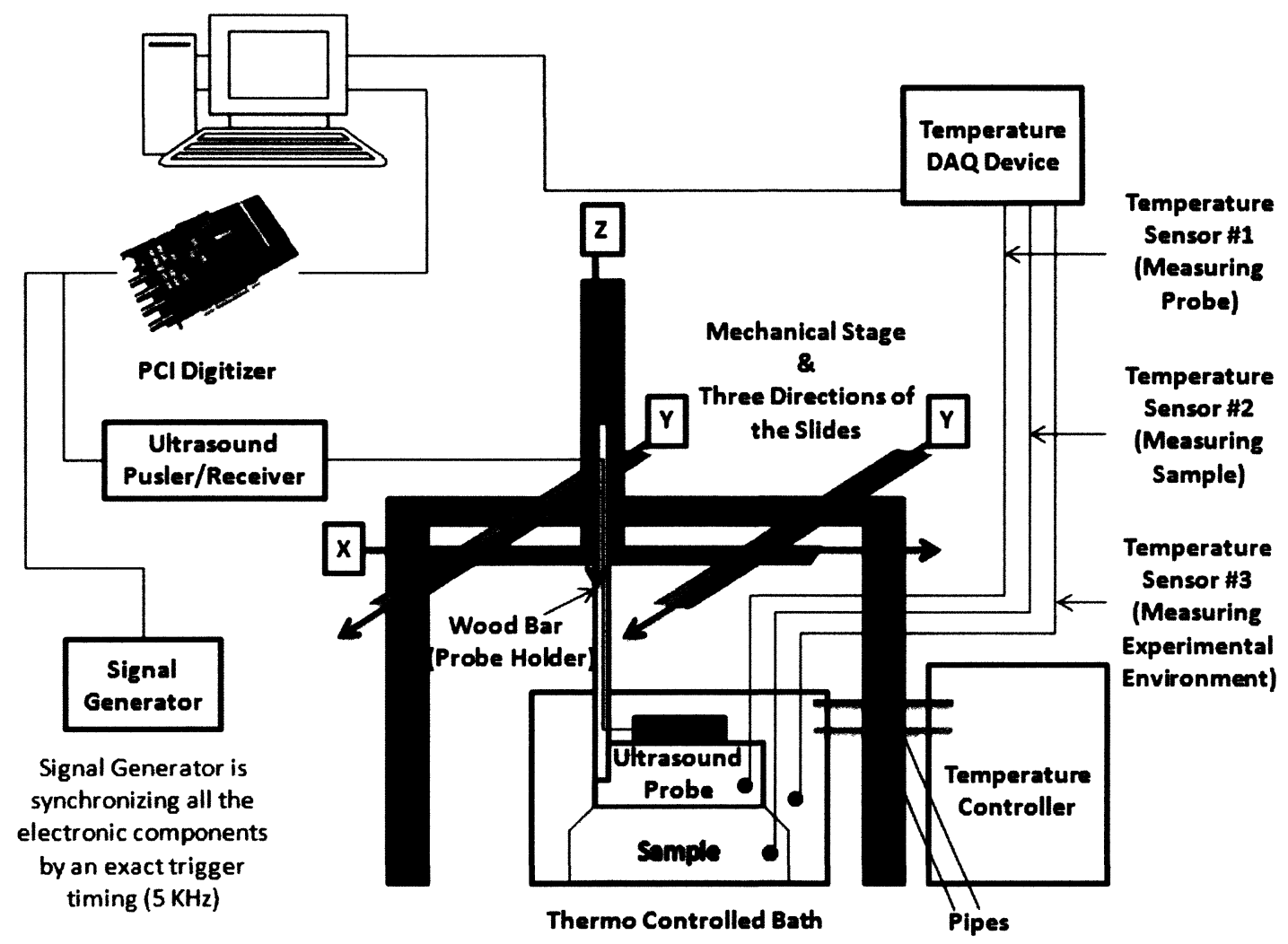

Figure. 3.1 - Diagram of the measurement system design.

As Figure 3.1 shows, the signal generator (HP 3312A, Hewlett Packard) supports a serial of stable frequency signals as exact trigger timing to synchronize all the electronic components. An ultrasound pulser/receiver (Olympus PANAMETRICS-NDT 5900PR) sends the ultrasound pulse repetition (PR) frequency signals to the UT. The ultrasound probe generates the longitudinal and shear wave simultaneously to measure the reflection coefficients at the interface between the substrate and test sample. Through the longitudinal and shear reflectance principle, the reflected signals are acquired by the PCI digitizer (AlazarTech ATS 460), and processed by the software programs. A temperature controlled device (Thermo Scientific RTE-7 D+ 115/60) and a temperature- 
controlled bath may be used during the experiments for keeping the experimental temperature constant if required.

The mechanical stage is designed for controlling the movement of the ultrasound probe along with z-direction. A wood bar is used to hold the probe to the stage. Choosing a lumber bar reduces thermal transmission. Three temperature sensors may be used to measure the temperature of transducer (Sensor \# 1), sample fluid internal temperature (Sensor \# 2), and the environmental temperature (Sensor \# 3), respectively. Data is collected by the temperature DAQ device (Vernier LabPro) and processed by the software program.

\subsection{Details of Hardware Components}

This section introduces the following devices, which are used and will be used for future research.

\subsubsection{Ultrasound Probes}

Before introducing the existing ultrasound probes which are available and being used for this thesis, here is the theoretical calculation for the design of a high sensitivity probe. The design is mainly for the substrate material selection and UT frequency choice. By considering the viscosity measurement sensitivity, all the theoretical calculation is based upon the SW investigation.

\subsubsection{Theoretical Calculation for Ultrasound Probe Design}

From the equations in Chapter 2, the relationship between each parameter is obtained. In this section, the shear performance of probe is investigated. Amplitude ratios $r$ and phase shifts $\Delta \phi$ are shown in Figures 3.2 - 3.4 (a) and (b), respectively. In the calculations, a 
sample is assumed to be a pure viscous fluid (silicone fluid, RT 1,000) with a density of $974 \mathrm{~kg} / \mathrm{m}^{3}$, and viscosity of $1000 \mathrm{cP}$ (data sheet will be presented in appendix).

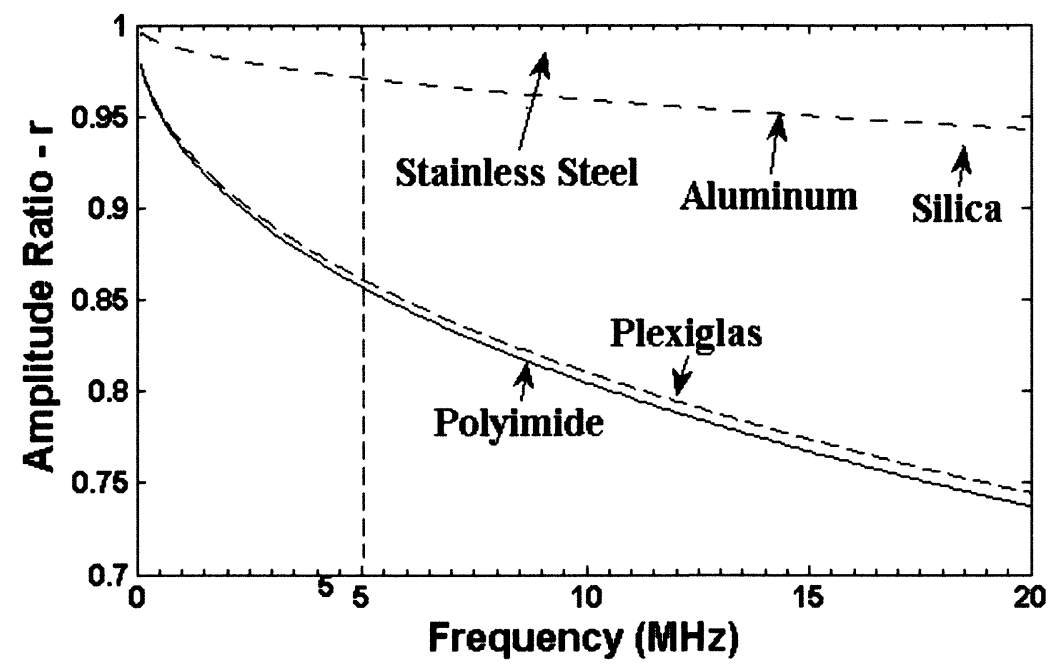

(a)

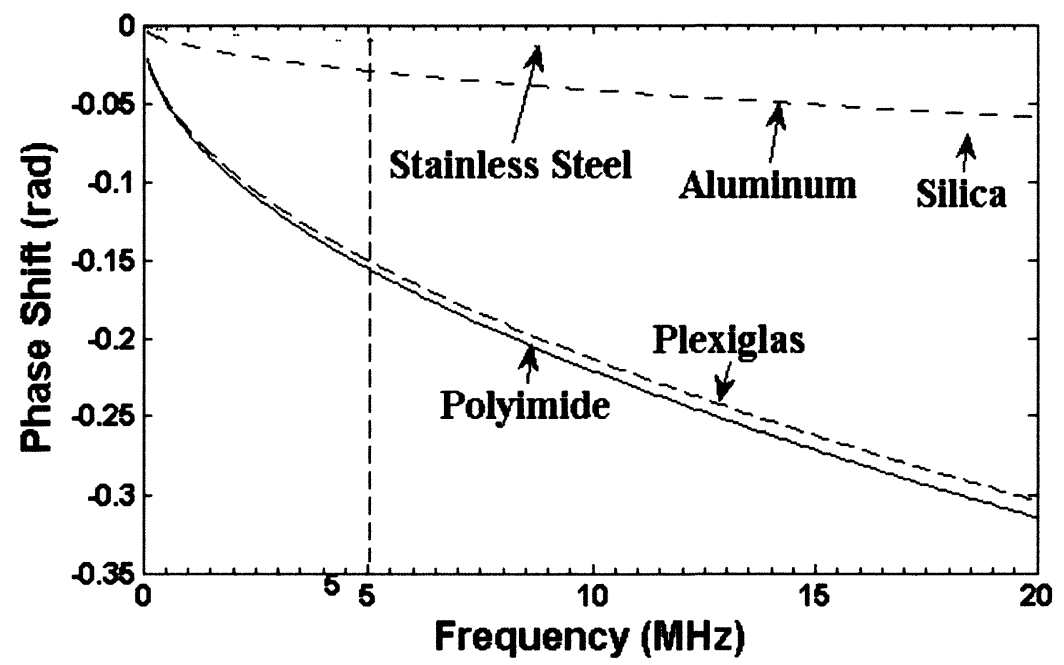

(b)

Figure. 3.2 $-r_{S}$ and $\Delta \phi_{S}$ with different pulse frequency: (a) Amplitude ratios - $r$, (b)

Phase shifts $-\Delta \phi$. 


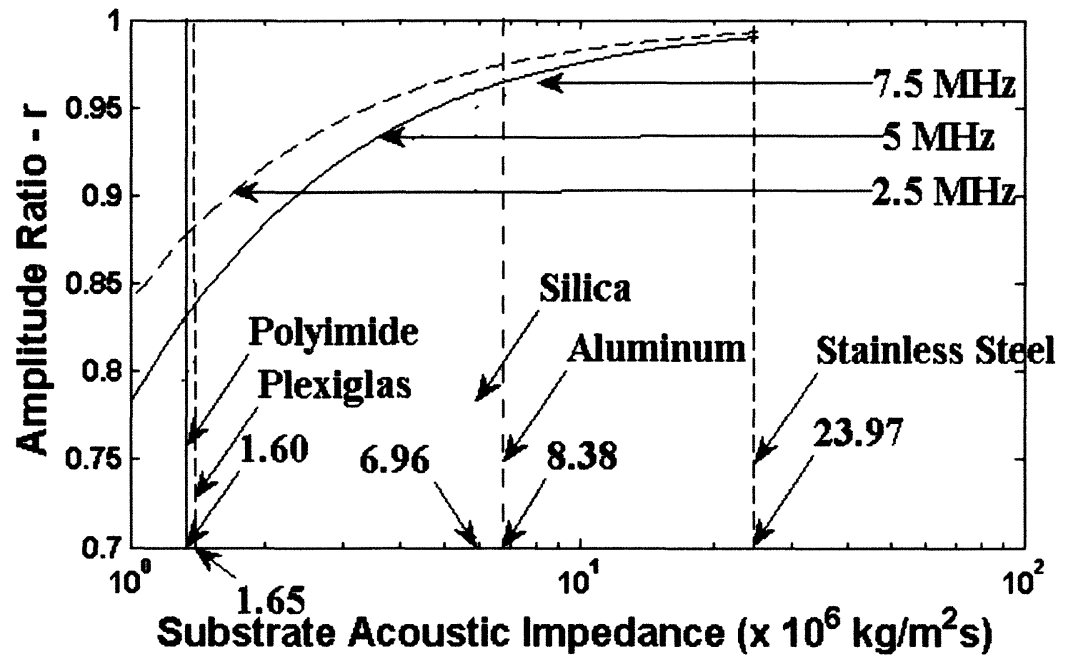

(a)

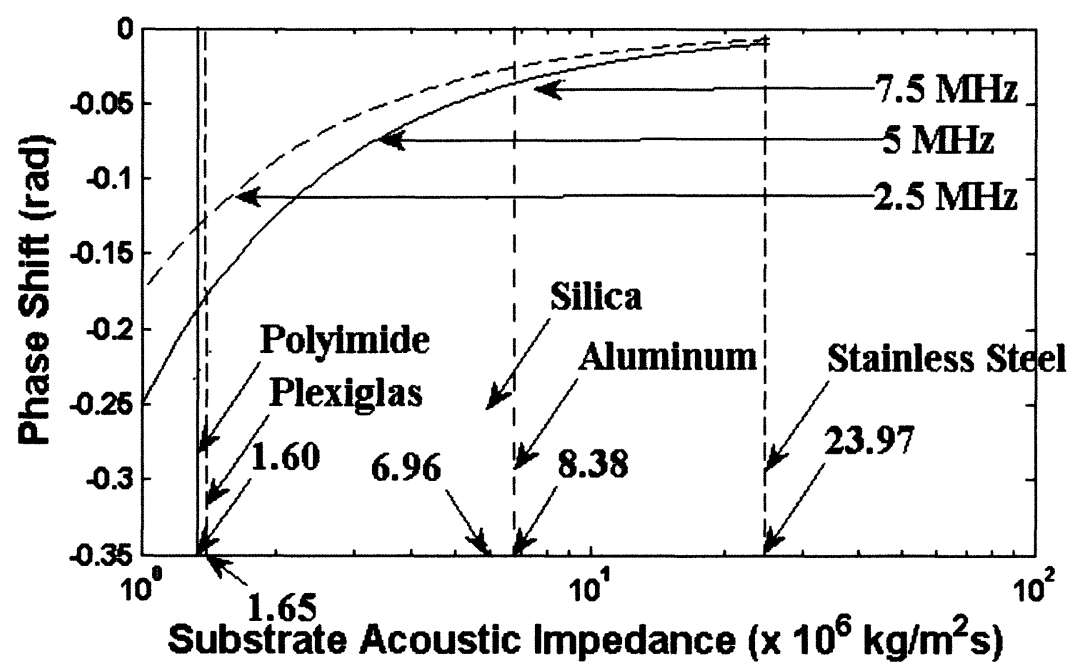

(b)

Figure. $3.3-r$ and $\Delta \phi$ with different $Z_{s u b}$ : (a) Amplitude ratios - $r$, (b) Phase shifts $\Delta \phi$. 


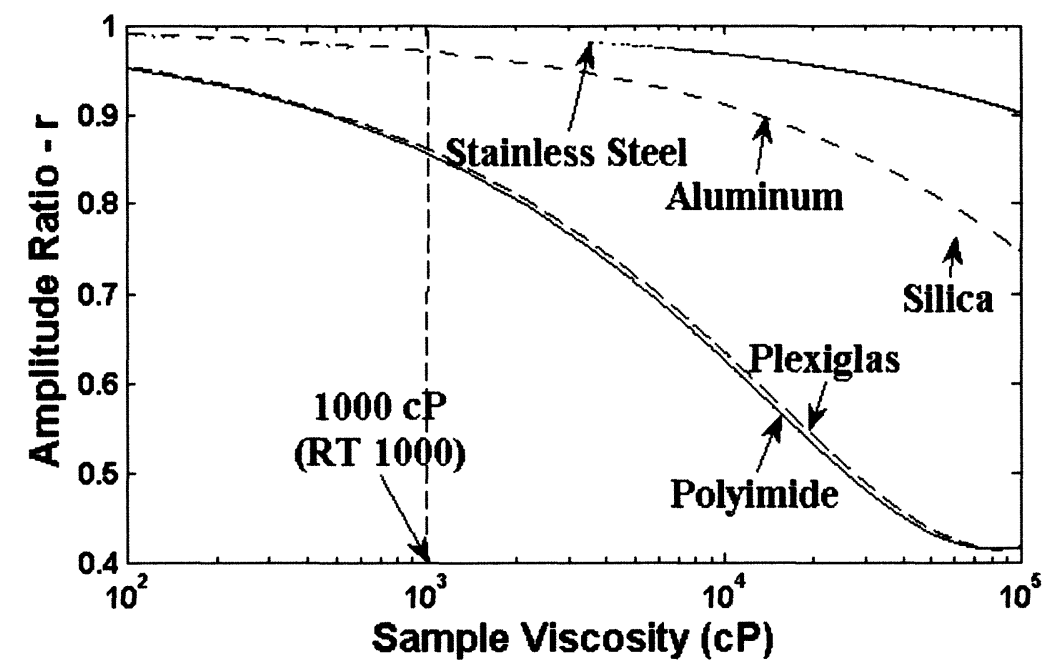

(a)

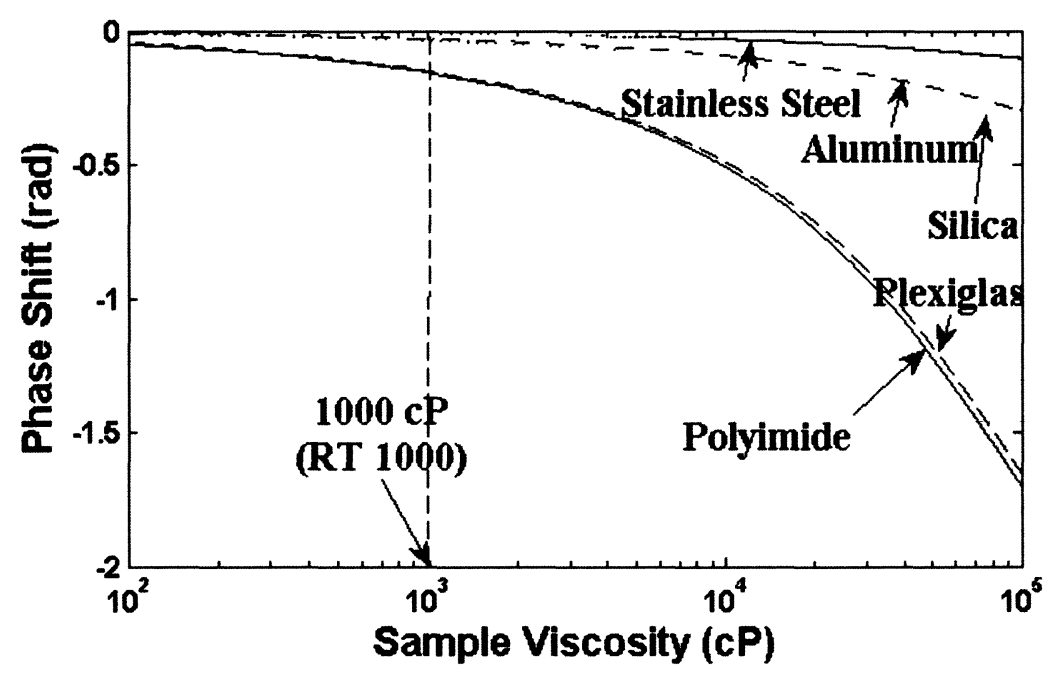

(b)

Figure. 3.4 - $r$ and $\Delta \phi$ with different $\eta$ : (a) Amplitude ratios - $r$, (b) Phase shifts $\Delta \phi$.

Figures 3.2 and 3.3 show the results which relative to ultrasonic frequency and substrate impedance. The frequencies of the results in Figure 3.3 are $2.5 \mathrm{MHz}, 5 \mathrm{MHz}$, and $7 \mathrm{MHz}$. The substrates in Figure 3.2 and Figure 3.4 are stainless steel (SS), aluminum (Al), silica, Plexiglas, and polyimide. Figure 3.4, shows the results with respect to the 
viscosity. The density is kept the same at $974 \mathrm{~kg} / \mathrm{m}^{3}$, and the frequency is $5 \mathrm{MHz}$. Calculated results with these five substrates materials are shown in the Table 3.1.

Table. 3.1 - Amplitude ratio $r$ and phase shift $\Delta \phi$ with $\eta=1000 \mathrm{cP}, \rho_{S}=974 \mathrm{~kg} / \mathrm{m}^{3}$, and frequency is $5 \mathrm{MHz}$.

\begin{tabular}{|c|c|c|c|}
\hline $\begin{array}{c}\text { substrate } \\
\text { materials }\end{array}$ & $\begin{array}{c}\text { substrate acoustic impedance } \\
Z_{S_{-} s u b},\left(\mathrm{~kg} / \mathrm{m}^{2} \mathrm{~s}\right)\end{array}$ & Amplitude ratio $r_{S}$ & $\begin{array}{c}\text { Phase shifts } \\
\Delta \phi_{S,}(\mathrm{rad})\end{array}$ \\
\hline $\begin{array}{c}\text { Stainless Steel } \\
\text { (SS) }\end{array}$ & $2.397 \times 10^{7}$ & 0.9897 & 0.01032 \\
\hline Aluminum (Al) & $8.379 \times 10^{6}$ & 0.9709 & 0.02953 \\
\hline Silica & $6.957 \times 10^{6}$ & 0.9651 & 0.03557 \\
\hline Plexiglas & $1.651 \times 10^{6}$ & 0.8613 & 0.15040 \\
\hline
\end{tabular}

In Figure 3.3, $r$ and $\Delta \phi$ decrease monotonically from 1 (total reflection) and $0 \mathrm{rad}$ (no phase shift), respectively, as the frequency increases. In Figure 3.4, $r$ and $\Delta \phi$ increase monotonically toward the value of 1 (total reflection) and 0 rad (no phase shift), respectively, as $\mathrm{Z}_{\mathrm{UT}}$ increases. These results show that the absolute values for both amplitude shift and phase shift are increasing when the frequency increases, and they are both decreasing when substrate acoustic impedance increases. Therefore, the larger shift of amplitude and phase can be expected at the higher frequencies, and with a substrate possessing lower acoustic impedance. As shown in Table 3.1, the stainless steel (SS) has the largest acoustic impedance among the five substrate materials and the lowest sensitivity. Polyimide has the smallest acoustic impedance, and it shows the largest amplitude and phase change among the five substrate materials. 
These theoretical calculations show that the UT with a substrate possessing lower acoustic impedance and operating at a higher frequency is better for the viscosity measurement sensitivity [36].

In these theoretical calculations, the performances of five substrates are compared. Polymer substrates, such as polyimide and Plexiglas, are more suitable to be substrates in the viscosity measurements due to their lower acoustic impedance compared with the metal substrates. By measuring the $1,000 \mathrm{cP}$ viscosity sample at $5 \mathrm{MHz}$ frequency, polyimide substrate yields $r$ and $\Delta \phi$ of 0.8569 and $0.1556 \mathrm{rad}$, respectively. Plexiglas substrate yields $r$ and $\Delta \phi$ of 0.8613 and $0.1504 \mathrm{rad}$, respectively, in the same conditions. In the real experimental system, there is always a resolution of the measurement system, and this limits the measurement sensitivity. Therefore, low impedance substrate materials, such as polyimide and Plexiglas, are helpful to obtain more accurate results of viscosity in a realistic experiment.

There may be limitations to the real manufacture of the probe; the real ultrasonic frequency is not predictable precisely, as the ultrasonic frequency of the UT may be attenuated during the propagation through the substrate $[7,21,37]$ (higher frequencies especially may attenuate faster). Since higher ultrasonic frequency is better for sensitivity, it is suggested that a probe is designed and developed using the substrate of polyimide or Plexiglas, setting the ultrasonic frequency of the UT as high as it can be. 


\subsubsection{Diagram of the Ultrasound Probe Design}

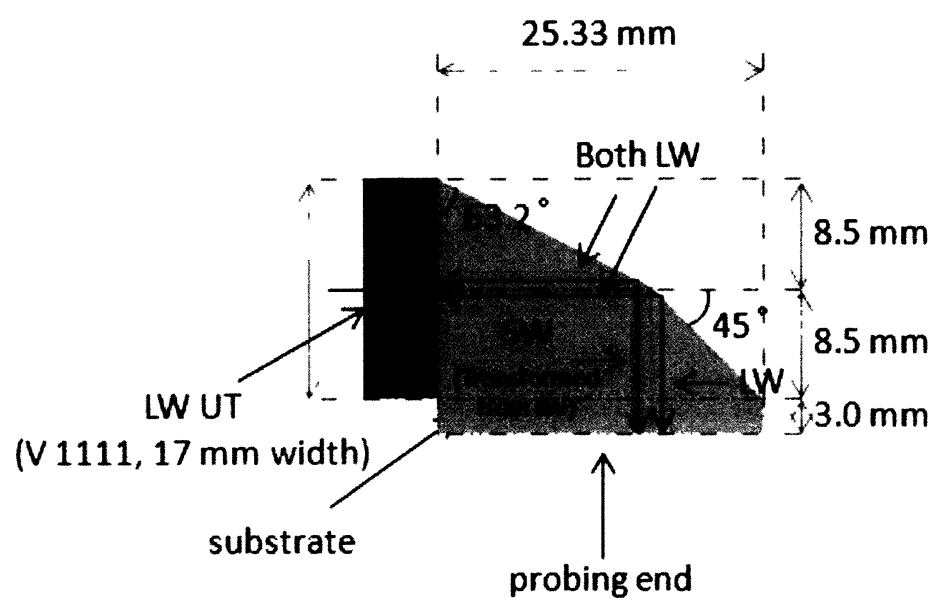

Figure. 3.5 - Diagram of the ultrasound probe design.

A new type of ultrasound probe is originally designed for tissue viscoelasticity measurement as shown in Figure 3.5. A Plexiglas substrate is designed to attach to an available LW UT (V 1111) working at a relative high frequency. The substrate is shaped with two angles: one with angle $63.2{ }^{\circ} \mathrm{C}$ transforms the incident $\mathrm{LW}$ to reflected $\mathrm{SW}$, the other one with angle $45^{\circ}$ reflects the incident LW in parallel to the nearby SW. The size designed for the probe is based on the size of the UT attached and the high attenuation of the Plexiglas substrate. The substrate based on this design has only been produced recently and will not be used in this thesis; it will be introduced in Chapter 7 .

The original purpose of designing such a probe which generates LW and SW simultaneously was to measure both tissue viscosity and elasticity simultaneously. In this thesis, parameters of SW, especially the sample viscosity estimation, is mainly used to investigate the system measurement sensitivity. 


\subsubsection{Available Ultrasound Probes for Current Research}

The designed probe was not available at the time. Instead, there are two similar ultrasound probes have been used for the research in this thesis, probe \#1 and probe $\# 2$, respectively, as shown in Figure 3.6 and Figure 3.8. These probes were designed and manufactured in collaboration with the Industrial Materials Institute, National Research Council Canada (Boucherville, QC).

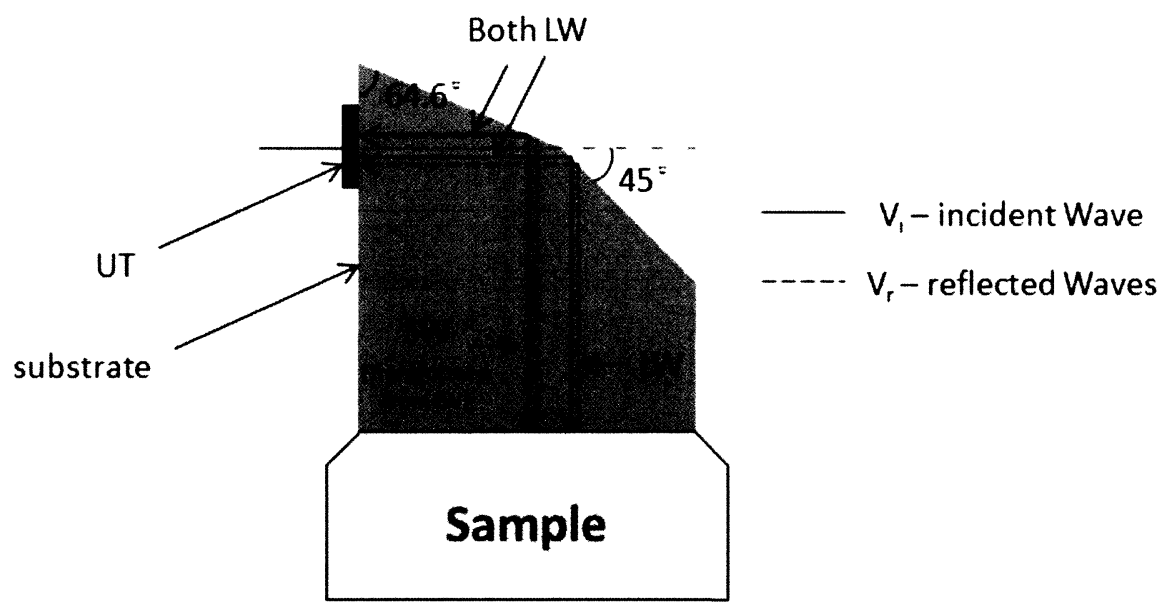

(a)

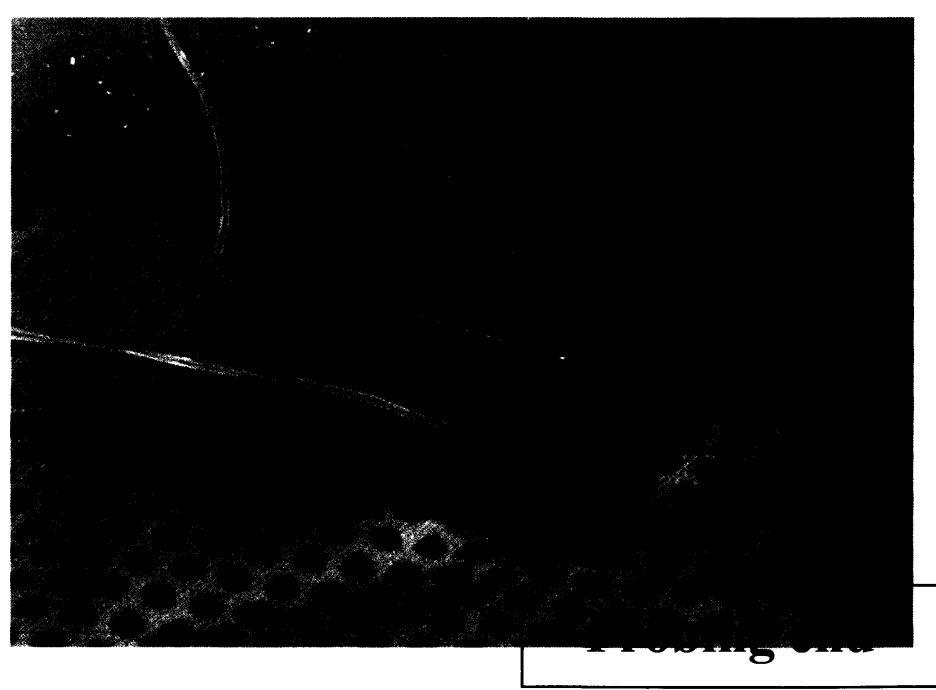

(b)

Figure. 3.6 - Probe \#1: (a) wave propagation path in probe \#1, (b) probe product. 
Probe \#1 has a substrate of aluminum [3]. There is an angle of $64.6^{\circ}$, to transform the outgoing $\mathrm{LW}$ into $\mathrm{SW}$, and an angle of $45^{\circ}$, to reflect the $\mathrm{LW}$ propagated in parallel with the SW. Therefore, this ultrasound probe can generate both longitudinal and shear waves simultaneously. The transducer is connected to the pulser/receiver by using a coaxial cable. The design and product of this probe are shown in Figure 3.6 [3].

This probe detects two echoes as shown in the Figure 3.7. The former is the LW and the SW is the latter [3]. This waveform figure is the first frame of the total collected data, obtained without a sample attached. With a window size $10.944 \mu$ s, starting from the $1^{\text {st }} \mathrm{LW}$ echo and ending after the $1^{\text {st }} \mathrm{SW}$ echo, the horizontal axis shows relative time delay.

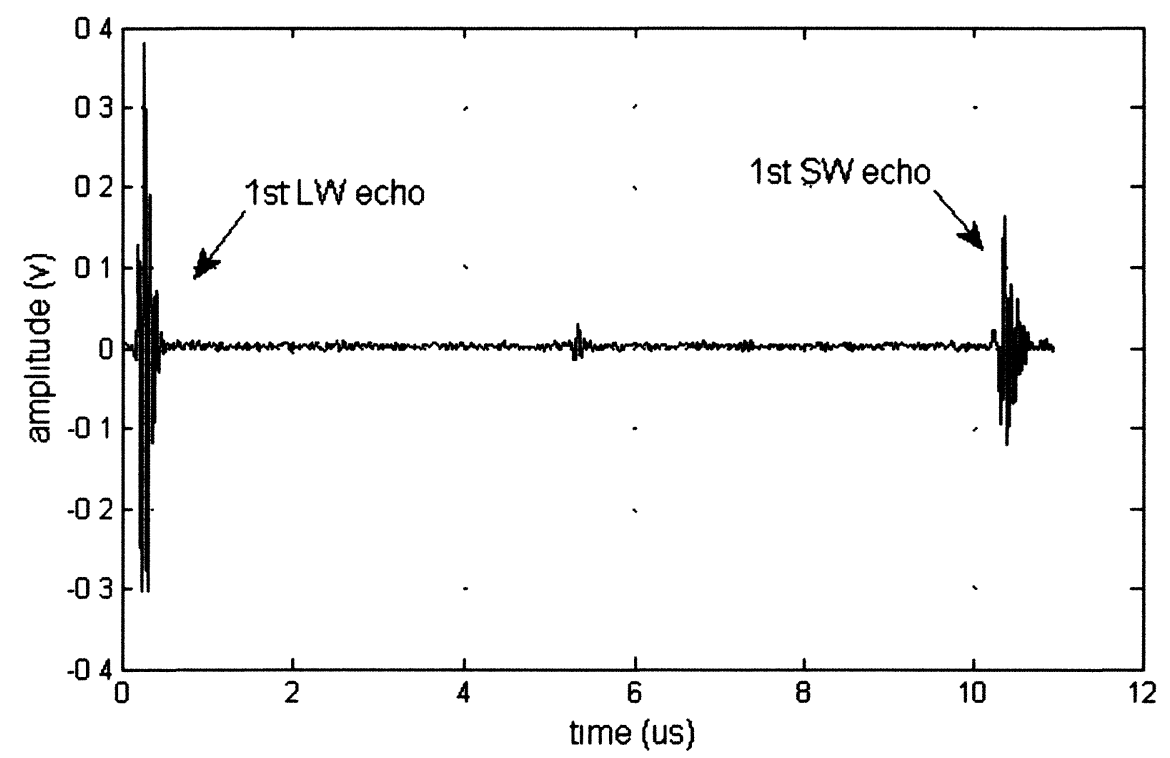

Figure. 3.7 - Waveform of the $1^{\text {st }}$ echo for both $\mathrm{LW}$ and SW in probe \#1. 
The $1^{\text {st }}$ frame's magnitude spectrum for LW and SW of this probe are shown in the Figure 3.8:

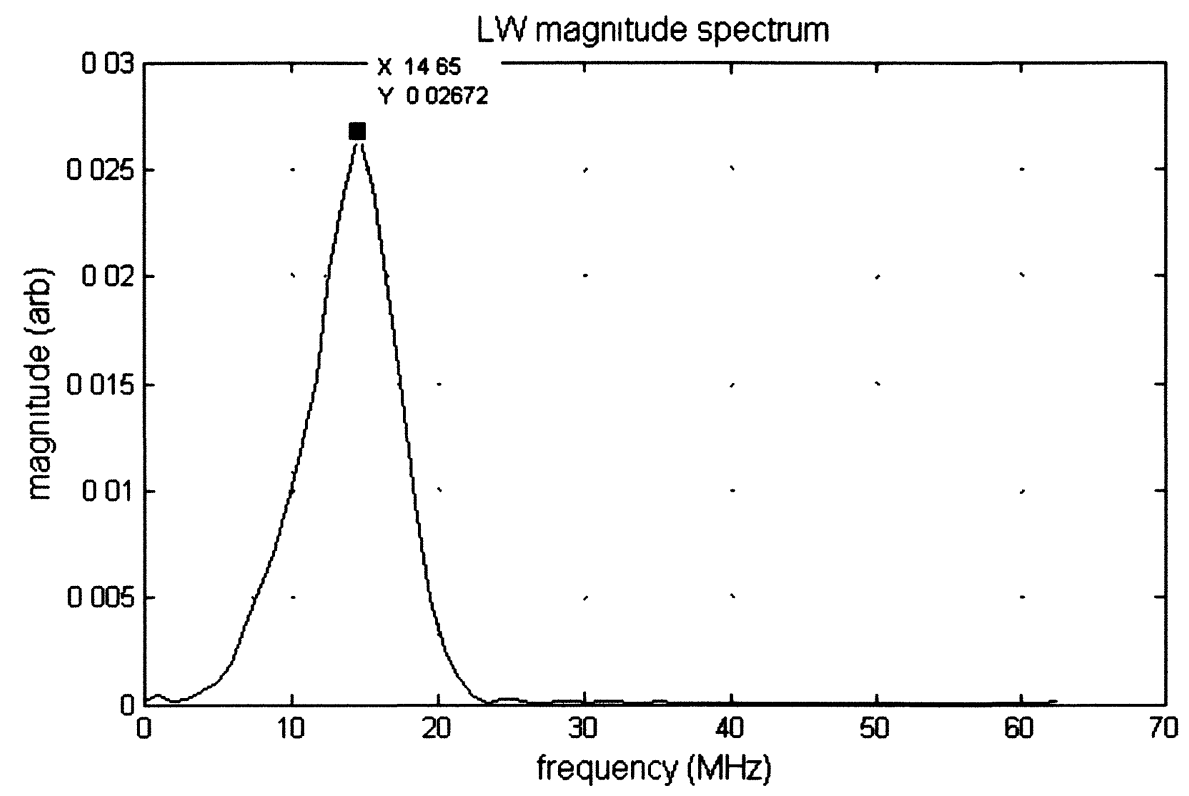

(a)

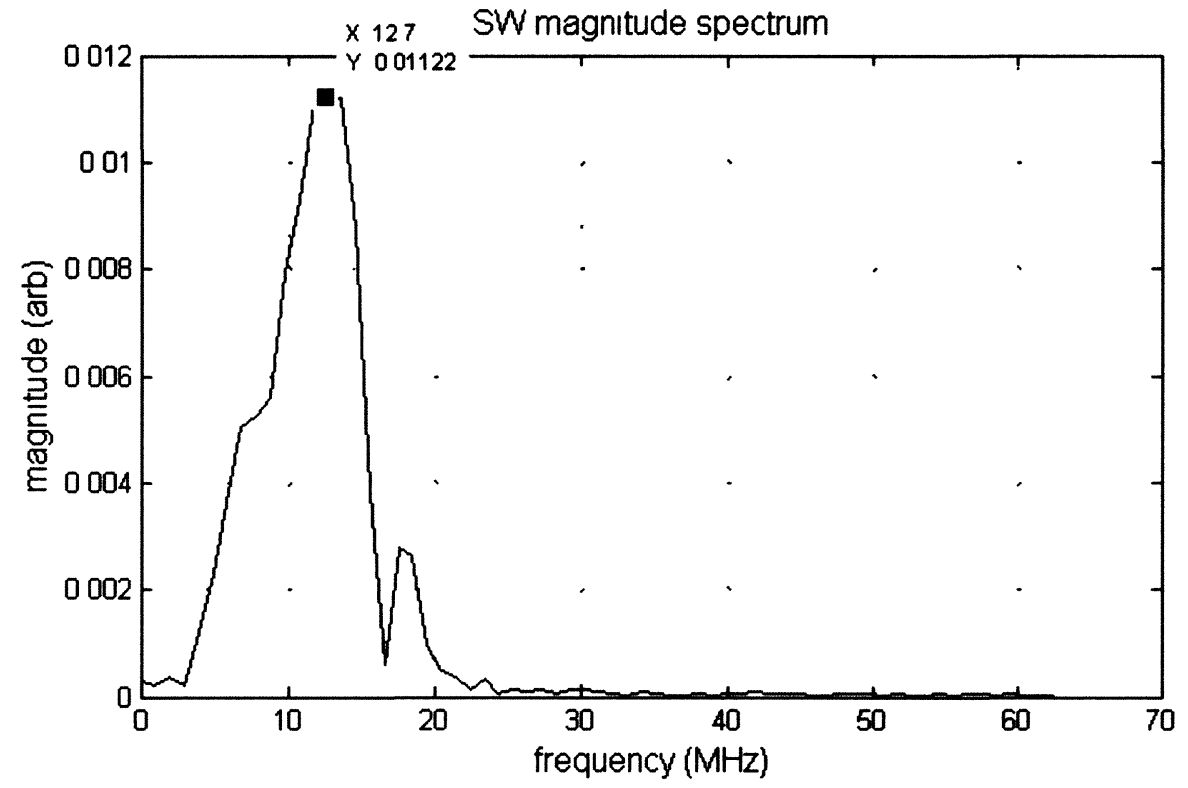

(b)

Figure. 3.8 - The magnitude spectrums for probe \#1: (a) LW spectrum, (b) SW spectrum.

This $\mathrm{Al}$ probe has center frequencies of $14.65 \mathrm{MHz}$ and $12.7 \mathrm{MHz}$, for $\mathrm{LW}$ and SW, respectively. Since the high frequency components of SW have more attenuation 
than those of $\mathrm{LW}[3,7,21,37]$, the SW center frequencies of this probe are therefore lower.

The $1^{\text {st }}$ frame's phase spectrums for this probe are shown in Figure 3.9:

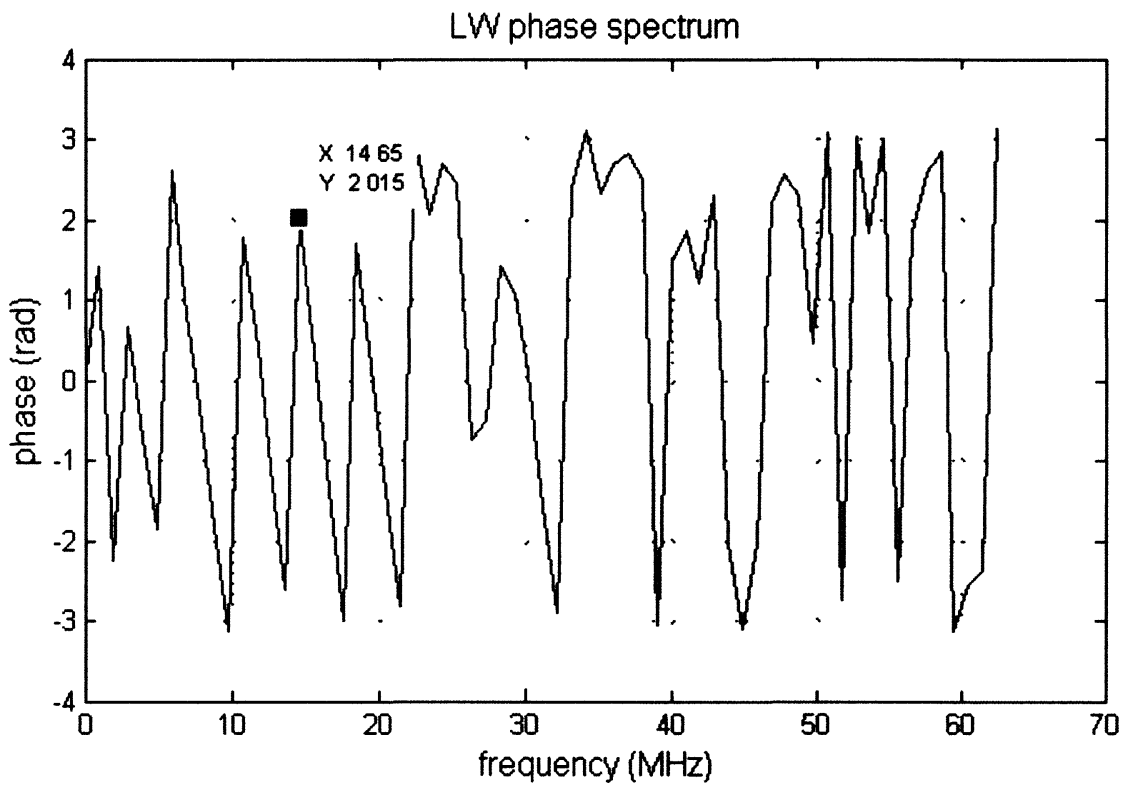

(a)

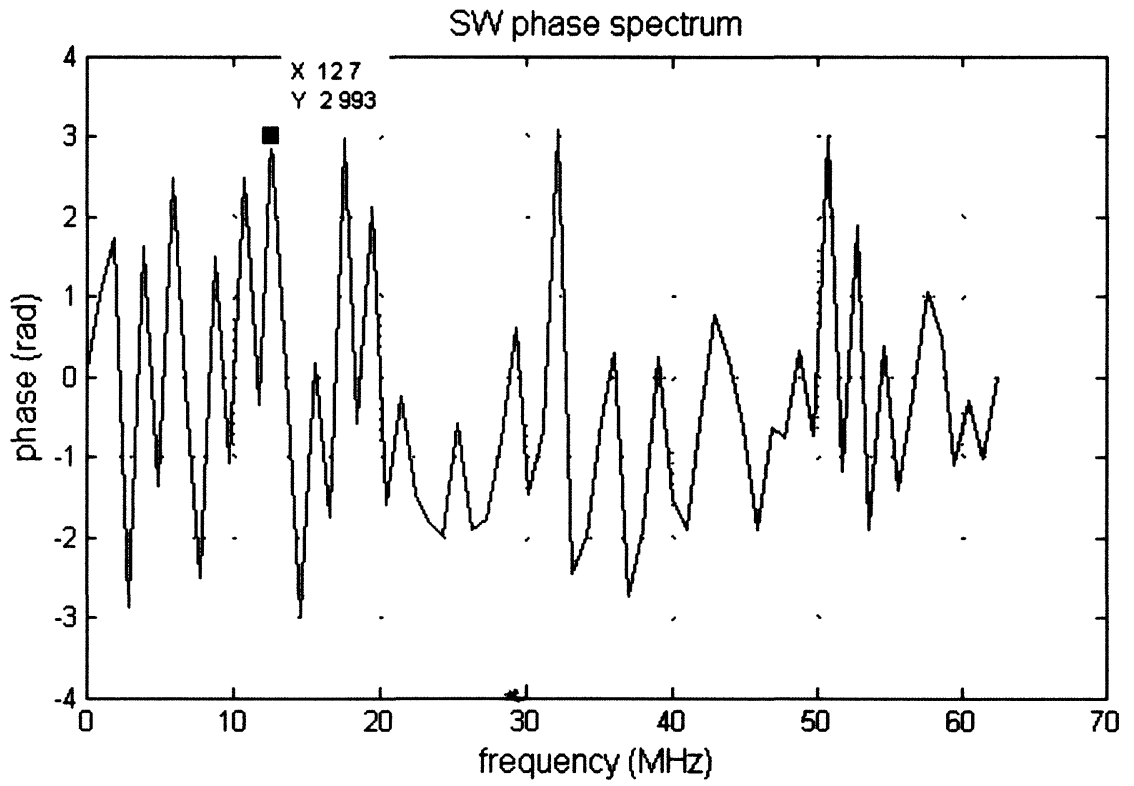

(b)

Figure. 3.9 - The phase spectrums for probe \#1: (a) LW spectrum, (b) SW spectrum. 
The substrate of Probe \#2 is made of Plexiglas. An angle of $63.2^{\circ}$ is designed to transform the LW into SW, shown as Figure 3.10:

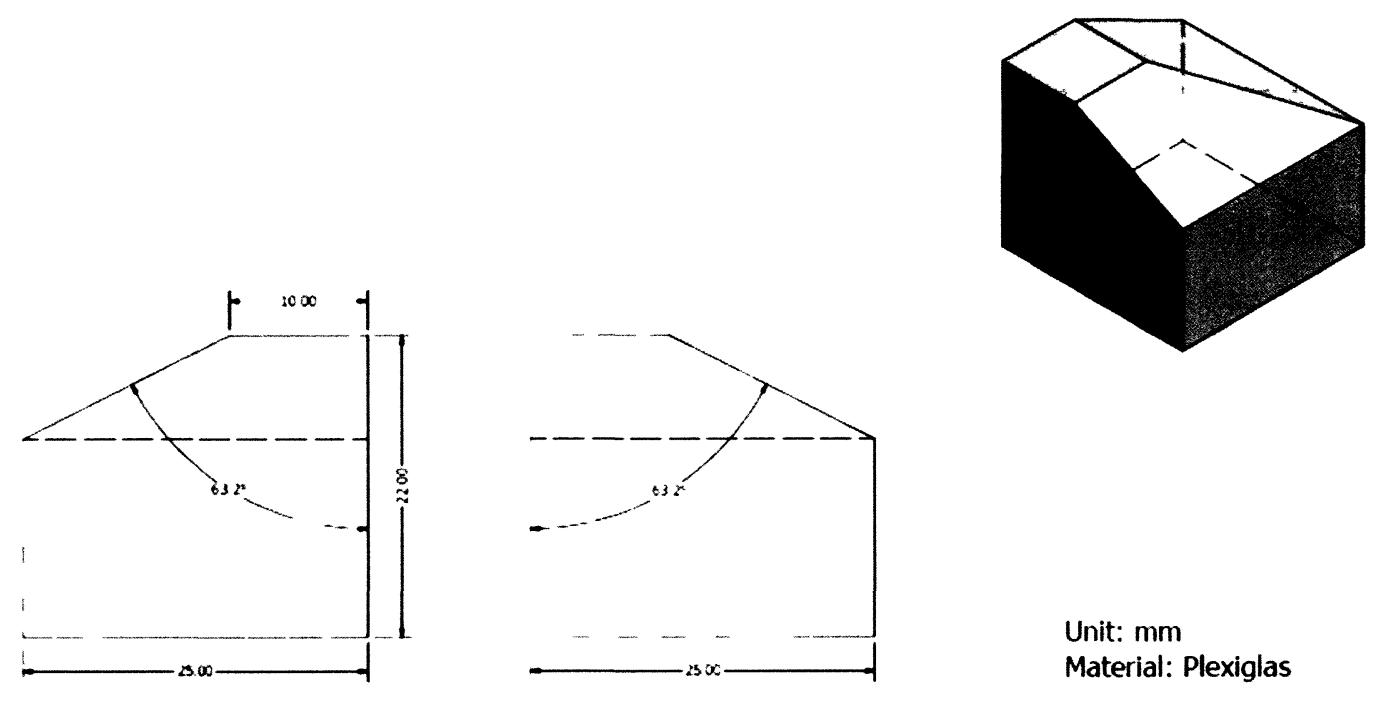

(a)

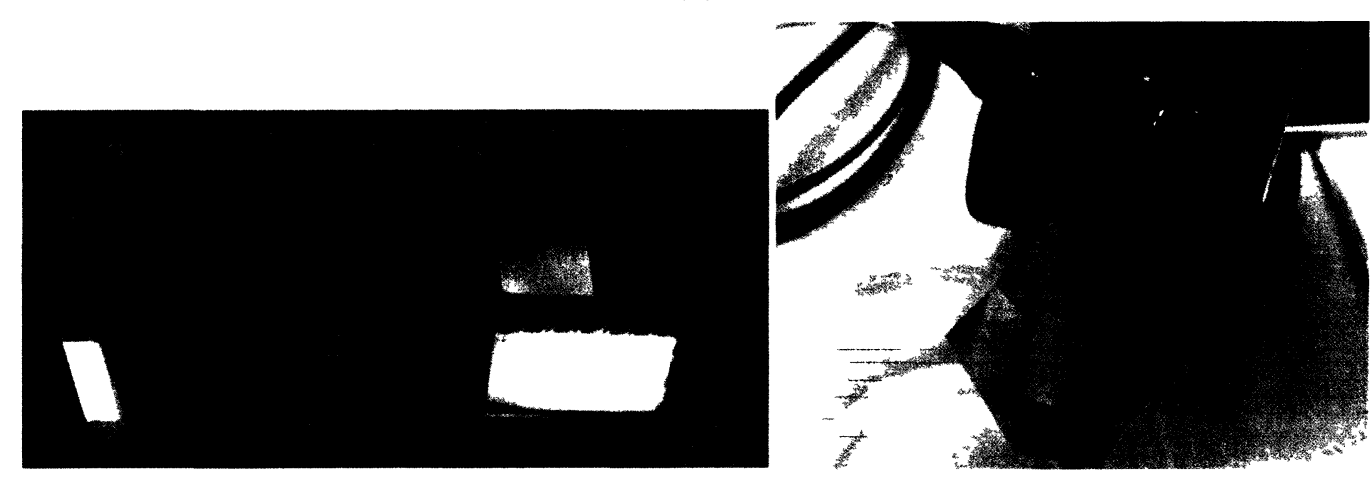

(b)

(c)

Figure. 3.10 - Probe \#2: (a) design, (b) buffer rod substrate, (c) probe (Plexiglas substrate and LW UT, V1111).

Probe \#2 is designed for generating SW from LW. The reason to use this probe is that probe \#2 has better sensitivity than probe \#1 based on the theoretical calculation in Section 3.2.1.1. Al substrate is produced for probe \#1, which is not the same as the design. Therefore, to test the performance with polymer substrate (polyimide or Plexiglas), probe \#2 is used. A LW UT (V1111, Panametrics), is attached to the Plexiglas substrate by using UT couplant. 
Waveform of this probe is shown as Figure 3.11. The first frame of the total collected data is shown, obtained without sample attachment. Window size $2.048 \mu \mathrm{s}$ includes the $1^{\text {st }} \mathrm{SW}$ echo, and the horizontal axis shows relative time delay.

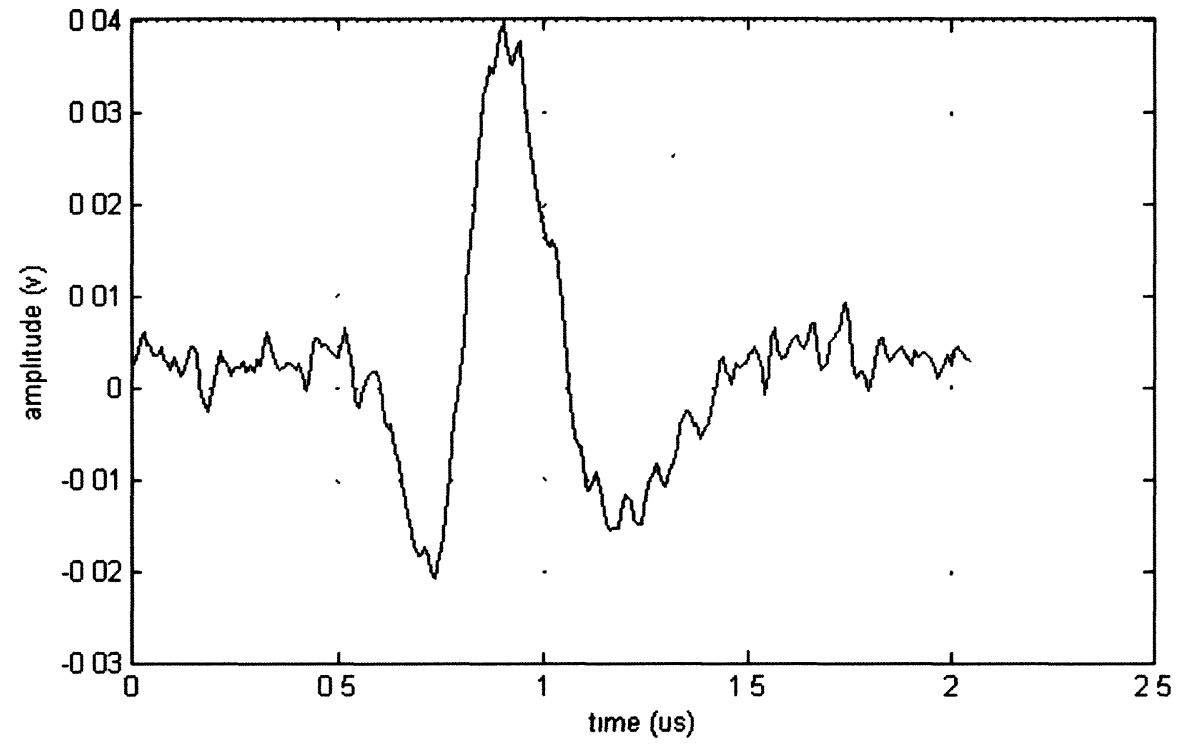

Figure. 3.11 - Waveform of $1^{\text {st }}$ echo for SW in probe \#2.

The center frequency for SW of this probe is $1.465 \mathrm{MHz}$, as shown in Figure 3.12:

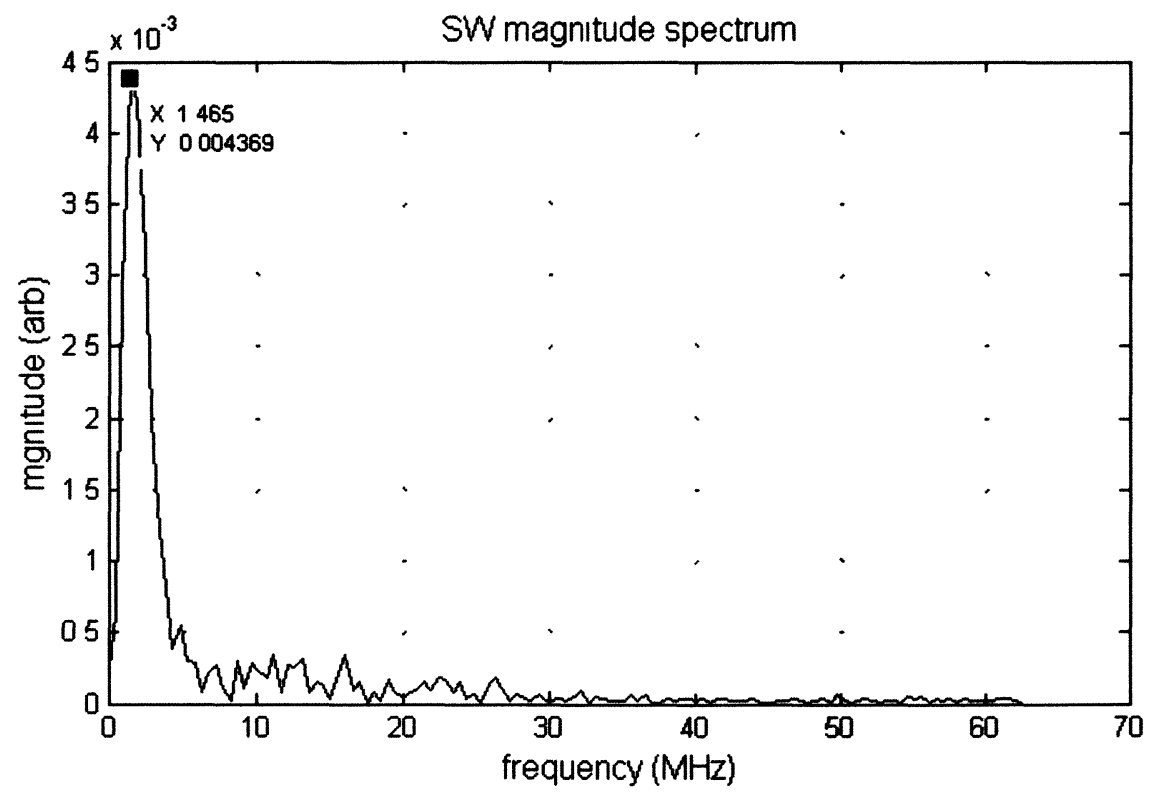

Figure. 3.12 - The magnitude spectrum for $\mathrm{SW}$ of probe \#2. 
For this probe, as the Plexiglas has much more shear attenuation than $\mathrm{Al}[4,7,38]$ therefore high frequency components are almost attenuated and the center frequency reduces to $1.465 \mathrm{MHz}$. Therefore, comparing with the probe \#1, which uses $\mathrm{Al}$ as substrate, probe $\# 2$ has a much lower center frequency. The $1^{\text {st }}$ frame's phase spectrums for this probe are shown in Figure 3.13:

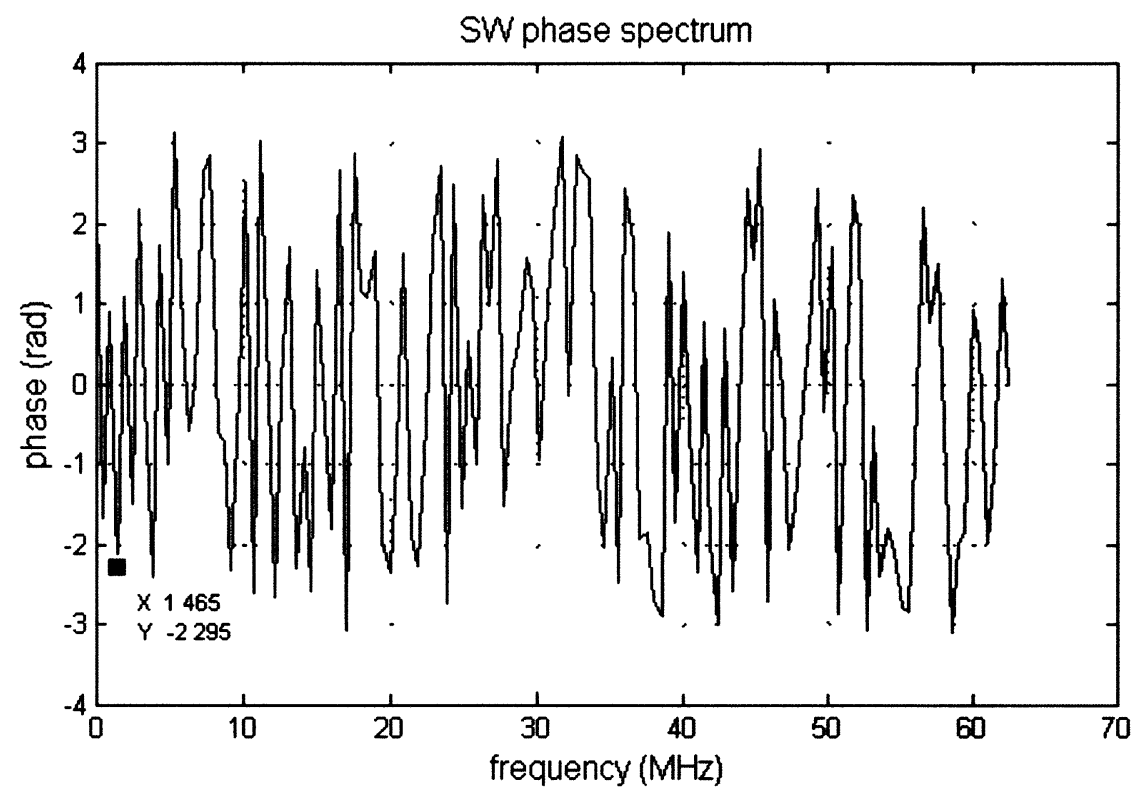

Figure. 3.13 - The phase spectrums for SW of probe $\# 2$.

Data are analyzed by implementing a Fourier transformation to the selected frequency components. Amplitude and phase are obtained after the Fourier transformation. The units for the amplitude and phase in this thesis are an arbitrary unit (arb) and in radians (rad), respectively. 


\subsubsection{Mechanical Stage}

The mechanical stage is designed and constructed using components purchased from VELMEX Inc. as shown in Figure 3.14. It is designed for holding and moving the ultrasound probe in $\mathrm{X}, \mathrm{Y}, \mathrm{Z}$ directions by its control system.
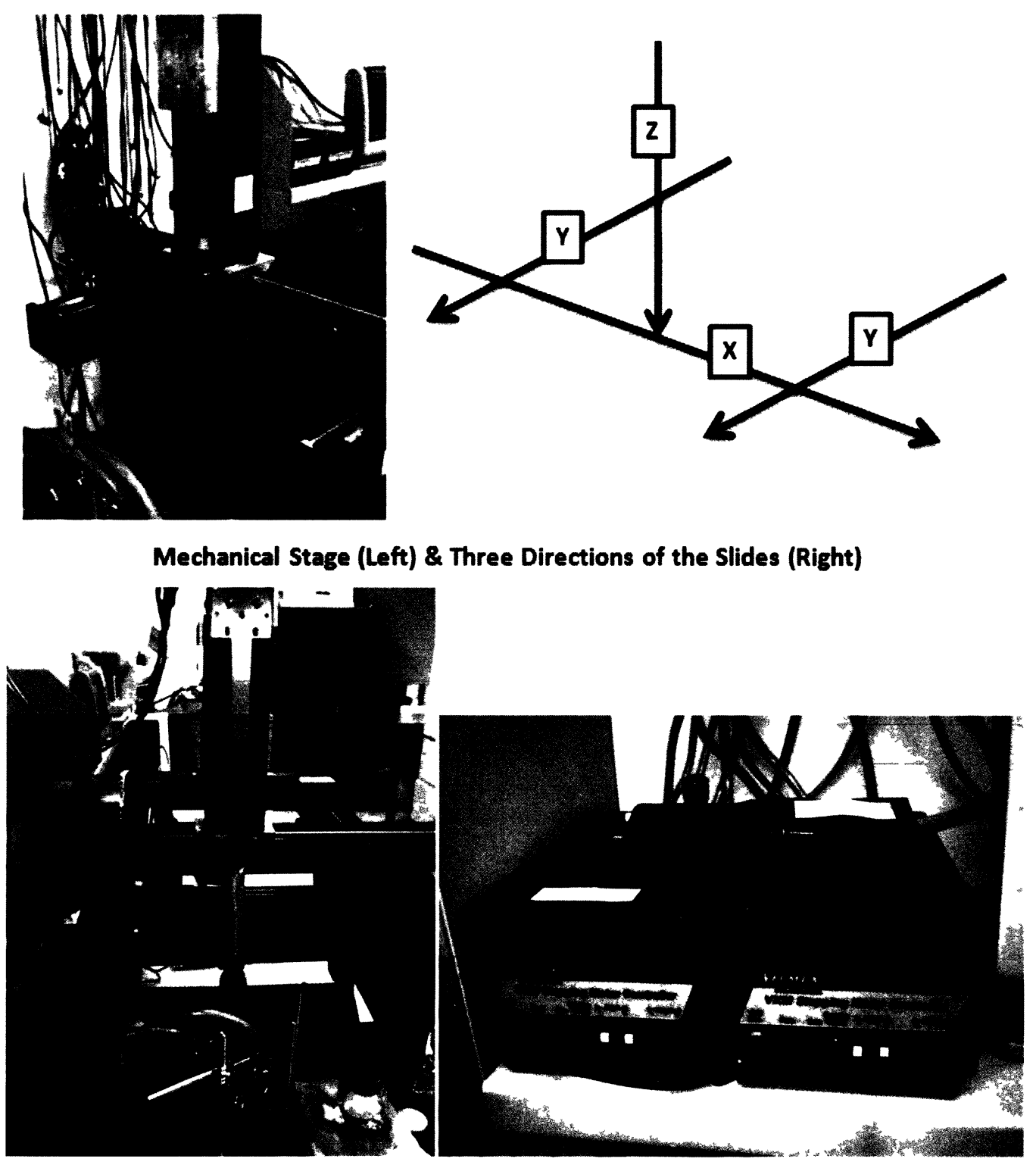

Figure. 3.14 - Mechanical stage and Slides Controllers.

This mechanical stage can stably hold and keep the probe for a long time. Both hardware and software can control the movement of the slides. 


\subsubsection{Temperature Measurement Device}

The temperature measurement device is consisted of two parts: temperature sensors (Vernier), and a DAQ device (LabPro, Vernier). The temperature data is recorded and processed by the software program, which will be implemented in future research. The DAQ device (shown as Figure 3.15) is connected to the computer with a USB cable.

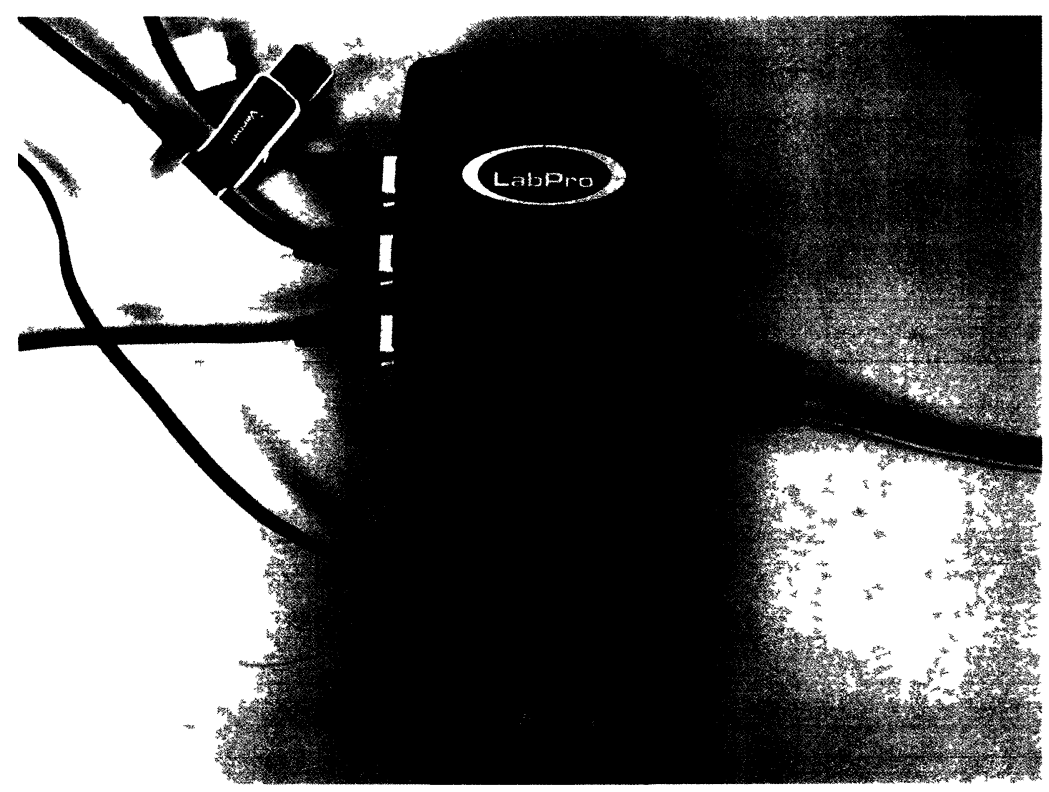

Figure. 3.15 - Temperature DAQ device.

The temperature sensors include two surface sensors (sensor \#1 and \#2) with a resolution of $0.025^{\circ} \mathrm{C}$, and one $\mathrm{K}$-type thermocouple (sensor \#3) with a resolution of $0.3^{\circ} \mathrm{C}$. Surface sensors observe and measure the temperature of the ultrasound probe and the test sample, and the thermocouple is placed near the probe and sample to observe the environmental temperature.

\subsubsection{Temperature Control System}

RTE-7 D $+115 / 60$ by Thermo Scientific is used as the temperature control system. High temperature and pressure pipes are connected to this machine to circulate the 
temperature-controlled water to the temperature-controlled bath. The device is shown in Figure 3.16.
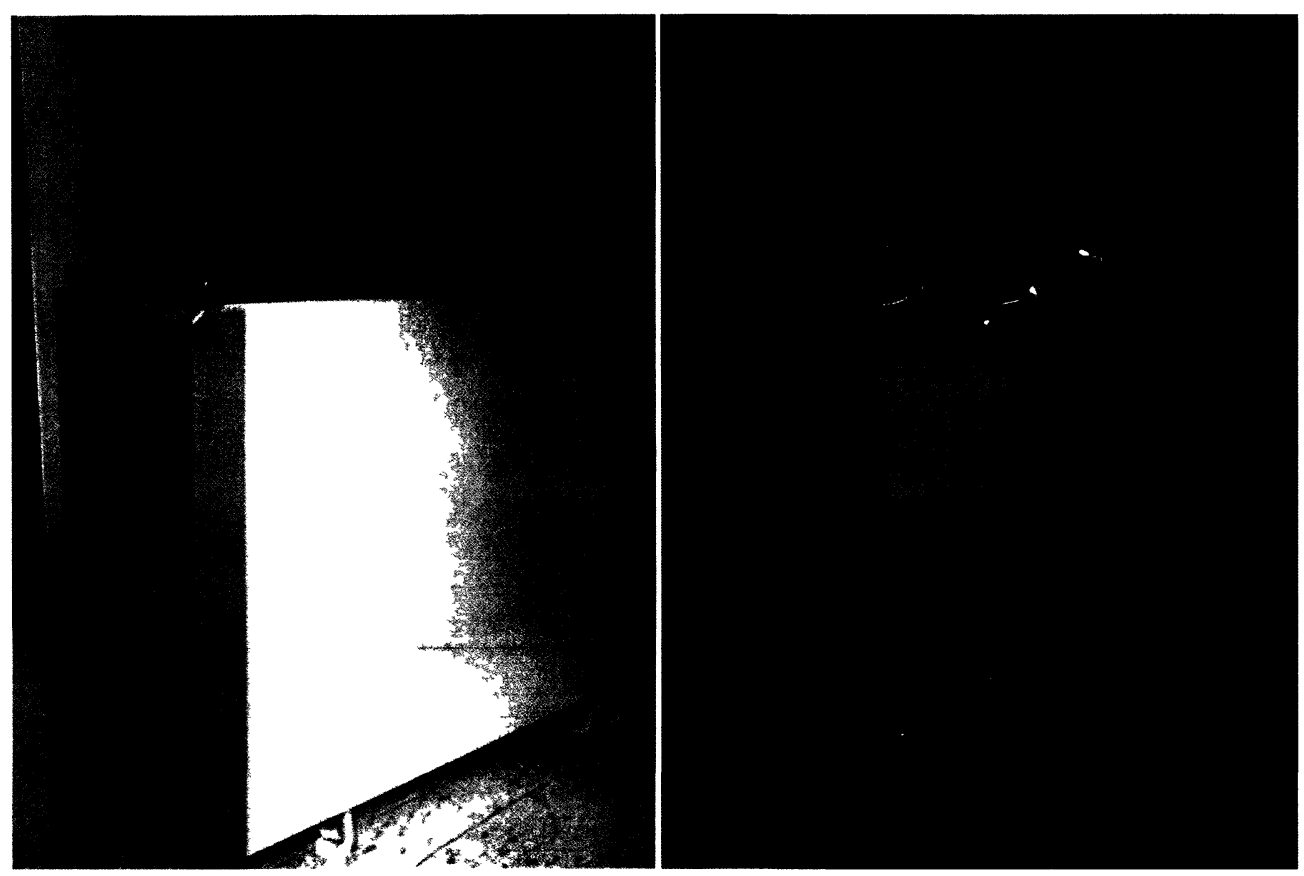

Figure. 3.16 - Refrigerated bath, RTE-7 D+ 115/60.

Our device can process a fluid temperature range from $-25^{\circ} \mathrm{C}$ to $150^{\circ} \mathrm{C}$, with $1.2^{\circ} \mathrm{C} / \mathrm{min}$ temperature changing rate, and the temperature stability (at $20^{\circ} \mathrm{C}$, near the sensor in the RTE-7's tank) is $\pm 0.01^{\circ} \mathrm{C}$.

This temperature controller is planned to be used in future research, for the investigation of the temperature dependence of viscosity in tissue or tissue-like materials. 


\subsubsection{Electronics}

The connection of all the electronic devices is shown as Figure 3.17.

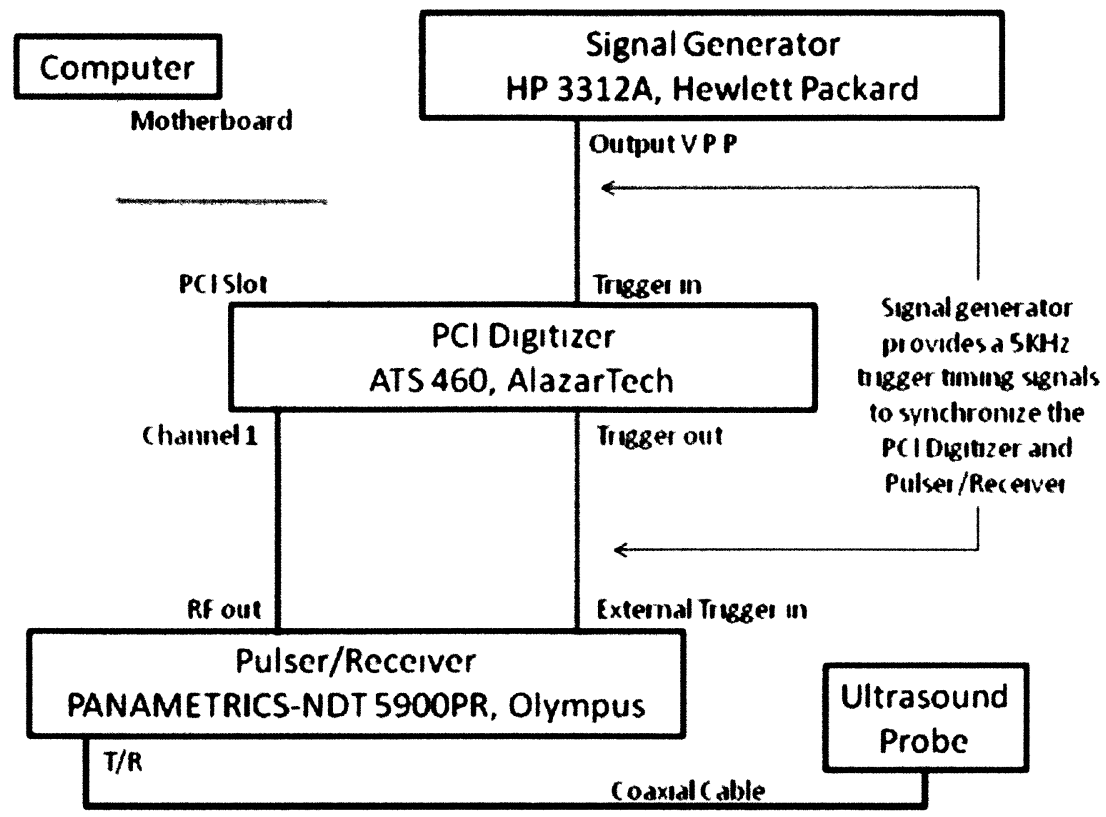

Figure. 3.17 - Electronic devices connection.

In this research, a HP 3312A Function Generator, Hewlett Packard, is used as the signal generator, and a PANAMETRICS-NDT 5900PR, Olympus, is used as the ultrasound pulser and receiver, showed in the Figure 3.18.

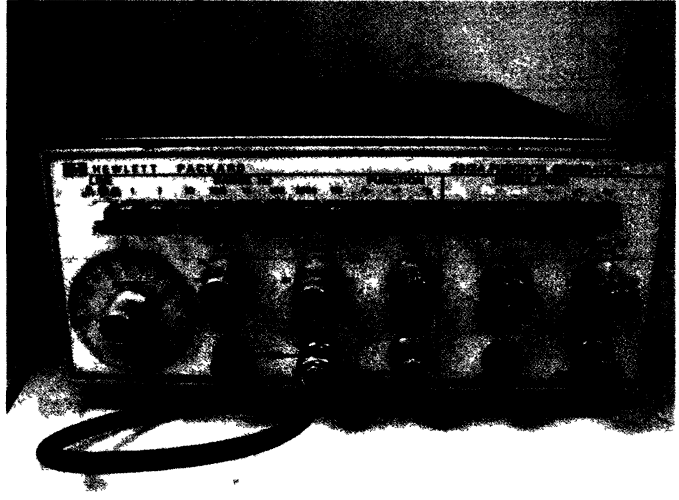

(a)

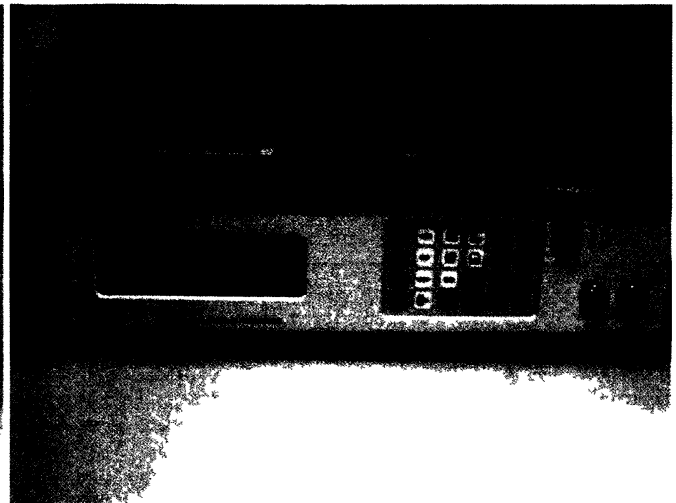

(b)

Figure. 3.18 - Electronic devices: (a) signal generator, (b) ultrasound pulser /receiver. 
A $5000 \mathrm{~Hz}$ serial square wave is created by the signal generator stably, to trigger the PCI digitizer (to be introduced in Section 3.2.6). The pulser/receiver is triggered by the digitizer, and passes the ultrasound signals from the probe to the digitizer. All devices are synchronized by the signal generator.

\subsubsection{Ultrasound Data Acquisition System}

The ultrasound DAQ system consists of the PCI digitizer and DAQ software programs.

AlazarTech ATS 460 (shown as Figure 3.19), which has 14-bit resolution and a $10 \mathrm{KHz}$ to $125 \mathrm{MHz}$ sampling rate range, is used as the PCI digitizer to acquire the signals in the current research. It is synchronized with the signal generator and the ultrasound pulser/receiver, to reduce the wave jitter during measurements. In current research, all experiments use $125 \mathrm{MHz}$ as sampling rate.
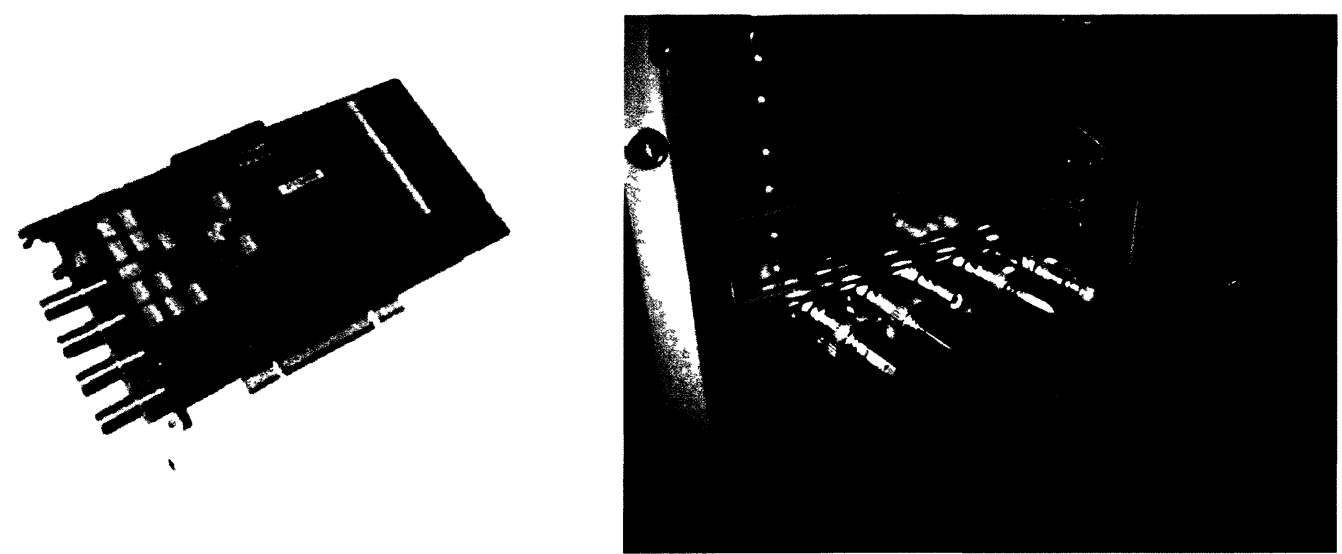

Figure. 3.19 - PCI digitizer, ATS 460.

For current research, the DAQ software application is designed and programmed by the platform LabVIEW 8.2. This is a basic DAQ program, which can only acquire data once each time and cannot save the collected data onto PC hard disk and is provided by AlazarTech. For the purposes of research and this thesis, this program is modified to 
allow acquiring data continuously and saving the data collected from a selectable DAQ time period. The application is shown in Figure 3.20. Data is collected, displayed, and saved directly on the computer hard disk. Signal processing is conducted through the programs by MATLAB 2009.

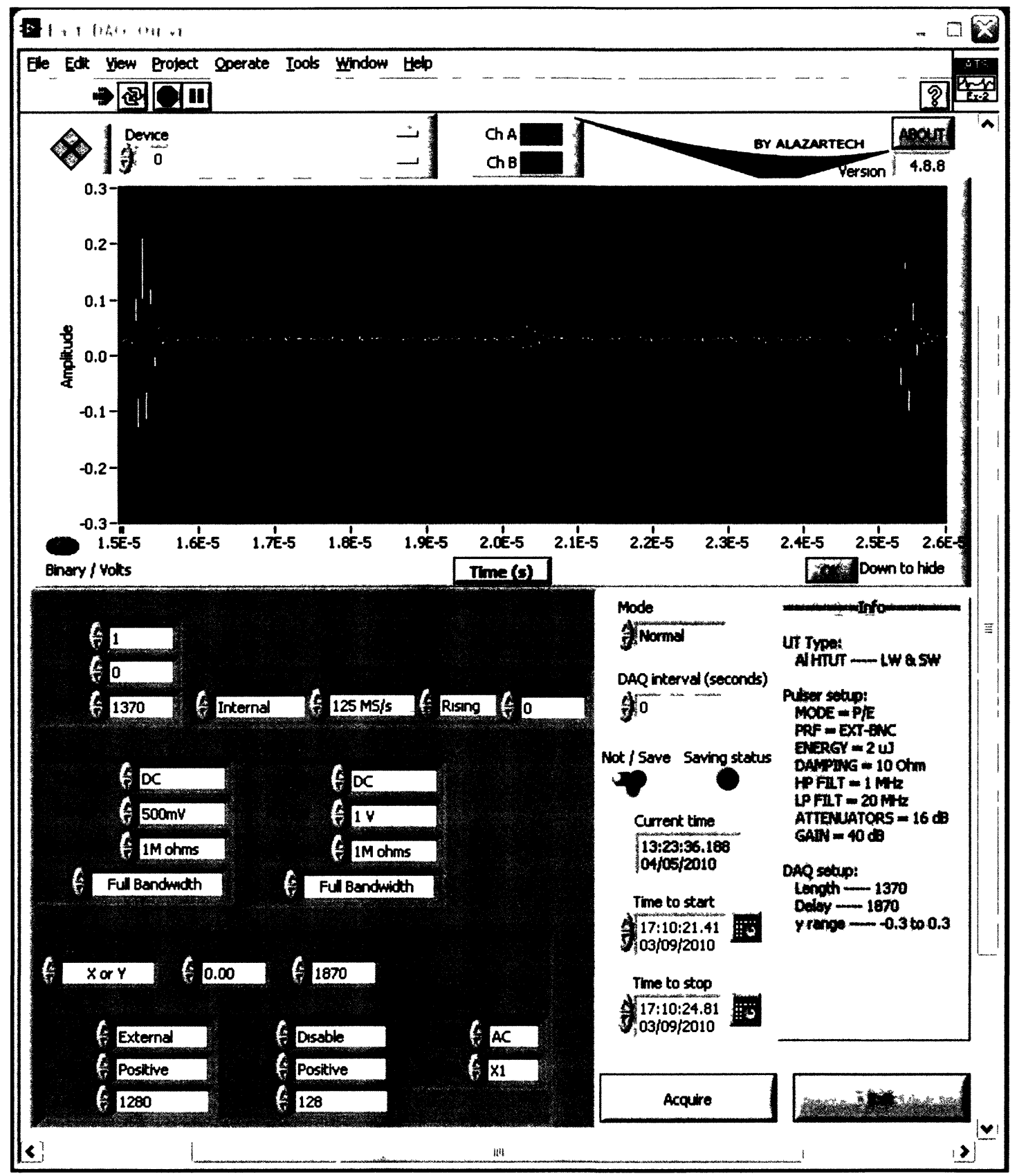

Figure. 3.20 - DAQ program by LabVIEW. 


\subsection{Calibration of the Temperature Sensors}

There are three temperature sensors used to detect the temperatures of the ultrasound probe, sample, and experimental environment. In current research, sensor \#1 and \#2 are calibrated to remove the measured temperature difference.

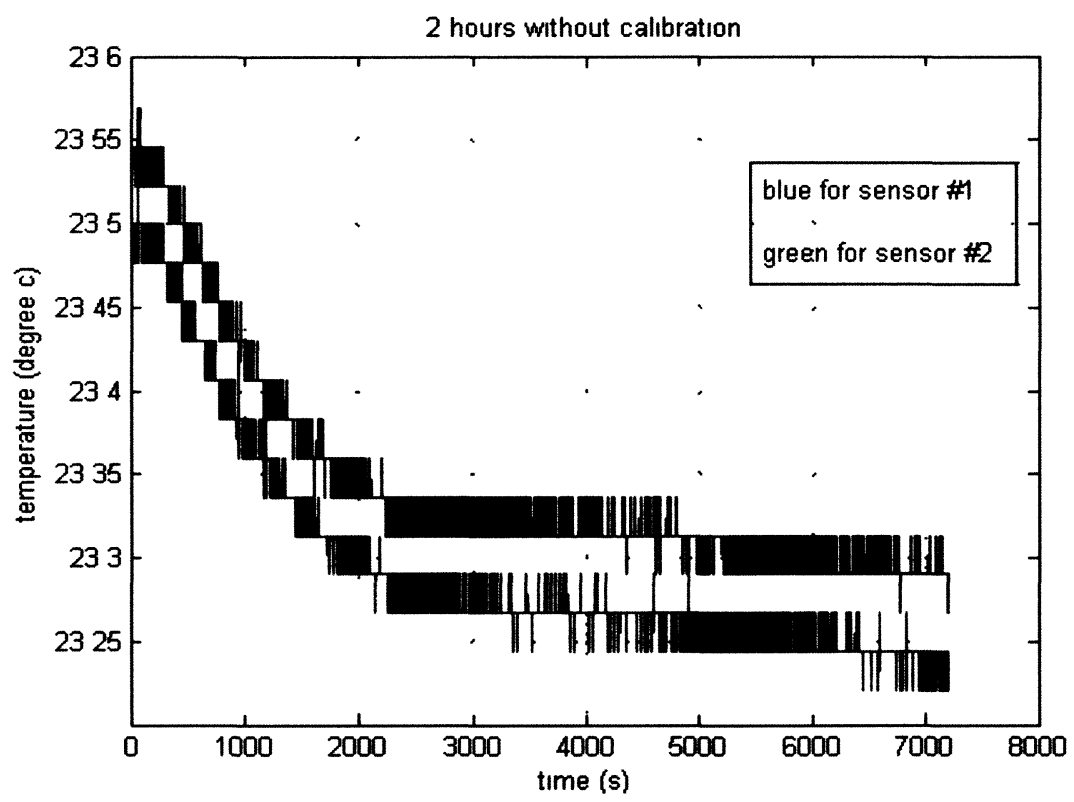

Figure. 3.21 - Temperature detected for sensor \#1 and \#2.

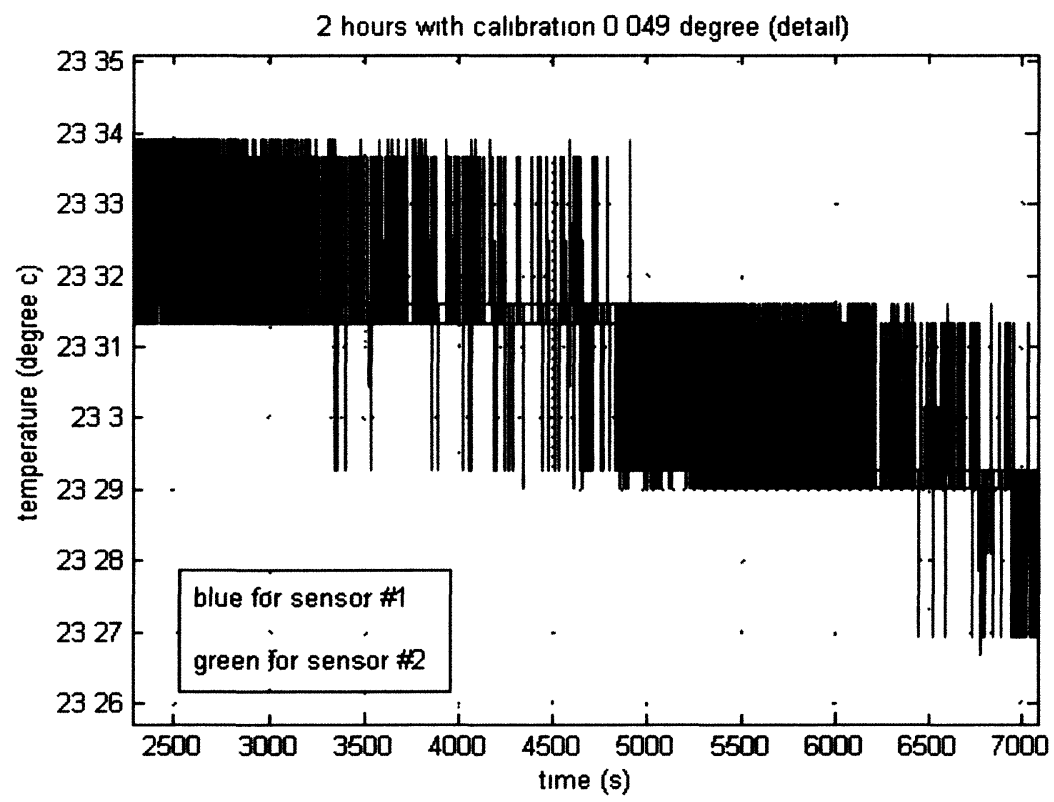

Figure. 3.22 - Temperature detected after calibration for sensor \#1 and \#2. 
Assuming sensor \#1 is the reference sensor, from Figure 3.21 it can be estimated that the mean difference between the two sensors is $0.049{ }^{\circ} \mathrm{C}$ when they are detecting temperatures simultaneously at very close locations (where it can be assumed that the temperatures detected for both sensors should be the same). Sensor \#2 is calibrated by adding $0.049{ }^{\circ} \mathrm{C}$ to its original measured value, then the measured values form both sensors are the same. The result is shown in Figure 3.22.

\subsection{System Stability and Accuracy}

For tissue viscoelastic characterization research using the ultrasound reflectance method, amplitudes and phases of the reflection coefficients are measured. The measurement sensitivity and accuracy directly affect the amplitude and phase shifts measurement results. In this section, the stability and the accuracy of the experimental system are investigated. In addition, the error sources are discussed.

\subsubsection{Experimental Environment}

In this research, experiments are all conducted in the laboratory. One important factor, which may affect the measurement accuracy, is environmental temperature change. In the laboratory where the experiments are carried out, air conditioners are working 24 hours a day, 7 days a week with a fixed setting. In fact, there is constant air flow, thus the temperature cannot be controlled constant. Therefore, a closed chamber was originally planned to be used as a temperature-controlled bath to prevent temperature change due to the air flow, and keep the temperature stable. Sample and probe should all be contained in this chamber and experiments should be carried out inside as well. However, due to the limited time and experimental conditions, the making of the temperature-controlled bath has not been finished yet. The cover seal is imperfect, and the connection with the 
temperature controller still needs to be fixed. In addition, the pressure of the circulated water is not stable, possibly leading to overflow of the inside temperature-controlled bath. The basic design of this device will be presented in Chapter 6 .

Therefore, at present, temperature cannot be easily stabilized. Figure 3.23 shows the temperature fluctuations at the ultrasound probe over a short time duration.

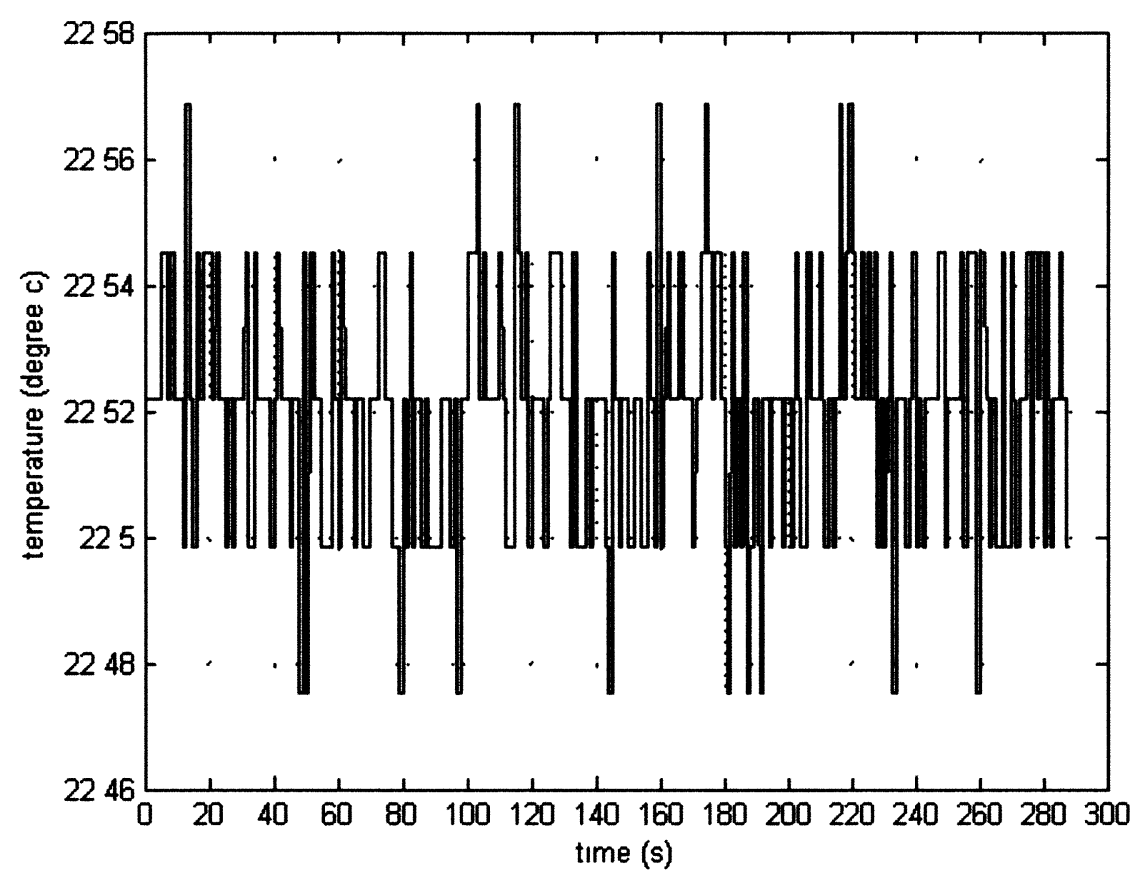

Figure. 3.23 - Temperature fluctuation of the ultrasound probe.

In such instance, the temperature fluctuates by $0.095{ }^{\circ} \mathrm{C}$ over 5 minutes. In the current research, it is assumed that all experiments have temperature fluctuations less than $0.095{ }^{\circ} \mathrm{C}$ and this is fine for the current research. Chapter 4 will introduce the influence of temperature on the amplitude and phase in detail. 


\subsubsection{Data Acquisition Device}

The precision of the hardware determines the resolution of the measurement system. Amplitude and phase from equation (11) are measured. With a $0.095{ }^{\circ} \mathrm{C}$ temperature fluctuation, the changes in $A$ and $\phi$ for an UT with frequency at $12.7 \mathrm{MHz}, \mathrm{LW}$, is shown in Figure 3.24. These data are acquired without any sample attachment and the whole test is conducted in a carton box to reduce the air flow. The entire test lasts 5 minutes and there are 10 acquired frames per second.

This shows the system resolutions for the current experimental condition. Linear least square was implemented through MATLAB to estimate the deviations of the measured amplitude and phase for both LW and SW, the obtained deviations are regarded as the resolutions.

The resolution is $7.721 \times 10^{-4}$ arb and $7.494 \times 10^{-4}$ arb for LW and SW amplitude measurement respectively. $0.0913 \mathrm{rad}$ and $0.1113 \mathrm{rad}$ is the resolution for LW and SW phase measurement, respectively. 
(a)

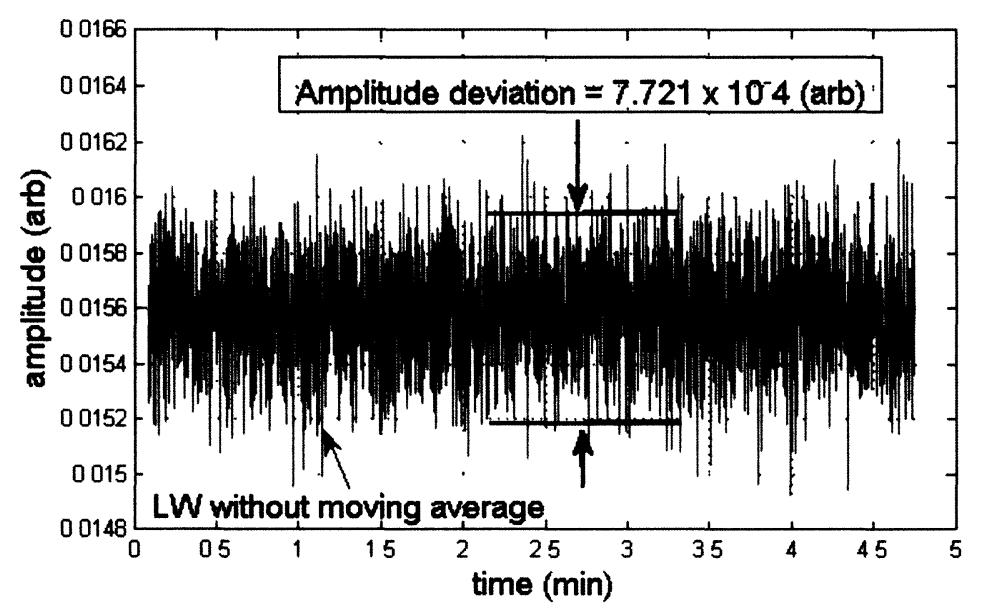

(c)

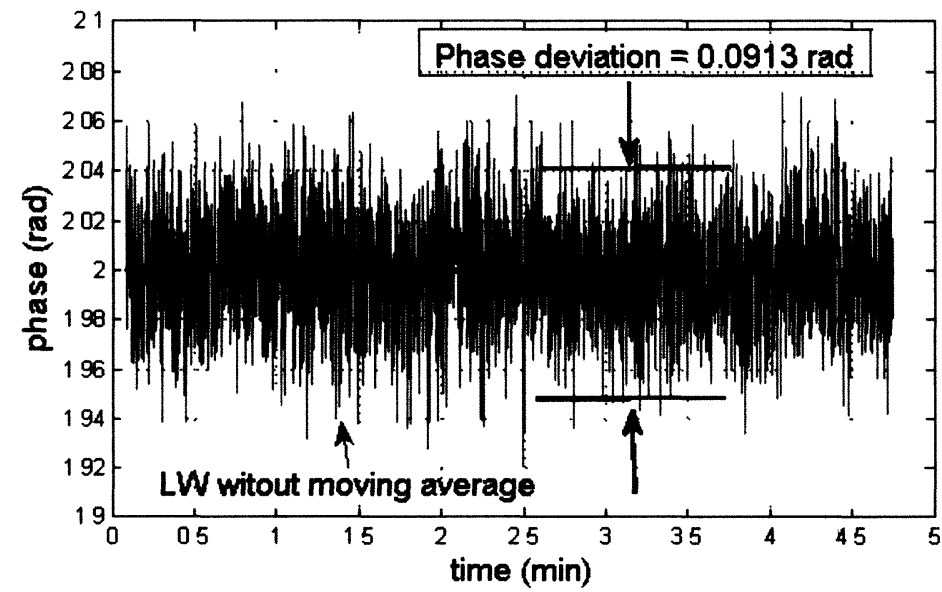

(b)

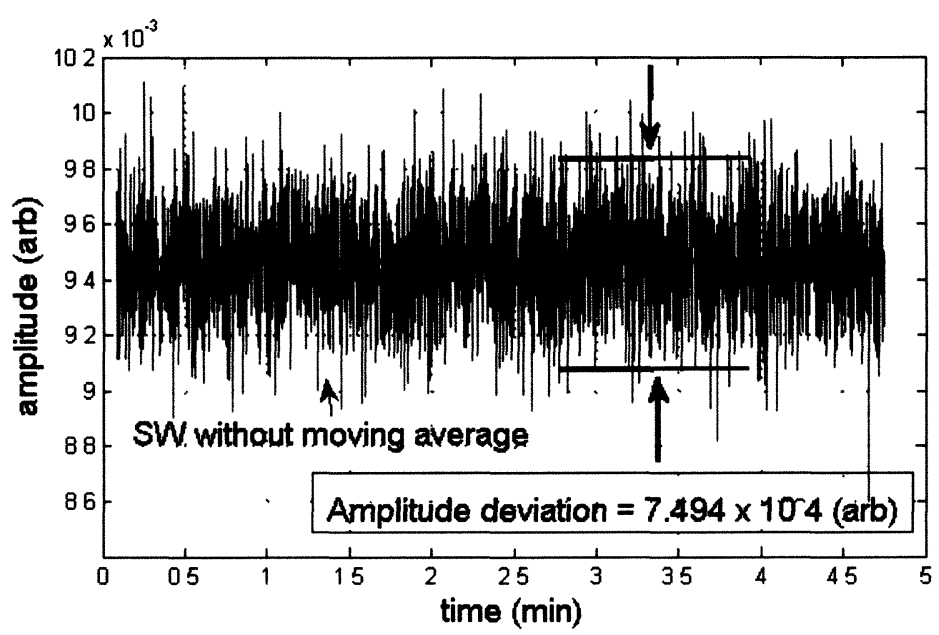

(d)

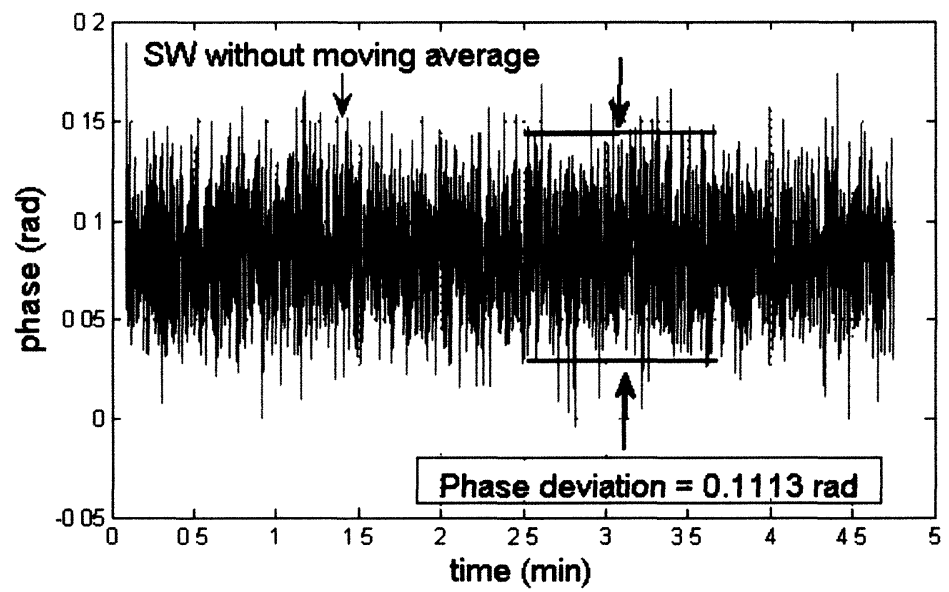

Figure. 3.24 - Measurement resolutions: (a) amplitude resolution for $\mathrm{LW}$, (b) amplitude resolution for $\mathrm{SW}$, (c) phase resolution for $L W$, (d) phase resolution for $S W$. 


\subsubsection{System Resolution Improvement}

To increase the sensitivity of the system measurement, a mathematical method is applied. The moving average is chosen and used in this thesis, to increase the system resolutions of $A$ and $\phi$, for both LW and SW.

A moving average of 100 points is implemented and the results are shown in Figure 3.25. Now the resolution becomes $6.768 \times 10^{-5}$ arb and $7.106 \times 10^{-5}$ arb for amplitude measurement of LW and SW, respectively. That is $0.0106 \mathrm{rad}$ and $0.0091 \mathrm{rad}$ for phase measurement resolution of LW and SW, respectively. Comparing to the values obtained before implementing the moving average, the new resolutions reduce to $8.77 \%$ and $9.48 \%$ of the original resolutions, for amplitude of LW and SW, respectively. The phase resolutions of LW and SW, reduce to $11.61 \%$ and $8.18 \%$ of the original resolutions, respectively. This means that the values obtained after 100 points moving average are approximately 10 times more sensitive than the original values. In addition, in current research for this thesis, the moving average method is used for the analysis of all amplitude and phase measurement data. 
(a)
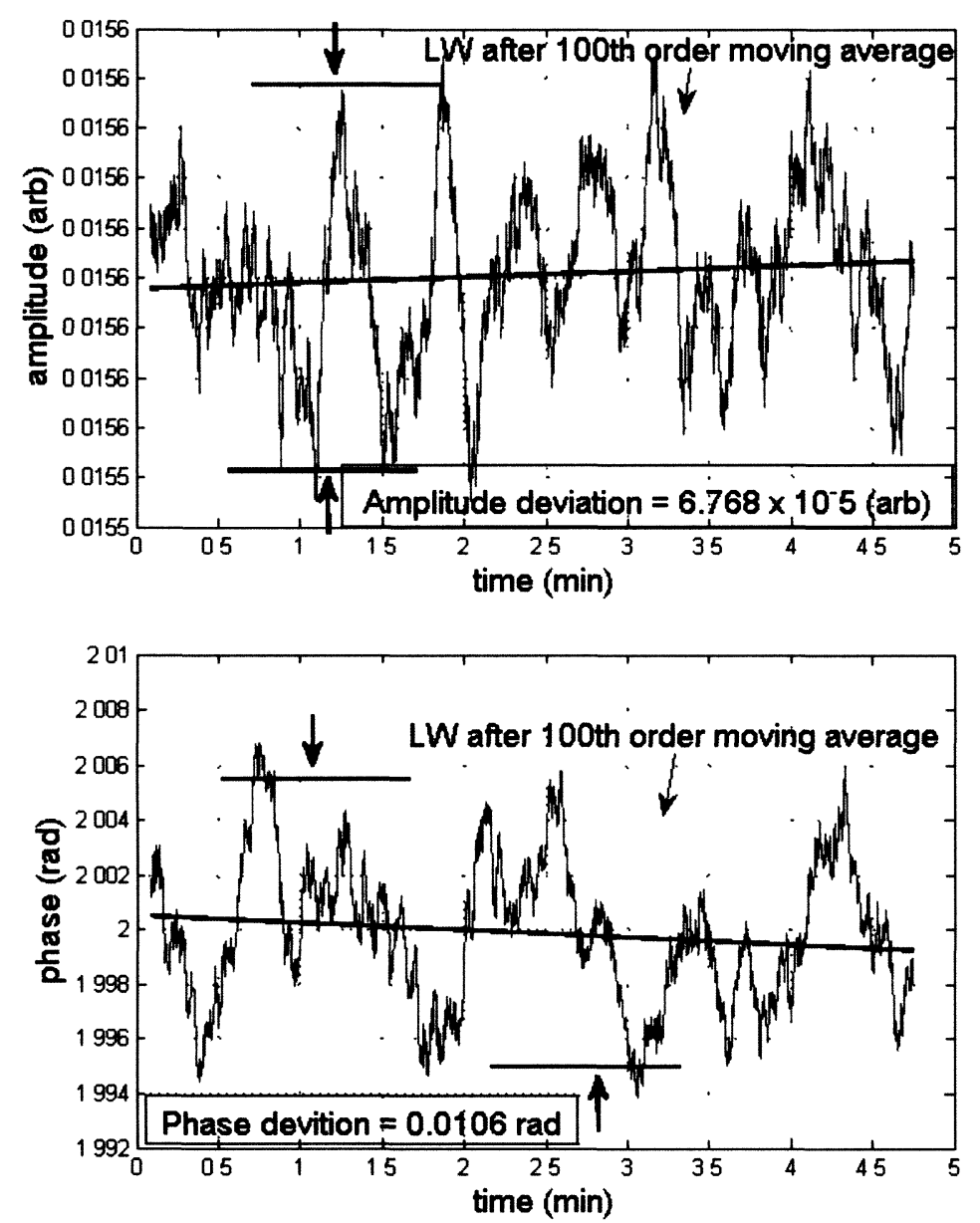

(b)
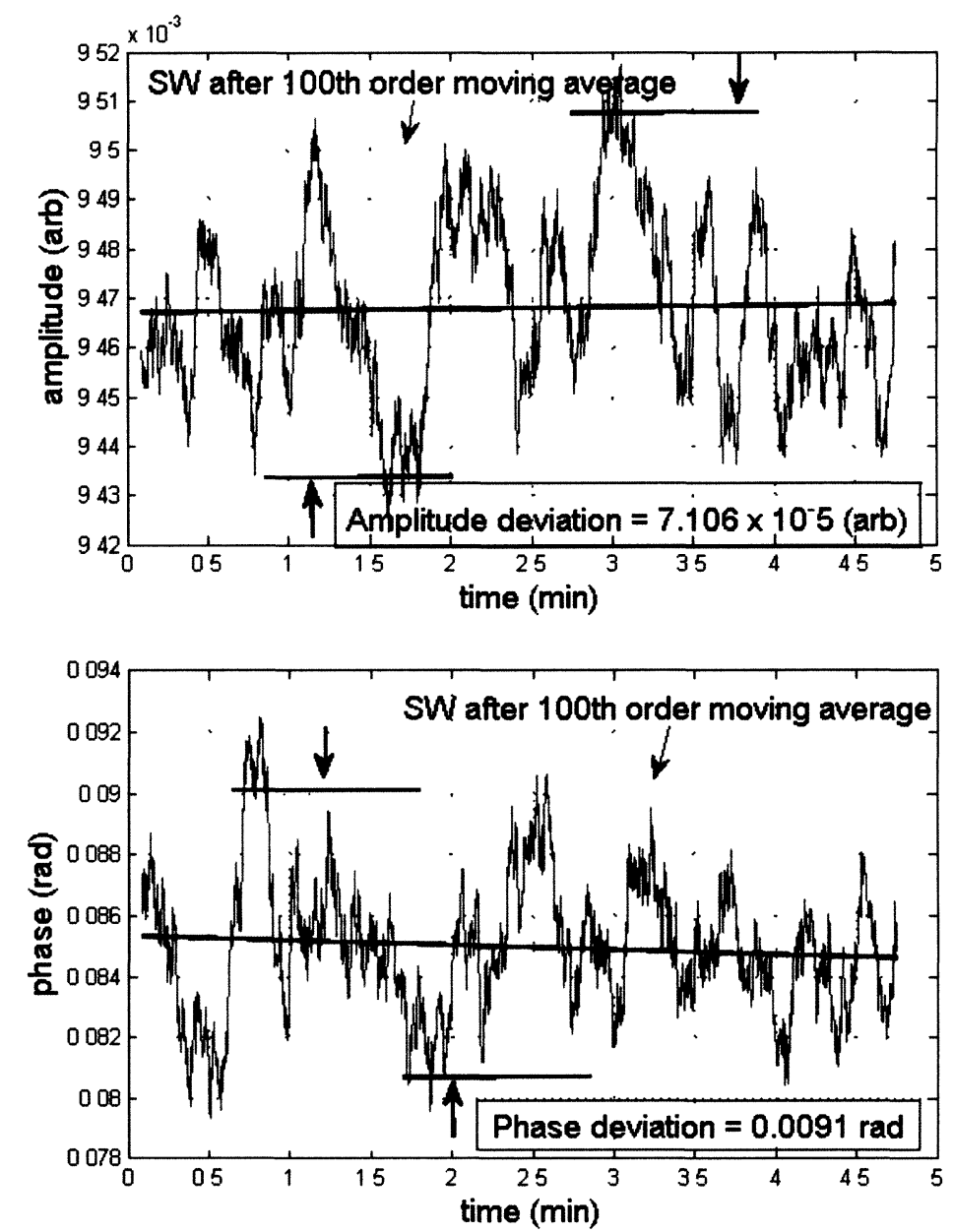

Figure. 3.25 - Measurement resolutions after 100 points moving average: (a) amplitude resolution for $L W$, (b) amplitude resolution for SW, (c) phase resolution for $\mathrm{LW}$, (d) phase resolution for SW. 


\section{Chapter 4: Temperature Compensation Method}

In this chapter, a temperature compensation method is introduced. The main purpose of using this method is to remove the temperature issue, which may affect the accuracy of the amplitude and phase measurement. This method is verified using probe \#1 which generates LW and SW simultaneously.

\subsection{Principle of the Method}

In the amplitude and phase measurements, temperature is a factor which affects accuracy $[2,39]$. The temperature changes cause the amplitude and phase to be unstable and this may be confused with amplitude and phase shifts due to viscosity. Therefore temperature issue affects the experimental accuracy. To reduce such measurement errors, highly precise equipment is needed, such as a thermostatic bath which can keep the experimental temperature constant [18]. However, due to our limited recourses, equipment with enough precision is not available at the time of this research. Therefore, an experimental method is developed to remove the error from temperature variations.

Given the unique design of ultrasound probe \#1, it can generate LW and SW simultaneously. Also LW and SW propagate closely in the substrate. Therefore, it can be assumed that the temperatures of the LW and SW propagation areas are the same. It also means that both LW and SW have the same temperature change during the measurement. 
On the other hand, for viscosity measurement, only SW is used. Therefore, LW can be used as a reference to remove the temperature change on SW.

The amplitude temperature coefficients of the substrate is $\alpha_{L}$ for LW and $\alpha_{S}$ for $\mathrm{SW}$. The phase temperature coefficient of the substrate is $\beta_{L}$ for LW and $\beta_{S}$ for SW. They are measured without the sample attachment in this thesis. The coefficients can be applied such that:

$$
\begin{aligned}
& A_{L}(T)=A_{L}\left(T_{0}\right)+\alpha_{L}(\Delta T) \\
& A_{S}(T)=A_{S}\left(T_{0}\right)+\alpha_{S}(\Delta T) \\
& \phi_{L}(T)=\phi_{L}\left(T_{0}\right)+\beta_{L}(\Delta T) \\
& \phi_{S}(T)=\phi_{S}\left(T_{0}\right)+\beta_{S}(\Delta T),
\end{aligned}
$$

Where $A$ is amplitude and $\phi$ is phase, the subscripts $L$ and $S$ represent LW and SW respectively. $T$ is the current temperature, $T_{0}$ is the initial temperature, $\Delta T$ is temperature difference between $T$ and $T_{0}$. We assume that there are two moments: $\mathrm{t}_{\mathrm{I}}$ when the temperature is $T_{0}$ and $\mathrm{t}_{\mathrm{II}}$ when the temperature is $T$. The following equations can be derived from equations (34) - (37):

$$
\begin{aligned}
& d A_{S}=\frac{d A_{L} \alpha_{S}}{\alpha_{L}} \\
& d \phi_{S}=\frac{d \phi_{L} \beta_{S}}{\beta_{L}},
\end{aligned}
$$

where the $d A_{S}$ and $d \phi_{S}$ represent both the SW's amplitude and phase differences only due to the temperature change, respectively between moments $t_{I}$ and $t_{I I}$. Therefore, once the 
amplitude and phase changes due to the temperature change ( $d A_{L}$ and $d \phi_{\mathrm{L}}$, respectively) at any two moments are known, the corresponding $d A_{S}$ and $d \phi_{S}$ can be estimated through the temperature coefficients.

From the discussion in Chapter 2, it is known that, for viscosity measurement, only shear reflectance measurement has a sudden phase shift when measuring a viscoelastic material. Therefore, theoretically it can be considered that: A measured amplitude value for LW consists of the amplitude value after the energy transmission from the substrate to the sample and the $d A_{L}$ due to temperature change [2]. Similarity, measured phase shift for LW is considered to consist of $d \phi_{L}$ due to temperature change, since it is introduced in Chapter 2 that sample attachment cannot lead to phase change in LW.

In addition, a measured amplitude value for SW consists of the amplitude value after the energy transmission from the substrate to the sample and the $d A_{S}$ due to temperature change [2]. A measured phase shift for SW consists of the $d \phi_{S}$ due to temperature change and the $\Delta \phi_{S}$ due to the sample property change, since it is introduced in Chapter 2 that sample viscosity may lead to a phase change in SW.

$A_{m}$ and $A_{m s}, \phi_{m}$ and $\phi_{m s}$, denote the measured values of amplitudes and phases, before and after the sample contacting, respectively. It can be considered that $A_{m}$ and $\phi_{m}$ are observed at moment $t_{I}$ when the temperature is $T_{0}$ - before the sample makes contact with the probing end of the substrate, and $A_{m s}$ and $\phi_{m s}$ are observed at moment $\mathrm{t}_{\mathrm{II}}$ when the temperature is $T$-after the sample makes contact. By implementing the temperature compensation method, once the changing rate of amplitude and phase for both LW and 
$\mathrm{SW}$ are known in advance, and $d \phi_{L}$ is observed as well, the other parameters $r_{L}, r_{S}$ and $\Delta \phi_{S}$ can be estimated afterwards. For SW, $d \phi_{S}$ can be removed due to the temperature change, and $\Delta \phi_{S}$ can be estimated due to the property change of the sample only. In addition, for both LW and SW, the amplitude value due to the ultrasound transmission from the substrate to sample can be estimated as well. This procedure is expressed as:

$$
\begin{aligned}
& \phi_{L_{-} m s}-\phi_{L_{-} m}=d \phi_{L} \\
& \Delta \phi_{S}=\left(\phi_{S_{-} m s}-\phi_{S_{-} m}\right)-\frac{d \phi_{L} \beta_{S}}{\beta_{L}} \\
& \Delta T=\frac{d \phi_{L}}{\beta_{L}} \\
& r_{L}=\frac{A_{L_{-} m s}-\Delta T \alpha_{L}}{A_{L_{-} m}} \\
& r_{S}=\frac{A_{S_{-} m s}-\Delta T \alpha_{S}}{A_{S_{-} m}},
\end{aligned}
$$

where $r$ represents the amplitude ratio. The subscript L and S represent the LW and SW, respectively. The two moments and their corresponding values of amplitude and phase for experiments will be explained later in detail in Section 5.3.1, Chapter 5. 


\subsection{Estimation of Temperature Coefficients}

Figure 4.1 shows the amplitude and phase changes with the temperature, and Figure 4.2 is the detailed view of Figure 4.1. The measurements in this section are all obtained at an ultrasonic frequency of $12.7 \mathrm{MHz}$.

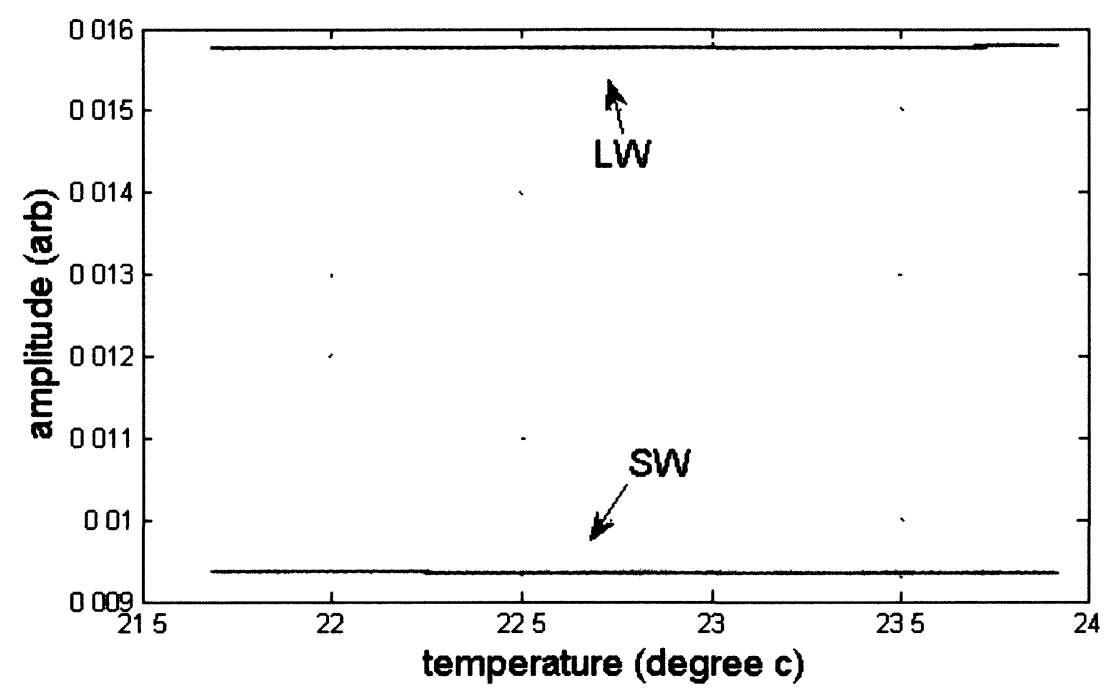

(a)

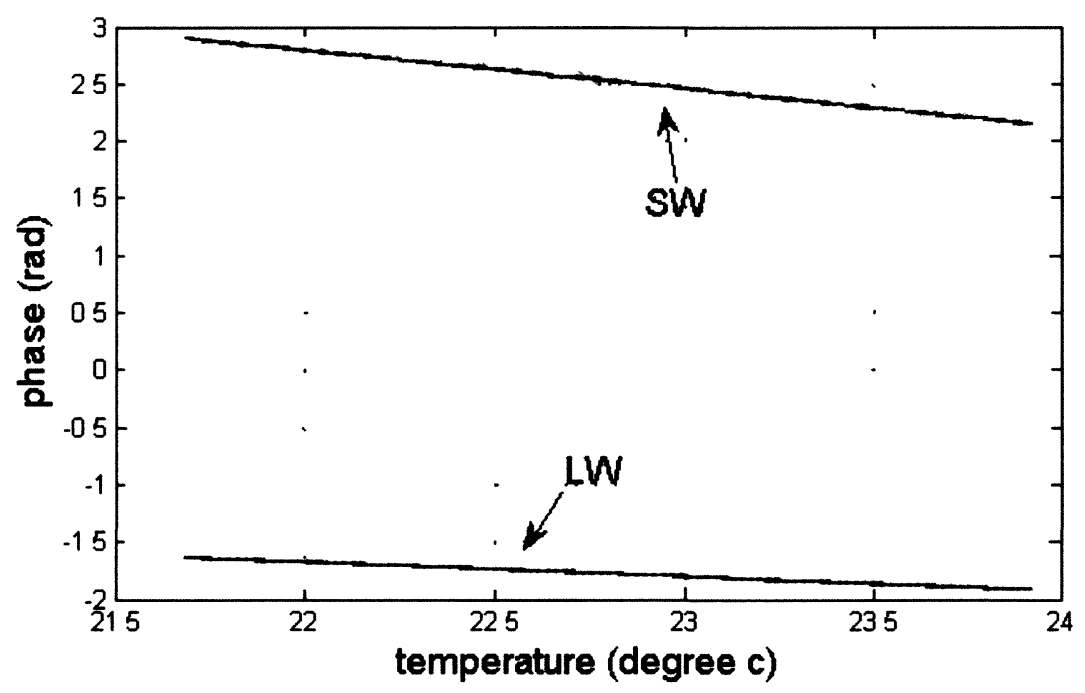

(b)

Figure. 4.1 - Amplitude and phase changes with temperature: (a) for amplitude, (b) for phase. 
(a)

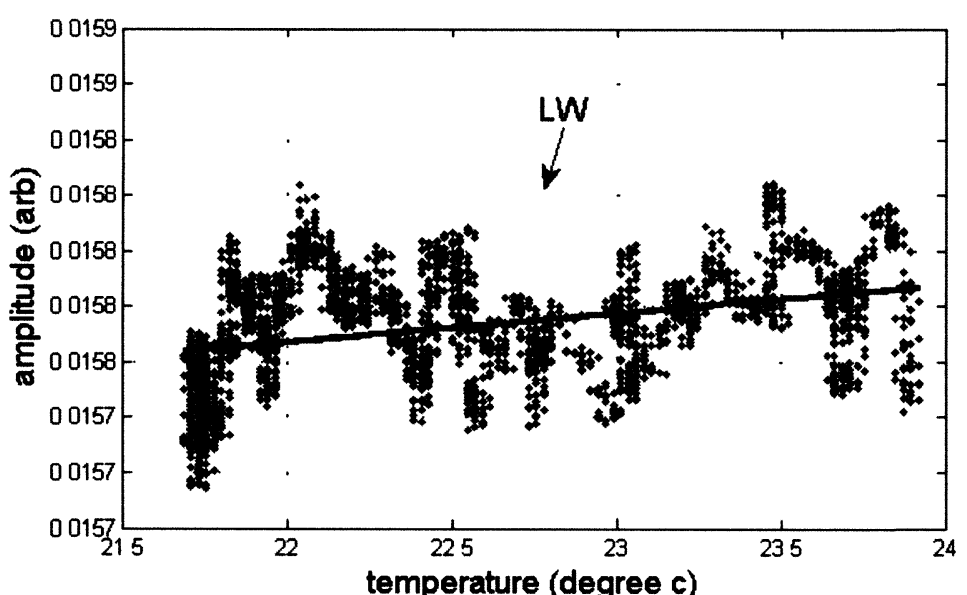

(c)

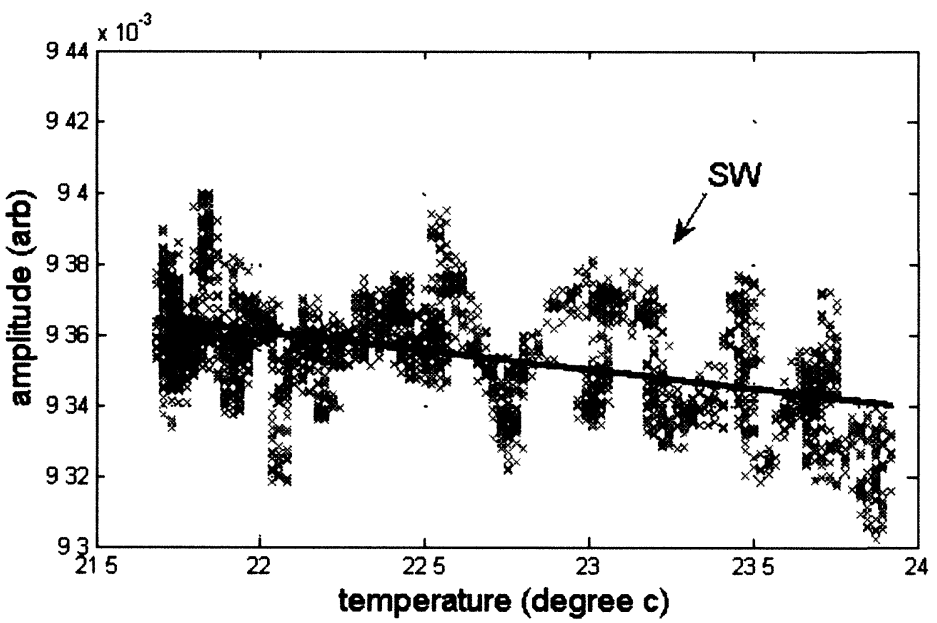

(b)

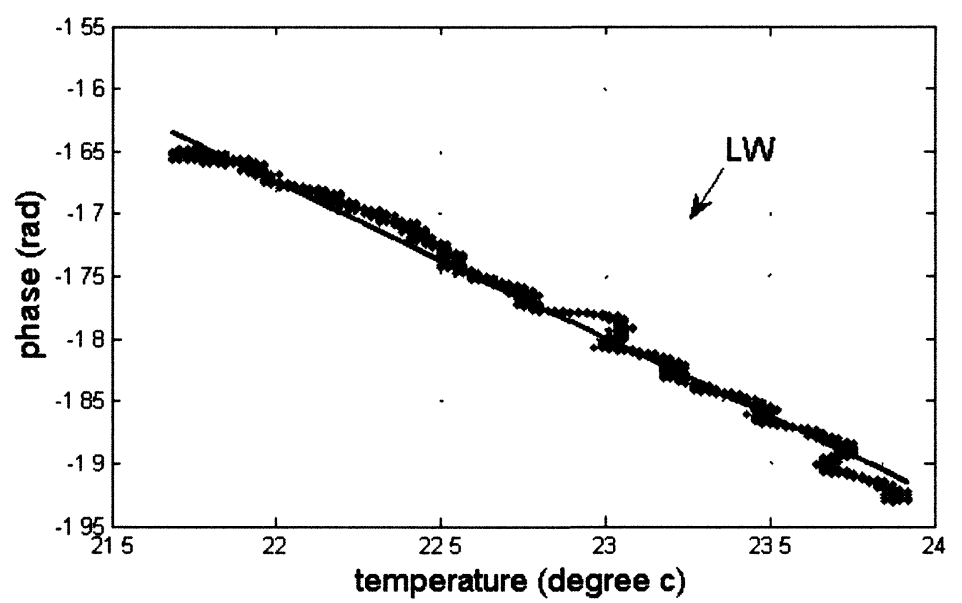

(d)

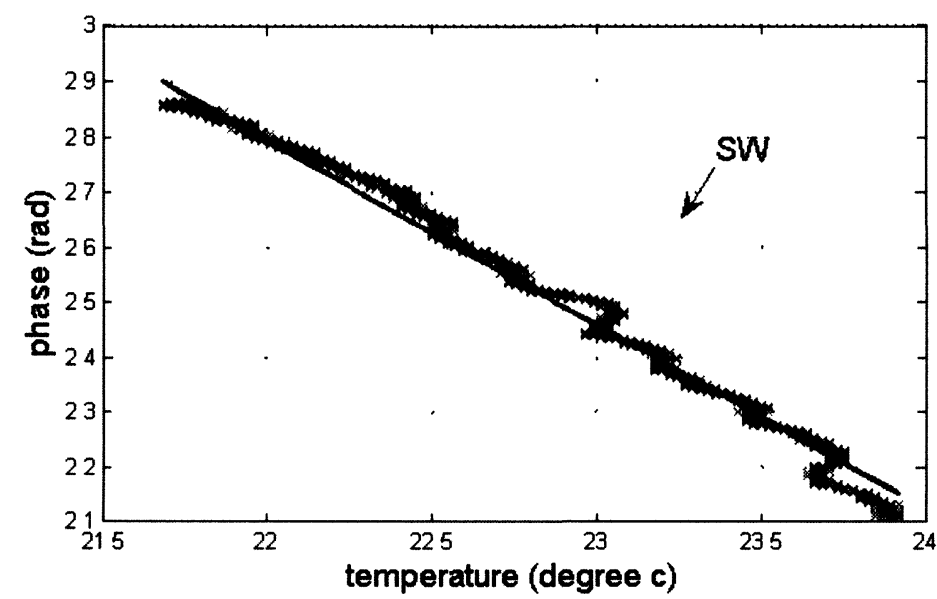

Figure. 4.2 - Detailed view of amplitude and phase changes with temperature: (a) for LW amplitude, (b) for LW phase, (c) for SW amplitude, (d) for SW phase. 
The measurement is carried out while heating the probe \#1 from $21.68{ }^{\circ} \mathrm{C}$ to $23.92{ }^{\circ} \mathrm{C}$ with a heating pad. Results for both amplitude and phase are processed with 100 points moving average and shown in Figure 4.2. The changing trend is estimated by implementing the linear least square and shown as the solid straight line (blue for LW, and red for SW). It can be seen that changes in amplitude and phase are linear in the temperature range employed. The $\alpha_{L}$ is $1.34 \times 10^{-5} \mathrm{arb} /{ }^{\circ} \mathrm{C}$, and $\alpha_{S}$ is $-1.12 \times 10^{-5} \mathrm{arb} /{ }^{\circ} \mathrm{C}$. The $\beta_{L}$ is $-0.125 \mathrm{rad} /{ }^{\circ} \mathrm{C}$, and $\beta_{S}$ is $-0.333 \mathrm{rad} /{ }^{\circ} \mathrm{C}$. The data are shown in the Table 4.1:

Table. 4.1 - Temperature coefficients.

\begin{tabular}{|c|c|c|}
\hline & $\begin{array}{c}\text { Amplitude coefficient } \\
\left(\mathrm{arb} /{ }^{\circ} \mathrm{C}\right)\end{array}$ & $\begin{array}{c}\text { Phase coefficient } \\
\left(\mathrm{rad} /{ }^{\circ} \mathrm{C}\right)\end{array}$ \\
\hline Longitudinal wave & $1.34 \times 10^{-5}$ & -0.125 \\
\hline Shear wave & $-1.12 \times 10^{-5}$ & -0.333 \\
\hline
\end{tabular}

These temperature coefficients will be used to compensate for the effect of temperature change on viscosity measurements in Chapter 5 .

\subsection{Effect of Temperature Change}

In Chapter 3, the temperature stability for the current measurement system is investigated. The temperature fluctuation of the system is around $0.1{ }^{\circ} \mathrm{C}$. This means that there are $1.273 \times 10^{-6}$ arb and $1.064 \times 10^{-6}$ arb amplitude fluctuations in the system for LW and $\mathrm{SW}$, respectively. By comparing with the system resolutions of amplitude measurements of $7.721 \times 10^{-4}$ arb and $7.494 \times 10^{-4}$ arb for LW and SW, respectively, they are $0.165 \%$ and $0.142 \%$. With a $1{ }^{\circ} \mathrm{C}$ temperature change, $1.34 \times 10^{-5}$ arb and $1.12 \times 10^{-5}$ arb 
amplitude changes are yielded, which correspond to $1.74 \%$ and $1.49 \%$ of the measurement resolutions, respectively. In addition, in this research, the experiments are conducted within the temperature change of $0.1{ }^{\circ} \mathrm{C}$. Therefore, only small temperature error may appear in the experiments. Therefore, in this thesis, it is assumed that amplitude is not affected by the temperature change in experiments, thus the temperature compensation method is applied only for the phase shift estimation.

Since there is a $0.1{ }^{\circ} \mathrm{C}$ system temperature fluctuation, it can be estimated that the phase fluctuations due to temperature issue for LW and SW are $0.012 \mathrm{rad}$ and $0.032 \mathrm{rad}$, respectively. Recall Section 3.4.2 in Chapter 3, where the phase measurement resolution is measured as $0.0913 \mathrm{rad}$ and $0.1113 \mathrm{rad}$ for $\mathrm{LW}$ and $\mathrm{SW}$, respectively. In these conditions, these values include the phase fluctuations due to temperature. Therefore, the hardware resolution can be estimated by subtracting $0.012 \mathrm{rad}$ and $0.032 \mathrm{rad}$ from the overall resolution $0.0913 \mathrm{rad}$ and $0.1113 \mathrm{rad}$, LW and SW respectively. The results for both waves are the same at $0.0793 \mathrm{rad}$, which can be considered as the resolution of the measurement system without temperature variation.

The theoretical calculation in Chapter 3 estimates the probable phase shifts due to the sample viscosity change for SW are around 0.04 rad for Al substrate, and 0.08 rad for Plexiglas substrate, they are smaller than this measurement resolution (around $0.1 \mathrm{rad}$ ) which means it may not differentiate between the real phase shifts and the noise accurately. As discussed in Section 3.4.3, Chapter 3, SW phase resolution can be improved to around 0.01 rad after a 100 points moving average. Therefore, the expected measured phase shifts $(0.04 \mathrm{rad}$ and $0.08 \mathrm{rad})$ are at least 4 times larger than the resolutions theoretically, which can observe the real phase shifts more precisely with 
$0.1^{\circ} \mathrm{C}$ temperature fluctuation. However, for future research, if the higher precision is necessary, the resolution must be improved. The temperature should be controlled to be more stable and a Plexiglas probe with high ultrasonic frequency is required. 


\section{Chapter 5: Experiments, Results and Discussions}

In this chapter, test samples for this research are first introduced. Then, the experimental results are presented. Two experiments are performed using probe \#1 and probe \#2, respectively.

\subsection{Samples}

Several samples are selected to be used in this thesis work. Since the research at this stage is focusing on the investigation of material viscosity, all of the selected samples are viscous fluid. They are engine oils and pure silicone fluids.

For engine oils, there are: Castrol GTX SAE 10W-30, MoterMaster Gear Oil SAE 80W-90, and MoterMaster Gear Oil SAE 85W-140. In this thesis, only SAE 140 is used and detailed parameters are in Table 5.1. The viscosity values are estimated by viscometer at $23^{\circ} \mathrm{C}[12]$.

Table. 5.1 - Experimental sample - engine oil [12].

\begin{tabular}{|c|c|c|}
\hline Sample material & Density $\left(\mathrm{Kg} / \mathrm{m}^{3}\right)$ & Viscosity $(\mathrm{cP})$ \\
\hline SAE 140 & 899 & 1050 \\
& & \\
\hline
\end{tabular}


The reason to choose engine oils is that they are widely used in industry and have been tested with other research groups by several methods. Thus there is reliable data as references for comparison. In addition, the engine oils have relatively low viscosity (most of them are lower than $1,000 \mathrm{cP}$ ) at room temperature. Therefore, these fluids can be treated as Newtonian fluids $[9,19,32]$.

For pure silicone fluids, there are: RT 10, RT 100, RT 1,000, RT 12,500, and RT 100,000. All of them are produced and certificated by CANNON Instrument Company, US. In this thesis, RT 1,000 is used and the detailed parameters are shown in Table 5.2. All values are measured at $23^{\circ} \mathrm{C}$. Viscosities are measured and supported by CANNON Instrument Company:

Table. 5.2 - Experimental sample - pure silicone fluid.

\begin{tabular}{|c|c|c|}
\hline Sample material & Density $\left(\mathrm{Kg} / \mathrm{m}^{3}\right)$ & Viscosity $(\mathrm{cP})$ \\
\hline RT 1,000 & 971.8 & 1014 \\
& & \\
\hline
\end{tabular}

For this thesis, two samples: gear oil SAE 85W-140, and silicone fluid RT 1,000, are used for the experiments with probe \#1, and probe \#2, respectively.

\subsection{Theoretical Calculation}

In Chapter 3, a general theoretical calculation is conducted for the optimized design of the probe. In this section, a specific theoretical calculation is presented to simulate the experiments using the parameters of the samples and probes employed in this thesis. Theoretical results will be compared to the experimental findings and discussed. 
To predict the amplitude ratio and phase shift due to the sample viscosity, the two samples used in the experiments are assumed to be Newtonian fluids $[9,19,32]$, which means that their shear elastic modulus $G^{\prime}$ is assumed to be 0 in equation (18) for the Voigt model given at Section 2.2 in Chapter 2.

In the first experiment, probe \#1 with $\mathrm{Al}$ substrate is used and SAE 140 is the sample. Therefore the parameters of probe \#1 and SAE 140 are used for the calculation in this section. For the second experiment, probe $\# 2$ with Plexiglas substrate is used and RT 1,000 is the sample. Parameters of probe \#2 and RT 1,000 are used for the theoretical calculation.

The theoretical calculation results for both probes are listed as Table 5.3.

Table. 5.3 - Specific theoretical calculation for $r_{S}$ and $\Delta \phi_{S}$ with both probes.

\begin{tabular}{|c|c|c|c|c|c|c|}
\hline & $\begin{array}{c}\text { Probe \#2 } \\
\text { (sample: RT 1,000 ) }\end{array}$ & \multicolumn{5}{|c|}{ Probe \#1 } \\
& & \multicolumn{5}{|c|}{ (sample: SAE 140) } \\
\hline Ultrasonic & $1.465 \mathrm{MHz}$ & 5.9 & 8.8 & 12.7 & 14.7 & 15.6 \\
frequency & & $\mathrm{MHz}$ & $\mathrm{MHz}$ & $\mathrm{MHz}$ & $\mathrm{MHz}$ & $\mathrm{MHz}$ \\
\hline$r_{S}$ & 0.9217 & 0.9683 & 0.9614 & 0.9539 & 0.9505 & 0.9490 \\
\hline$\Delta \phi_{S}(\mathrm{rad})$ & -0.0817 & -0.0322 & -0.0393 & -0.0473 & -0.0509 & -0.0524 \\
\hline
\end{tabular}

As shown in this table, amplitude and phase measurements for SW are frequency dependent. The shifts of both amplitude and phase are larger with the higher frequency. 
It can be seen that the Plexiglas probe has larger measurement sensitivity than the Al probe since larger amplitude and phase shifts are observed due to the better impedance matching. The results in Table 5.3 also show that even operating at a low frequency, the Plexiglas probe is still more sensitive than the Al probe. At the center frequency of 1.465 $\mathrm{MHz}$ of this probe, the $r_{S}$ and $\Delta \phi_{S}$ are expected to be 0.9217 and $-0.0817 \mathrm{rad}$, respectively. These values show more obvious amplitude and phase shifts than the values from probe $\# 1$, therefore, probe $\# 2$ is expected to have better measurement sensitivity than probe \#1 since Plexiglas has lower acoustic impedance.

\subsection{Experimental Results}

In this section, experiments with probe $\# 1$ and probe $\# 2$ are carried out to compare the measurement sensitivity.

\subsubsection{Results of the Experiment with Probe \#1}

In this experiment, gear oil SAE $85 \mathrm{~W}-140$ is selected as the test sample.

By using probe \#1, both LW and SW signals are measured at the same time. The same frequency of $12.7 \mathrm{MHz}$ is used to be the processed frequency component for each wave. The amplitude and phase shifts before and after the probe substrate contacts the sample are observed as shown in Figure 5.1. Raw data values are plotted wit thin gray lines, and the values after the moving average of the 100 raw data values are presented with blue line for LW and a red line for SW. 


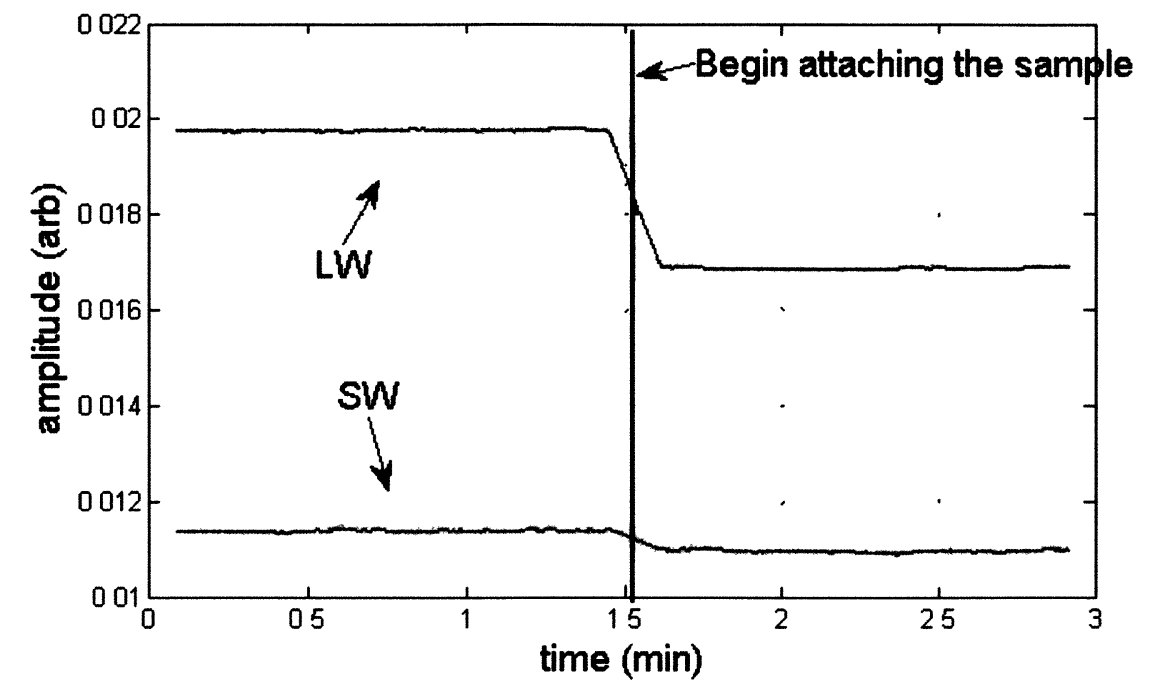

(a)

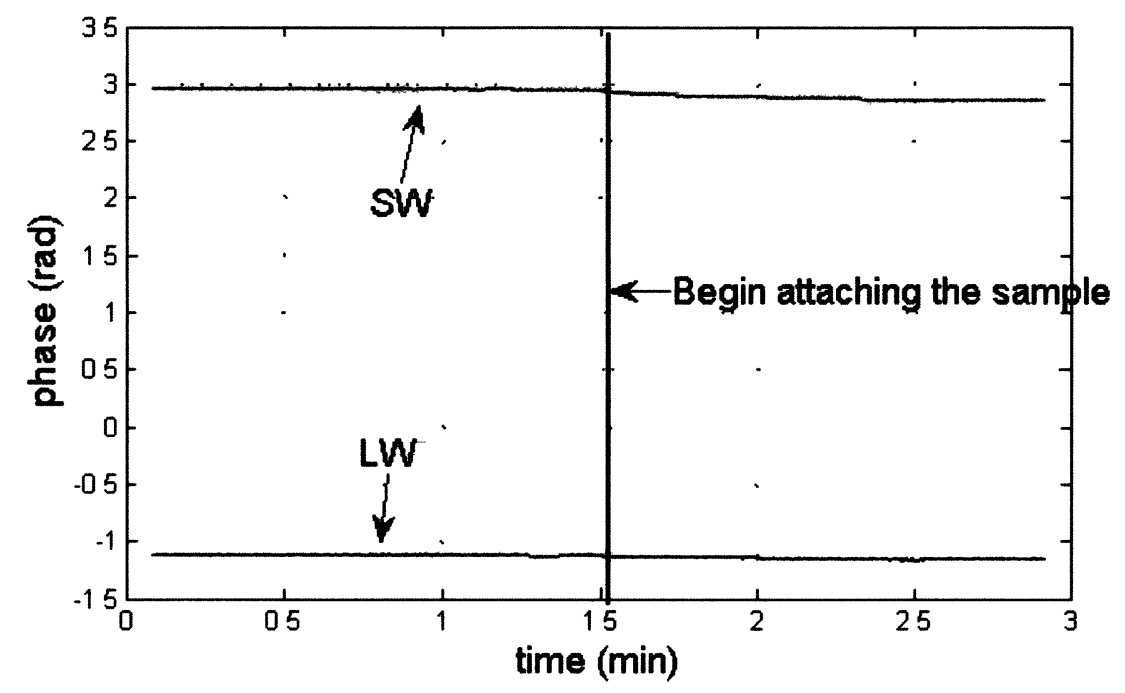

(b)

Figure. 5.1 - Amplitude and phase shifts for LW and SW with probe \#1: (a)

\section{Amplitude shift, (b) Phase shift.}

For the 3 minutes of total experimental time, the sample contacts the probe at about 1.5 minutes and this contact condition is kept until the end. It is obvious from Figure 5.1 that at the moment of attachment, LW has an amplitude shift. The enlarged results are shown in Figure 5.2. 


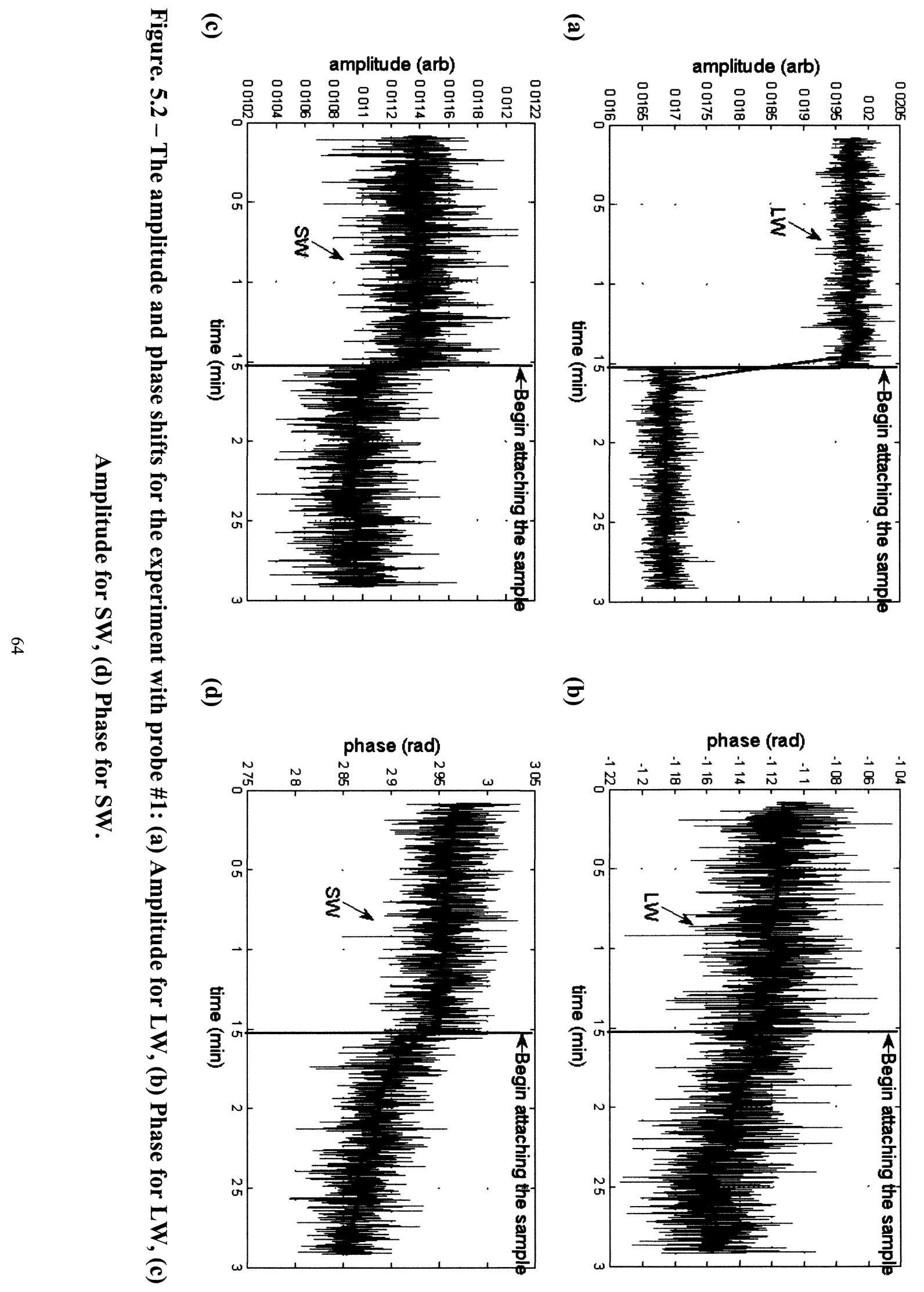


Amplitude shifts for both LW and SW are observed. A small phase shift for SW is detected as well. Phase change for LW shows a slow decrease, which means there has been a temperature change during the experiment, and the phase shift is not clearly observed due to insufficient measurement sensitivity.

Experimental data (after moving average) are shown in the Table 5.4.

Table. 5.4 - Amplitude and phase values for the experiment with probe \#1.

\begin{tabular}{|c|c|c|c|c|}
\hline Moment & \multicolumn{2}{|c|}{ Before sample attachment } & \multicolumn{2}{c|}{ After sample attachment } \\
\hline & $A_{m}$ & $\phi_{m}$ & $A_{m s}$ & $\phi_{m s}$ \\
& $\left(\times 10^{-2}\right)(\mathrm{arb})$ & $(\mathrm{rad})$ & $\left(\times 10^{-2}\right)(\mathrm{arb})$ & $(\mathrm{rad})$ \\
\hline LW (observed) & 1.977 & -1.118 & 1.687 & -1.148 \\
\hline SW (observed) & 1.138 & 2.958 & 1.096 & 2.877 \\
\hline SW (after & 1.138 & 2.958 & 1.096 & 2.957 \\
temperature & & & & \\
\hline
\end{tabular}

The temperature compensation method is used here to remove the effect of the temperature change during the measurements. The mean values of both amplitude and phase before sample attachment are used as the values known as "before sample attachment", and the mean values of both amplitude and phase after sample attachment are used as the values known as "after sample attachment", which is previously mentioned in Section 4.1, Chapter 4 as the value at the moments. Phase difference for LW between the two moments is observed and after using the phase temperature 
compensation, ideally the phase shift only due to the sample viscosity can be finally estimated. The phase changes after conducting the temperature compensation are shown in Figure 5.3.

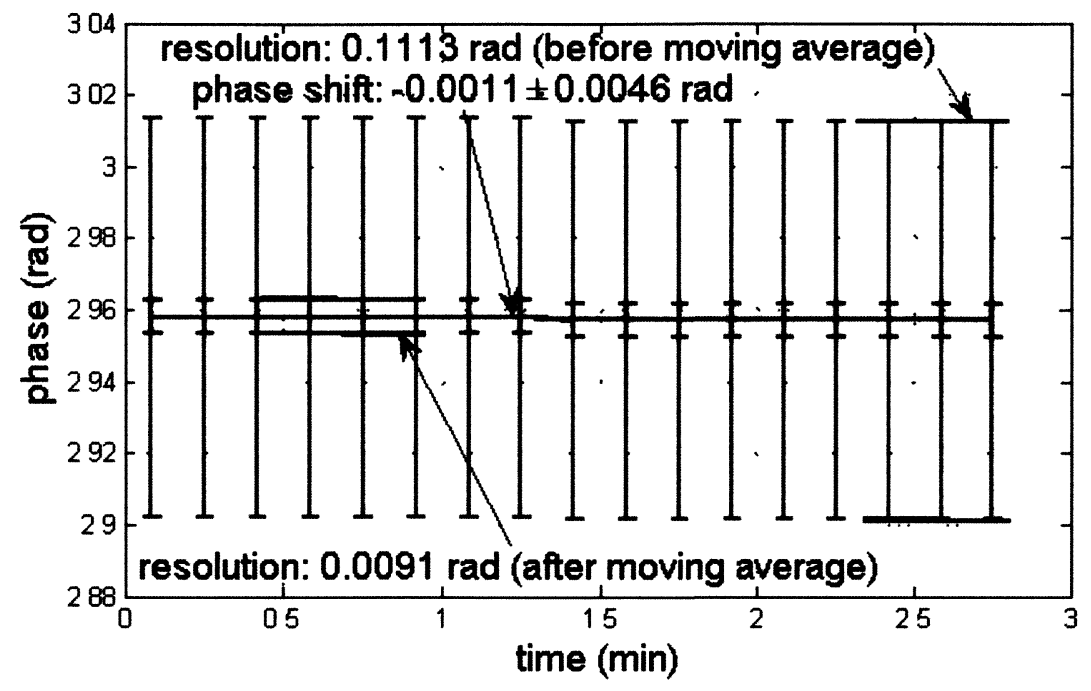

Figure 5.3 - Phase change of the experiment with probe \#1 after temperature compensation.

\subsubsection{Results of the Experiment with Probe \#2}

In this experiment, silicone fluid RT 1,000 is selected as the test sample. The experiment lasts 2 minutes. The operation is shown in Figure 5.4:

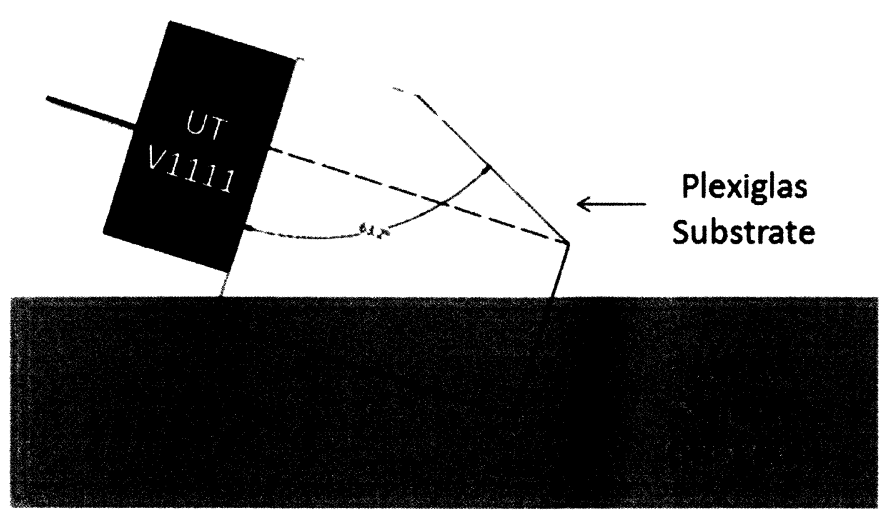

Figure. 5.4 - Sample measurement with probe \#2: immersed at an angle. 
The substrate of probe \#2 is provided by Dr. Jen at NRC. It has only one angle in the substrate edge to generate SW by transmitting the LW. Although this probe is not as fully functional as probe \#1, it still can generate SW for the viscosity measurement. In addition, since the substrate of this probe is Plexiglas, it is suitable to be used to compare with probe \#1, which has $\mathrm{Al}$ substrate, to see the different measurement sensitivity due to the substrate material. One thing to be noted is that there is no sufficient place between the probing end and UT bottom edge for immersion into the liquid sample. To prevent the sample liquid soaking the connecting surface between the UT and the substrate, the probe makes contact with the sample liquid at an angle. 
By using probe \#2, only SW signals are measured. The results of the amplitude and phase shifts are shown in Figure 5.5:

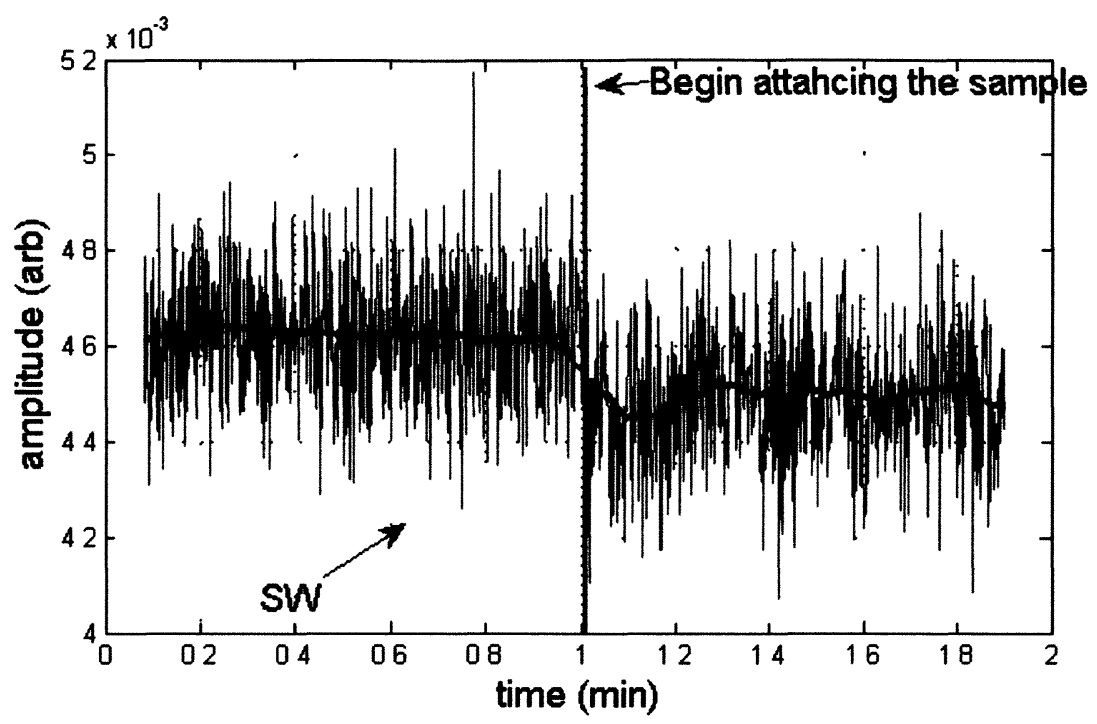

(a)

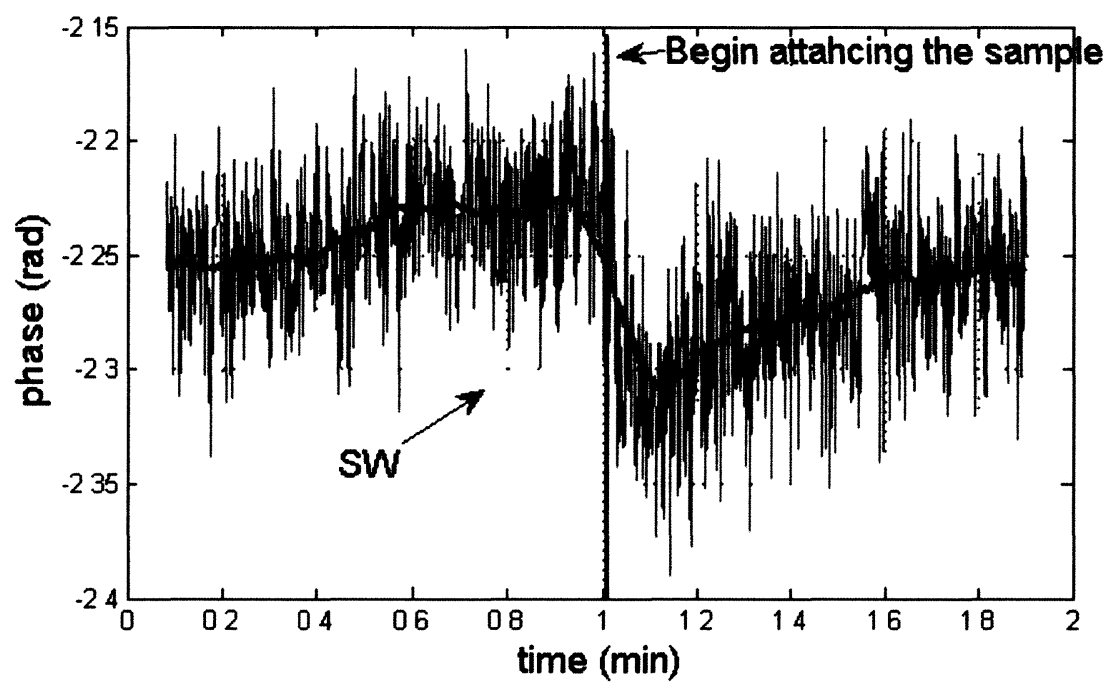

(b)

Figure. 5.5 - Amplitude and phase shifts for the experiment with probe \#2: (a)

\section{Amplitude shift, (b) Phase shift.}

In this experiment, the temperature compensation method is not applied since the

$\mathrm{SW}$ is only the signal component. Figure 5.5 (b) shows that the temperature keeps changing during the experiment. In this situation, moments with substantial time between 
them are considered to have different temperatures, and two close moments are assumed to have the same temperature. Therefore, the two selected moments are: $t_{I}$ at the 0.93 minute and $t_{\text {II }}$ at 1.10 minute, which represent the edge moments of the sample attaching after 100 points moving average. The experimental data results are shown in Table 5.5:

Table. 5.5 - Amplitude and phase values for the experiment with probe \#2.

\begin{tabular}{|c|c|c|c|c|}
\hline Moment & \multicolumn{2}{|c|}{$\mathrm{t}_{\mathrm{I}}$ at $0.92 \mathrm{~min}$} & \multicolumn{2}{c|}{$\mathrm{t}_{\mathrm{II}}$ at $1.10 \mathrm{~min}$} \\
\hline & $A_{m}$ & $\phi_{m}$ & $A_{m s}$ & $\phi_{m s}$ \\
& $\left(\times 10^{-3}\right)(\mathrm{arb})$ & $(\mathrm{rad})$ & $\left(\times 10^{-3}\right)(\mathrm{arb})$ & $(\mathrm{rad})$ \\
\hline $\mathrm{SW}$ & 4.617 & -2.227 & 4.447 & -2.303 \\
\hline
\end{tabular}

The experimental data results obtained in this section will be used for the estimation of sample material properties.

\subsection{Estimation of Material Properties}

In this section, the tissue viscoelasticity, especially viscosity, is characterized through the data obtained from the last section. There are two parts to present the works, for the parameters estimated from LW and SW, respectively. To simplify the calculation, the error due to the amplitude resolution will not be considered in this section, and only phase resolution will be considered to affect the accuracy of the measurement.

\subsubsection{Parameters Estimated from LW}

By using probe \#1, both viscosity and elasticity can be estimated at the same time. In this thesis, viscosity measurement sensitivity is mainly investigated. However, the longitudinal reflection coefficient $\left(\mathrm{R}_{\mathrm{L}}\right)$, longitudinal velocities of the sample $\left(v_{L_{-} s p}\right)$ and 
the bulk modulus of the sample $\left(K_{s p}\right)$ can still be obtained. The bulk modulus, particularly, is one of the key parameters for the characterization of viscoelastic materials [5].

By using the data from Table 5.4, results are estimated through the equations which presented in previous chapters and they are shown in Table 5.6. The experiment is carried out at the ultrasonic frequency of $12.7 \mathrm{MHz}$.

Table. 5.6 - Parameters for LW of the sample as gear oil SAE 140 at $12.7 \mathrm{MHz}$ for the experiment with probe \#1: (a) Known parameters, (b) Measured parameters, (c)

Estimated parameters.

\begin{tabular}{|c|c|c|c|}
\hline \multicolumn{4}{|c|}{ (a) Known parameters $[4,40]$} \\
\hline$\rho_{\text {sub }}\left(\mathrm{kg} / \mathrm{m}^{3}\right)$ & $K_{\text {sub }}(\mathrm{Pa})$ & $G_{\text {sub }}(\mathrm{Pa})$ & $\rho_{\text {sp }}\left(\mathrm{kg} / \mathrm{m}^{3}\right)$ \\
\hline 2700 & $78.1 \times 10^{9}$ & $25 \times 10^{9}$ & 899 \\
\hline
\end{tabular}

\begin{tabular}{|c|c|}
\hline \multicolumn{2}{|c|}{ (b) Measured parameters } \\
\hline$r_{L}$ & $\mathrm{~d} \phi_{L}(\mathrm{rad})$ \\
\hline 0.8533 & -0.030 \\
\hline
\end{tabular}

\begin{tabular}{|c|c|c|c|}
\hline \multicolumn{4}{|c|}{ (c) Estimated parameters } \\
\hline$v_{L_{-} s u b}(\mathrm{~m} / \mathrm{s})$ & $R_{L}$ & $v_{L_{-} s p}(\mathrm{~m} / \mathrm{s})$ & $K_{s p}(\mathrm{~Pa})$ \\
\hline 6424.3 & -0.8533 & 1527.3 & $2.097 \times 10^{9}$ \\
\hline
\end{tabular}




\subsubsection{Parameters Estimated from SW}

In the experiment with probe $\# 1$, amplitude and phase shifts are measured. In this experiment, the analyzed ultrasound data is from the ultrasonic frequency component of 12.7 MHz. At $12.7 \mathrm{MHz}$, the phase measurement resolution is estimated to the $0.0091 \mathrm{rad}$ after 100 points moving average. Therefore, the error bar for the $\Delta \phi_{S}$ is $\pm 0.0046 \mathrm{rad}$. The values of the parameters are shown in Table 5.7:

Table. 5.7 - Shear properties of the sample as gear oil SAE 140 for the experiment with probe \#1 operating at 12.7 MHz: (a) Known parameters, (b) Measured parameters (c) Estimated parameters.

\begin{tabular}{|c|c|c|c|}
\hline \multicolumn{4}{|c|}{ (a) Known parameters $[\mathbf{4 , 4 0 ]}$} \\
\hline$\rho_{\text {sub }}\left(\mathrm{kg} / \mathrm{m}^{3}\right)$ & $G_{\text {sub }}(\mathrm{Pa})$ & $Z_{S_{-} \text {sub }}\left(\mathrm{kg} / \mathrm{m}^{2} \mathrm{~s}\right)$ & $\rho_{\text {sp }}\left(\mathrm{kg} / \mathrm{m}^{3}\right)$ \\
\hline 2700 & $25 \times 10^{9}$ & $8.216 \times 10^{6}$ & 899 \\
\hline
\end{tabular}

\begin{tabular}{|c|c|}
\hline \multicolumn{2}{|c|}{ (b) Measured parameters } \\
\hline$r_{S}$ & $\Delta \phi_{S}(\mathrm{rad})$ \\
\hline 0.9631 & $-0.0011 \pm 0.0046$ \\
\hline
\end{tabular}

\begin{tabular}{|c|c|c|c|c|}
\hline \multicolumn{5}{|c|}{ (c) Estimated parameters } \\
\hline$R_{S}{ }^{*}$ & $\eta(\mathrm{cP})$ & $\alpha\left(\mathrm{m}^{-1}\right)$ & $G^{\prime}(\mathrm{Pa})$ & $v_{S_{-} p}(\mathrm{~m} / \mathrm{s})$ \\
\hline$-0.9631+0.0011 \mathrm{j} \pm$ & $19.45 \pm$ & $(1.30 \pm 5.59) \times$ & $(2.61 \pm 0.02) \times$ & \\
$0.0044 \mathrm{j}$ & 81.32 & $10^{4}$ & $10^{7}$ & \\
\hline
\end{tabular}

From the theoretical calculation, it is known that the viscosity measurement with the SW is highly frequency dependent. Since the probe \#1 has a broad band of frequency 
variance, more frequency components are therefore used in this experiment for the investigation of the frequency dependency of shear properties. Data at each frequency are shown in Table 5.8 .

Table. 5.8 - Parameter estimation for different frequency components with probe \#1.

\begin{tabular}{|c|c|c|c|c|c|}
\hline $\begin{array}{c}\text { Frequency } \\
\text { component }\end{array}$ & $5.86 \mathrm{MHz}$ & $8.79 \mathrm{MHz}$ & $12.7 \mathrm{MHz}$ & $14.65 \mathrm{MHz}$ & $15.63 \mathrm{MHz}$ \\
\hline$r_{S}$ & 0.9672 & 0.9716 & 0.9631 & 0.9621 & 0.9566 \\
\hline$\Delta \phi_{S}(\mathrm{rad})$ & $-0.0034 \pm$ & $0.0001 \pm$ & $-0.0011 \pm$ & $-0.0044 \pm$ & $0.0022 \pm$ \\
& 0.0046 & 0.0046 & 0.0046 & 0.0046 & 0.0046 \\
\hline$\eta(\mathrm{cP})$ & $115.55 \pm$ & $-1.96 \pm$ & $19.45 \pm$ & $69.29 \pm$ & $-37.29 \pm$ \\
& 156.33 & 90.05 & 81.32 & 72.44 & 77.96 \\
\hline$G^{\prime}(\mathrm{Pa})$ & $(2.03 \pm 0.06)$ & $(1.518 \pm$ & $(2.61 \pm 0.02)$ & $(2.73 \pm 0.08)$ & $(3.65 \pm 0.04)$ \\
& $\times 10^{7}$ & $0.002) \times 10^{7}$ & $\times 10^{7}$ & $\times 10^{7}$ & $\times 10^{7}$ \\
\hline$\alpha\left(\mathrm{m}^{-1}\right)$ & $(2.31 \pm 3.17)$ & $(-0.13 \pm$ & $(1.30 \pm 5.59)$ & $(5.63 \pm 5.90)$ & $(-2.32 \pm$ \\
& $\times 10^{4}$ & $6.53) \times 10^{4}$ & $\times 10^{4}$ & $\times 10^{4}$ & $4.93) \times 10^{4}$ \\
\hline$v_{S_{s} s p}(\mathrm{~m} / \mathrm{s})$ & $156.85 \pm$ & $134.99 \pm$ & $174.48 \pm$ & $181.30 \pm$ & $205.37 \pm$ \\
& 4.29 & 0.15 & 1.23 & 4.79 & 2.09 \\
\hline
\end{tabular}

One thing to be noted in this table is that, at $8.79 \mathrm{MHz}$ and $15.63 \mathrm{MHz}$, the viscosity and attenuation are estimated as negative value. These are due to the measurement error. 
Experiments with probe \#2 can only estimate properties from SW. Since probe \#2 observes a narrow frequency band, the center frequency of $1.465 \mathrm{MHz}$ is only investigated. Parameters are shown in Table 5.9:

Table. 5.9 - Shear properties of the sample as silicone fluid RT 1,000 for the experiment with probe \#2 operating at $1.465 \mathrm{MHz}$ : (a) Known parameters, (b) Measured parameters, (c) Estimated parameters.

\begin{tabular}{|c|c|c|}
\hline \multicolumn{3}{|c|}{ (a) Known parameters [36, 38] } \\
\hline$\rho_{\text {sub }}\left(\mathrm{kg} / \mathrm{m}^{3}\right)$ & $Z_{S_{-} \text {sub }}\left(\mathrm{kg} / \mathrm{m}^{2} \mathrm{~s}\right)$ & $\rho_{s p}\left(\mathrm{~kg} / \mathrm{m}^{3}\right)$ \\
\hline 1190 & $1.651 \times 10^{6}$ & 971.8 \\
\hline
\end{tabular}

\begin{tabular}{|c|c|}
\hline \multicolumn{2}{|c|}{ (b) Measured parameters } \\
\hline$r_{S}$ & $\Delta \phi_{S}(\mathrm{rad})$ \\
\hline 0.9632 & $-0.076 \pm 0.0046$ \\
\hline
\end{tabular}

\begin{tabular}{|c|c|c|c|c|}
\hline \multicolumn{5}{|c|}{ (c) Estimated parameters } \\
\hline$R_{S}{ }^{*}$ & $\eta(\mathrm{cP})$ & $\alpha\left(\mathrm{m}^{-1}\right)$ & $G^{\prime}(\mathrm{Pa})$ & $v_{S_{-} s}(\mathrm{~m} / \mathrm{s})$ \\
\hline$-0.9604 \pm 0.0003+$ & $434.8 \pm$ & $(1.147 \pm 0.042)$ & $(-3.078 \pm 0.491)$ & $163.09 \pm$ \\
$0.0731 \mathrm{j} \pm 0.0044 \mathrm{j}$ & 26.4 & $\times 10^{5}$ & $\times 10^{6}$ & 15.82 \\
\hline
\end{tabular}

$\mathrm{G}^{\prime}$ in the Table 5.9 is estimated as a negative value and it is due to the measurement error.

Figure 5.6 presents the results. In the next section, these experimental results will be discussed with the results from theoretical calculations. 


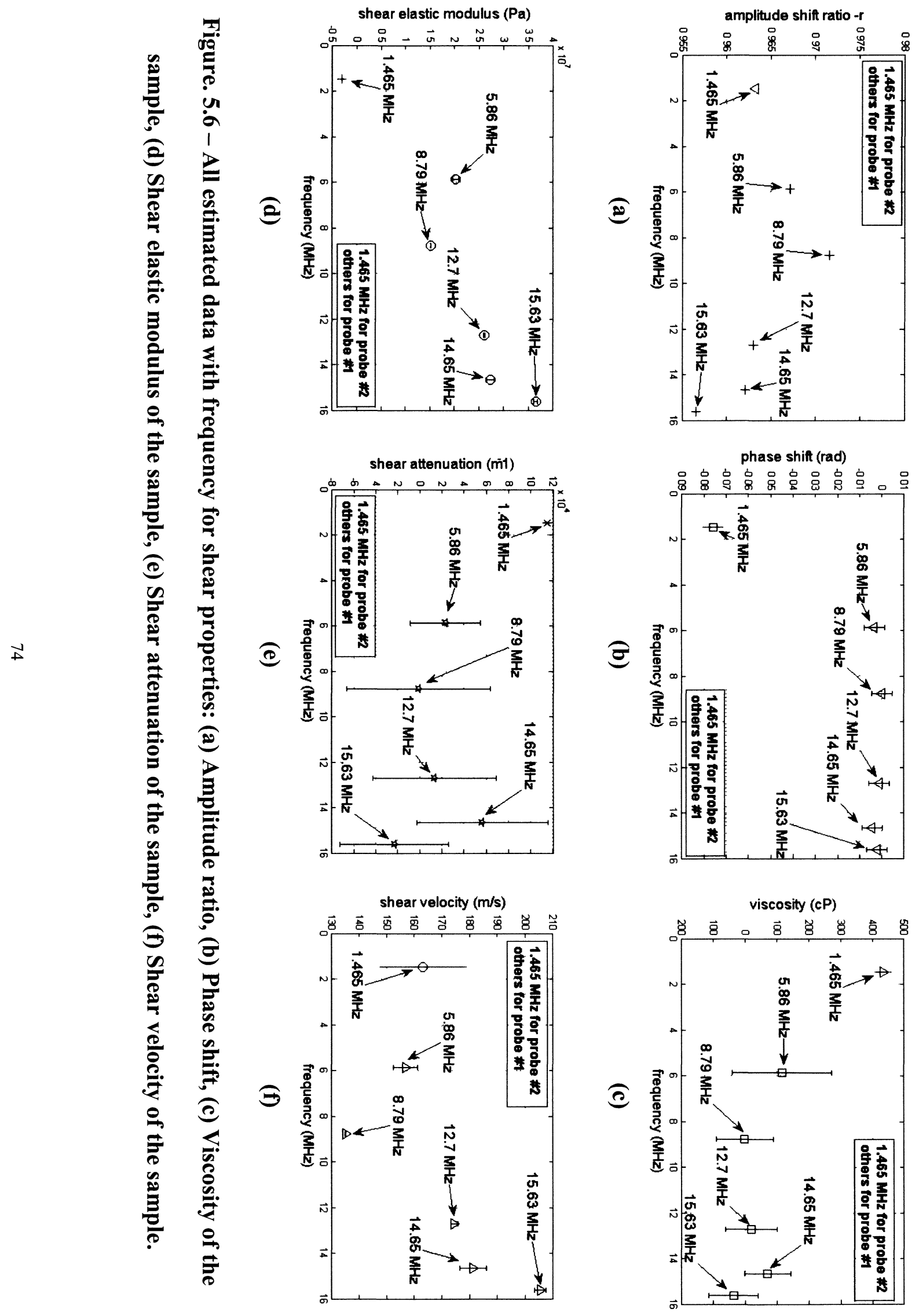




\subsection{Discussion}

(a)

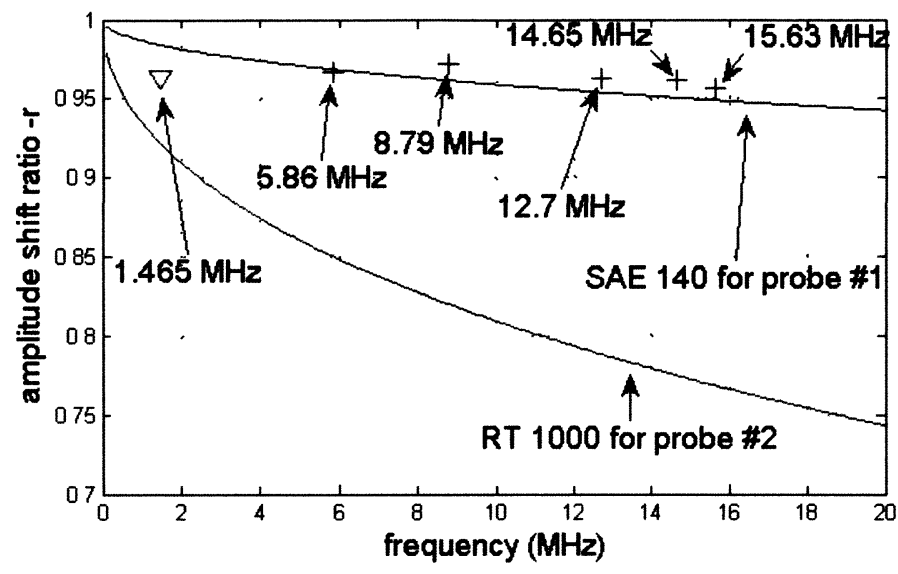

(b)
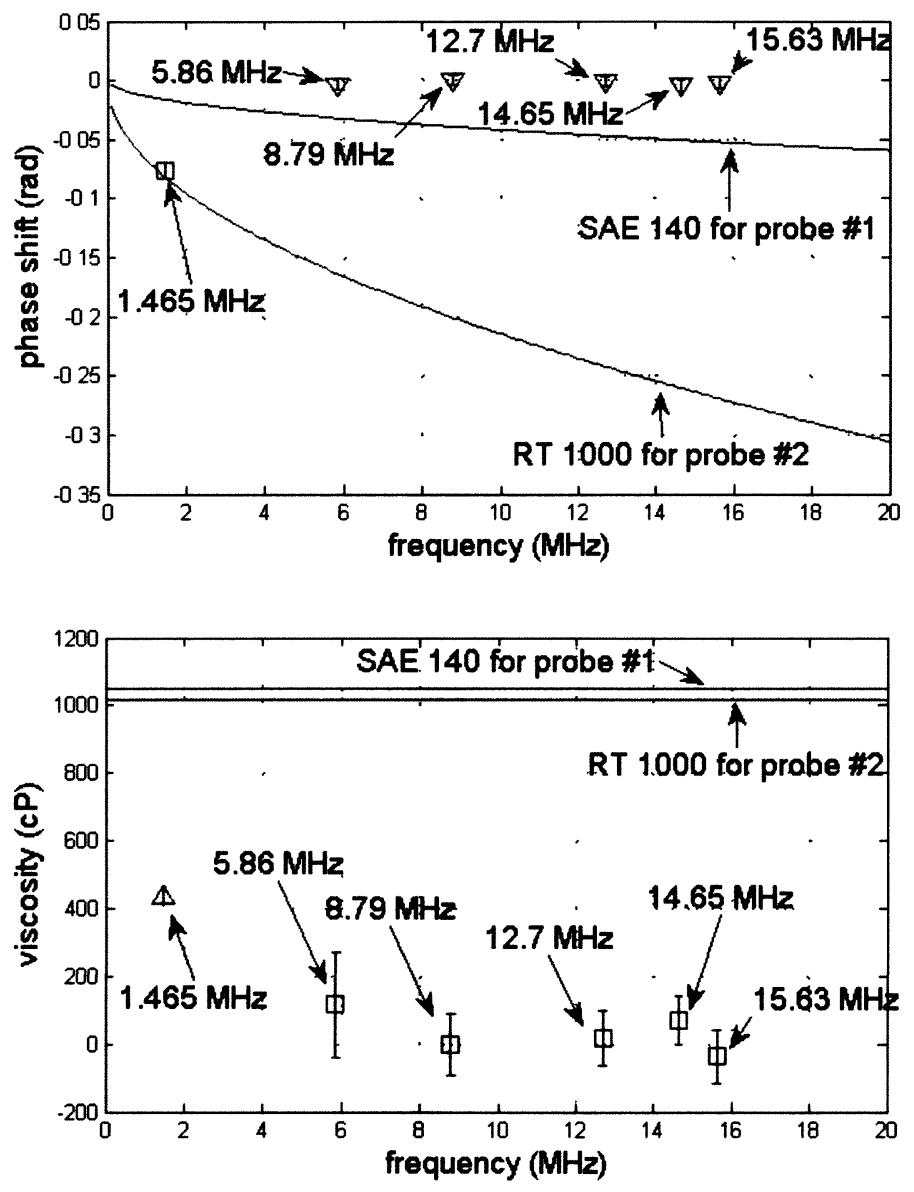

Figure. 5.7 - Comparison between the theoretical and experimental SW Results: (a)

Amplitude ratio - $r_{S}$, (b) Phase shift $-\Delta \phi_{S}$, (c) Viscosity $-\eta$. 
Only results from SW are discussed in this section since there are more parameters that can be estimated from SW measurements than from LW measurement. Figure 5.7 presents the comparison between specific theoretical calculation (Section 5.2) results and experimental results of (a) Ultrasonic frequency vs. Amplitude ratio of SW, (b) Ultrasonic frequency vs. Phase shift of SW, (c) Ultrasonic frequency vs. Viscosity of the samples.

For the experiment with probe $\# 1$ at $12.7 \mathrm{MHz}$, the measured $r_{S}$ and $\Delta \phi_{S}$ for $\mathrm{SW}$ are 0.9631 and $-0.0011 \pm 0.0046$, and the estimated viscosity is $19.45 \pm 81.32 \mathrm{cP}$. The theoretical results are $0.9539,-0.04726 \mathrm{rad}$, and $1050 \mathrm{cP}$ for $r_{S}, \Delta \phi_{S}$ and viscosity, respectively. After implementing the temperature compensation method in the experiment with probe \#1, the amplitude shift measurement with this system has a small deviation, which is less than $1.3 \%$ (absolute value) for all situations compared to the theoretical results. However, for the phase shift measurement, the deviation is very large and deviates from the theoretical results by $97 \%$ (absolute value) on average. Hence the measured viscosity is deviating from its literature value. Detailed data at each frequency component is listed in Table 5.10. 
Table. 5.10 - Comparison between the theoretical and experimental SW Results of $r_{s}, \Delta \phi_{S}$, and $\eta$.

\begin{tabular}{|c|c|c|c|c|c|c|}
\hline \multicolumn{7}{|c|}{ Note: Deviation $=($ Experimental value - Theoretical Value $) /$ Theoretical Value } \\
\hline & \multicolumn{5}{|c|}{ Probe \#1 } & \multirow{3}{*}{$\begin{array}{c}\text { Probe \#2 } \\
1.465 \\
\mathrm{MHz}\end{array}$} \\
\hline Frequency & 5.86 & 8.79 & 12.7 & 14.65 & 15.63 & \\
\hline component & $\mathrm{MHz}$ & $\mathrm{MHz}$ & $\mathrm{MHz}$ & $\mathrm{MHz}$ & $\mathrm{MHz}$ & \\
\hline $\begin{array}{c}\text { Theoretical } \\
r_{S}\end{array}$ & 0.9684 & 0.9615 & 0.9539 & 0.9505 & 0.9490 & 0.9217 \\
\hline $\begin{array}{c}\text { Experimental } \\
r_{S}\end{array}$ & 0.9672 & 0.9716 & 0.9631 & 0.9621 & 0.9566 & 0.9632 \\
\hline Deviation & $-0.12 \%$ & $1.05 \%$ & $0.96 \%$ & $1.22 \%$ & $0.80 \%$ & $4.50 \%$ \\
\hline $\begin{array}{l}\text { Theoretical } \\
\Delta \phi_{S}(\mathrm{rad})\end{array}$ & -0.0321 & -0.0393 & -0.0473 & -0.0508 & -0.0524 & -0.0817 \\
\hline $\begin{array}{c}\text { Experimental } \\
\Delta \phi_{S}(\mathrm{rad})\end{array}$ & $\begin{array}{c}-0.0034 \pm \\
0.0046\end{array}$ & $\begin{array}{c}0.0001 \pm \\
0.0046\end{array}$ & $\begin{array}{c}-0.0011 \pm \\
0.0046\end{array}$ & $\begin{array}{c}-0.0044 \pm \\
0.0046\end{array}$ & $\begin{array}{c}0.0022 \pm \\
0.0046\end{array}$ & $\begin{array}{c}-0.0760 \\
\pm 0.0046\end{array}$ \\
\hline Deviation & $\begin{array}{c}-103.74 \% \\
\text { to } \\
-75.08 \%\end{array}$ & $\begin{array}{c}-111.96 \% \\
\text { to } \\
-88.55 \%\end{array}$ & $\begin{array}{c}-106.89 \% \\
\text { to } \\
-92.60 \%\end{array}$ & $\begin{array}{c}-100.39 \% \\
\text { to } \\
-82.28 \%\end{array}$ & $\begin{array}{c}-112.98 \% \\
\text { to } \\
-95.42 \%\end{array}$ & $\begin{array}{c}-12.61 \% \\
\text { to } \\
-1.35 \%\end{array}$ \\
\hline $\begin{array}{c}\text { Theoretical } \eta \\
\text { (cP) }\end{array}$ & 1050 & 1050 & 1050 & 1050 & 1050 & 1014 \\
\hline $\begin{array}{c}\text { Experimental } \\
\eta(\mathrm{cP})\end{array}$ & $\begin{array}{c}115.55 \pm \\
156.33\end{array}$ & $\begin{array}{c}-1.96 \pm \\
90.05\end{array}$ & $\begin{array}{c}19.45 \pm \\
81.32\end{array}$ & $\begin{array}{c}69.29 \pm \\
72.44\end{array}$ & $\begin{array}{c}-37.29 \pm \\
77.96\end{array}$ & $\begin{array}{c}434.8 \pm \\
26.4\end{array}$ \\
\hline Deviation & $\begin{array}{c}-103.88 \% \\
\text { to } \\
-74.11 \%\end{array}$ & $\begin{array}{c}-108.76 \% \\
\text { to } \\
-91.61 \%\end{array}$ & $\begin{array}{c}-105.89 \% \\
\text { to } \\
-90.40 \%\end{array}$ & $\begin{array}{c}-100.30 \% \\
\text { to } \\
-86.50 \%\end{array}$ & $\begin{array}{c}-110.98 \% \\
\text { to } \\
-96.13 \%\end{array}$ & $\begin{array}{c}-59.72 \% \\
\text { to } \\
-54.52 \%\end{array}$ \\
\hline
\end{tabular}

Ideally, the temperature compensation method can compensate the phase changes due to the change of temperature. However, as shown in this table, results are not as 
expected. A possible reason is that the measured phase temperature coefficient of the probe is not precise enough: one or both of $\beta_{L}$ and $\beta_{S}$ may be imprecise. In addition, since the temperature change leads to both the velocity and attenuation changes in the substrate as well, the temperature coefficient of phase between conditions in which the probe is connected and disconnected to the sample may not be exactly the same. For further research in future, a more precise coefficient is required for measurement in order to increase the practicality and accuracy of the temperature compensation method.

The results of the experiment with probe \#2 are better than those of the experiment with probe $\# 1$. The substrate made of Plexiglas has higher sensitivity for viscosity measurement than $\mathrm{Al}$. The experiment with probe \#2 shows a larger phase shift. Since the SW phase change cannot be compensated in this probe, the temperature issue may have affected the accuracy in this experiment. In future research, LW and SW probe made of Plexiglas will be designed and developed so that the temperature compensation method will be applied in order to improve the measurement accuracy.

For all of the theoretical calculations, it is assumed that the test sample is pure viscous liquid $[9,32]$ to investigate the performance of the ultrasound probe. Therefore the shear elastic modulus is assumed to be 0 in that situation. However, since real gear oil cannot be perfectly Newtonian, the real quantities $G^{\prime}, v_{S}$, and $\alpha$ should always exist. These parameters can be estimated from equations (29), (32), and (33).

In the experiment with probe $\# 1$, the $v_{L_{-} s p}$ is measured as $1527.3 \mathrm{~m} / \mathrm{s}$ by analysing the LW amplitude shift, and this value yields the bulk modulus for gear oil SAE 140, which is $2.097 \times 10^{9} \mathrm{~Pa}$. 
Again, the purpose of conducting the experiments presented in this thesis is to investigate the measurement sensitivity of the probe and to test the measurement system's performance. Tissue or tissue-like material characterization of both viscosity and elasticity will be investigated in future research, after reinforcement of the stability of the measurement system and the development of all optimized probe. 


\section{Chapter 6: Conclusions and Future Work}

In this chapter, an overall review and conclusion of the research will be presented. Further research work will be discussed in the last section.

\subsection{Overall Conclusions}

This thesis presents a preliminary study of an ultrasound measurement system developed for tissue or tissue-like material viscoelastic characterization. The parameters of viscoelastic properties of the tested samples have been estimated. The research focused on theoretical simulation and the development of the measurement system. In addition, a temperature compensation method which can improve the viscosity measurement sensitivity has been proposed.

It has been found that temperature change and electrical noise may generate errors and the main issue affecting the measurement accuracy is temperature instability $[1,2]$. Environmental temperature fluctuation is $0.1{ }^{\circ} \mathrm{C}$ with the presented measurement conditions. The ultrasound velocity, attenuation in the substrate of the ultrasound probe and the viscoelastic properties of the sample will change with temperature. Due to the temperature instability, the accuracy of amplitude and phase measurement is affected. Therefore, there is a $0.012 \mathrm{rad}$ for $\mathrm{LW}$ and $0.032 \mathrm{rad}$ for SW fluctuations in this system under current conditions. 
A theoretical calculation for the probe design is presented in Chapter 3. The result shows that polymer substrates such as Plexiglas and polyimide have better measurement sensitivity for tissue viscosity than metallic substrates due to their low acoustic impedance; this results from the better impedance matching with a fluid sample [7, 8, 41]. Probe \#1, made of Al has high acoustic impedance therefore such substrate has low measurement sensitivity. Probe \#2 made of Plexiglas shows better measurement sensitivity. In addition, the design of a probe which can generate LW and SW simultaneously is feasible for future research on tissue viscoelastic characterization.

\subsection{Evaluation of the Measurement System and Experimental Results}

The design and construction for each part of the system for tissue viscoelastic measurement is almost finished. However, there are several issues which limit the performance of the system. They are the following:

Recalling Chapter 4, the resolution of the current system is limited, at $0.0793 \mathrm{rad}$ for the phase measurement when there is no temperature fluctuation, and it is still limits the sensitivity of the viscoelasticity measurement. Currently, the highest frame rate of data acquisition is $10 \mathrm{~Hz}$. A moving average of 100 points method can improve the system resolution by removing random noise from the measurement signals. Therefore, at a $10 \mathrm{~Hz}$ frame rate, the signal information for each continuous 10 seconds is averaged into a mean value, and it is presented as the middle moment of this 10 seconds. If the frame rate increases to $100 \mathrm{~Hz}$, then the program may average every continuous 1000 data within 10 seconds to a mean value, which may increase the measurement sensitivity. 
The environment of the experiment has a $0.1{ }^{\circ} \mathrm{C}$ temperature fluctuation at present, which leads to $0.012 \mathrm{rad}$ for $\mathrm{LW}$ and $0.032 \mathrm{rad}$ for $\mathrm{SW}$ fluctuations. In addition, there is a temperature difference between the probe and sample. When the sample is attached to the probe, the temperature difference leads to thermal transmission from a high temperature to low temperature. Therefore, this may cause an unpredictable phase change since the temperature measurement is not conducted at present. These values resulting from temperature instability can be reduced by the temperature compensation method with a high sensitive system.

In this thesis, an ultrasound probe is designed for the implementation of viscoelasticity measurement. Two types of probes are used for the experiments to investigate the system performance. Probe \#2 uses Plexiglas as substrate thus the viscosity measurement sensitivity is high compared with probe \#1 using $\mathrm{Al}$ as substrate at the current measurement system.

The results of the experiment compared with the theoretical calculation, present a deviation. For the experiment with probe \#1, the temperature compensation method has been implemented. The sample viscosity is $1050 \mathrm{cP}$ and the experiment yields the result of viscosity $19.45 \pm 81.32 \mathrm{cP}$, which is less than one tenth. For the experiment with probe \#2, the sample viscosity is $1014 \mathrm{cP}$ and the experiment result is $434.8 \pm 26.4 \mathrm{cP}$, which is less than one half. The experiment has better measurement accuracy with the probe $\# 2$ as predicted in the theoretical investigation of the probe substrate material. 


\subsection{Future Research}

An ultrasound probe that can generate LW and SW simultaneously will be produced with a polyimide or Plexiglas substrate. The research and experiments for characterizing the tissue viscosity and elasticity are planned to be implemented with these probes. To increase the accuracy of the results, a temperature-controlled bath is implemented to keep the temperature more constant.

A temperature-controlled bath system is under construction to prevent the external air flow and control the measurement temperature. The design for the bath is shown in Figure 6.1:
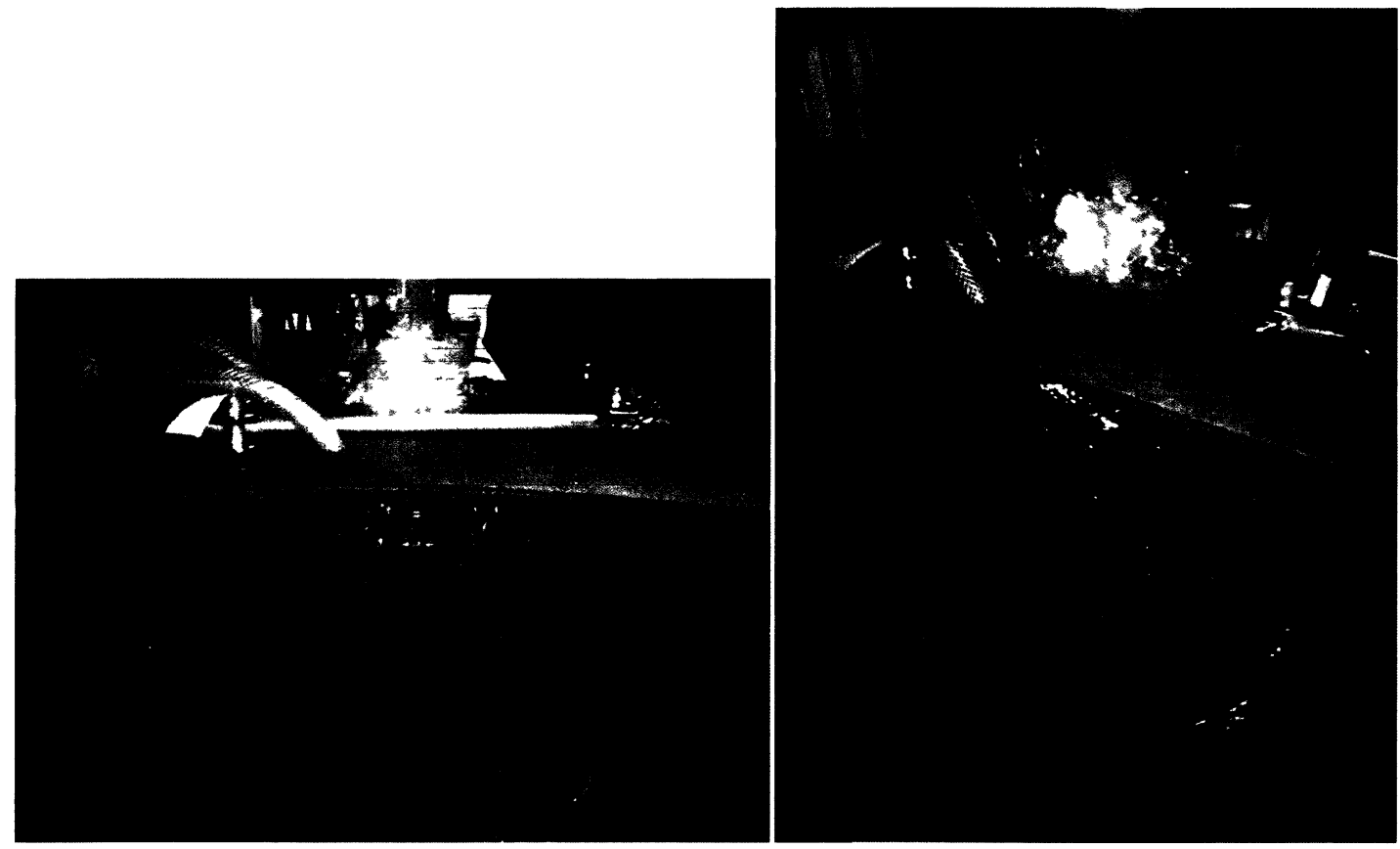

Figure. 6.1 - Basic temperature-controlled bath design.

In addition, by combining with the temperature controller RTE-7 D+ 115/60, further research to investigate the viscoelasticity temperature dependency of tissue or 
tissue-like materials can be implemented. A long term observation of the change of the sample viscoelasticity in the desired temperature range can be implemented.

Finally, the new substrate which follows the design in Chapter 3 has just been produced recently. Since this thesis was already finished, it has been omitted. One product is shown in Figure 6.2. Testing of this probe is planned in the near future.

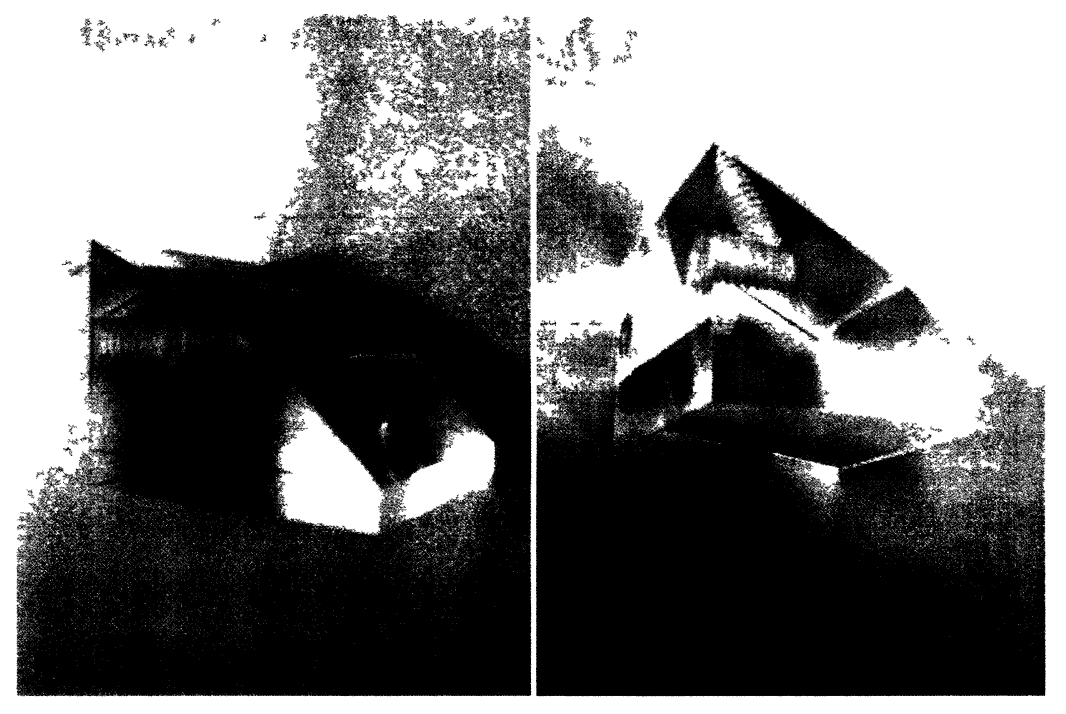

Figure. 6.2 - Plexiglas substrate with two angles shaped design.

In addition, flexible UTs are now designed and produced by several research groups [41-45]. Due to the limited size of the new Plexiglas substrate, a small, flexible UT may be more suitable for the research. More studies on this kind of UT will be carried out in future research. 


\section{Appendix}

Data sheet of RT 1,000 from CANNON Instrument Company (scanned images):

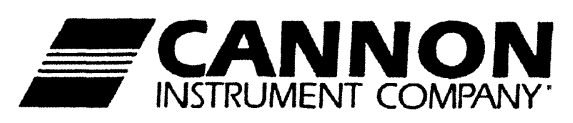

\section{CERTIFICATE OF ANALYSIS}

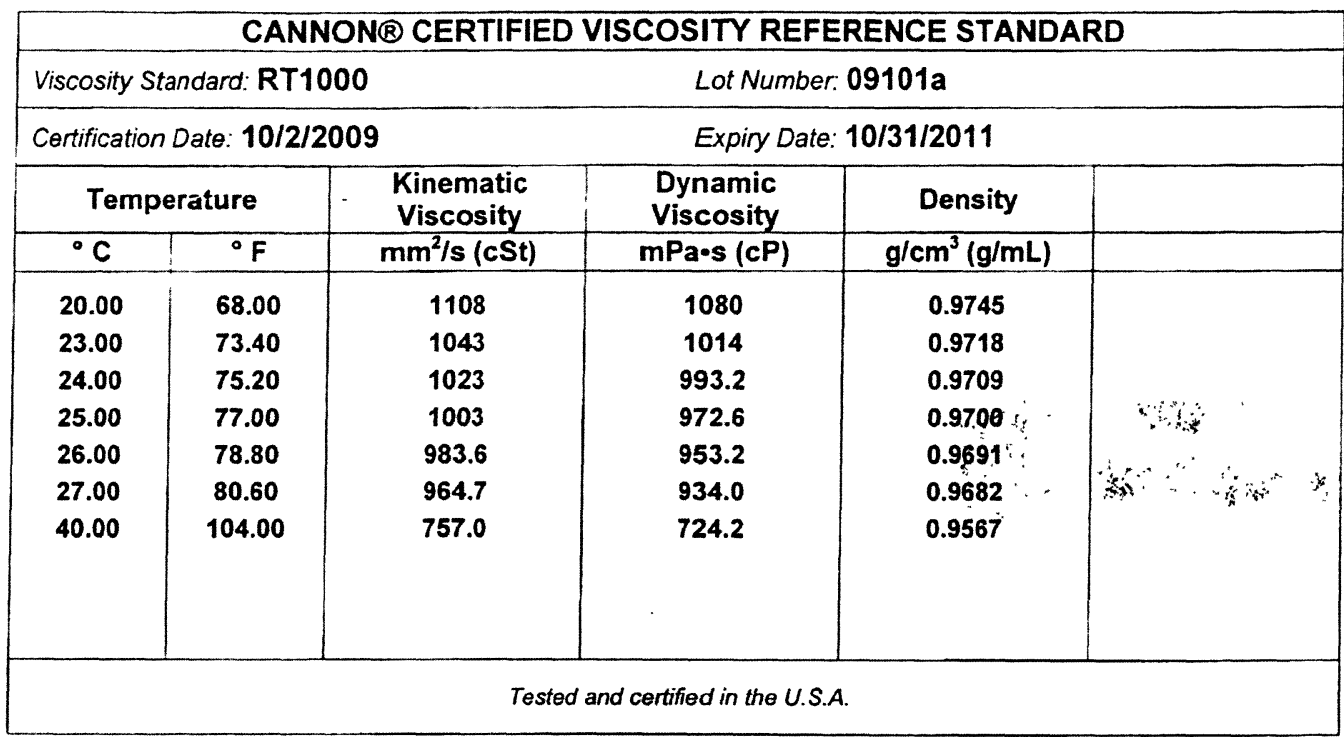

This Certificate of Analysis shall not be reproduced, except in full, without the written approval of CANNON Instrument Company.

\section{USAGE INFORMATION'}

Intended Use and Instructions: This CANNONB Certified Viscosity Reference Standard is intended for but not restricted to the calibration and performance verification of various types of viscometers or density measurement equipment. Consult user's manual and test methods specific to your equipment for operating instructions and procedures.

Storage and Handling: This CANNONO Certified Viscosity Reference Standard should be stored in the original container with the lid tightly closed, away from direct light, and at ambient temperatures and normal laboratory conditions. The standard is homogeneous and mixing is unnecessary before use.

Composition and Product Safety: This CANNON® Certified Viscosity Reference Standard is composed of: Silicone (100\%) [CAS\#(s) 63148-62-9]. Consult MSDS for complete product safety information.

Expiration of Certification: The certification of this CANNON® Certified Viscosity Reference Standard is valid, within the stated measurement uncertainty, until the expiry date that appears on this certificate, provided the material is stored and handled as stated. This certification is deemed null and void if the standard is modified or contaminated. The shelf life was determined empirically through a historical evaluation of material stability. If substantive technical changes occur to the product which affects the certification before the expiry date, CANNON Instrument Company will contact the purchaser.

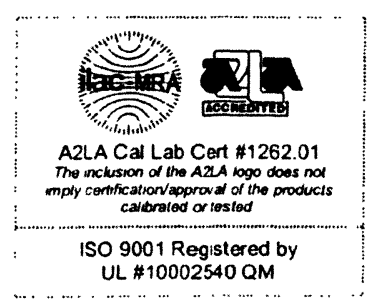

CIC GP Std Data Grid

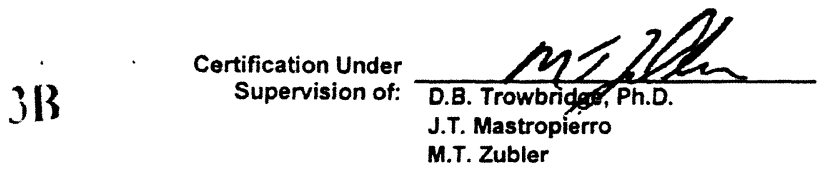

Page 1 of 2

02009 


\section{DISCUSSION OF DATA'}

Derivation of Certified Values: CANNON Instrument Company certifies that the kınematic viscosities were determıned by the Master Viscometer technique reported in the Journal of Research of the National Bureau of Standards, (Vol 52. No 3, March 1954 Research Paper 2479) using CANNON@ Laboratory Standard viscometers All temperature measurements were conducted according to The International Temperature Scale of 1990 (ITS-90) using SPRTs with fixed point calibrations The provided viscosity data are based upon the primary standard water at $20^{\circ} \mathrm{C}$, with a kınematic viscosity of $10034 \mathrm{~mm} / \mathrm{s}$ and an assigned accuracy of $\pm 017 \%$ as per ISO 3666 See also ASTM methods D2162 D445, D446 D2161 and ISO methods 3104 and 3105

Kınematic viscosity $(v)$ measurements in $\mathrm{mm}^{2} / \mathrm{s}$ at temperatures of 20,25 , and $40{ }^{\circ} \mathrm{C}$, and other temperatures as appropriate, were generally made using Cannon-Ubbelohde Laboratory Standard viscometers, as described in ASTM methods D445 and D446

Density $(\rho)$ in $\mathrm{g} / \mathrm{cm}^{3}$ ( $\mathrm{g} / \mathrm{mL}$ ) was generally determıned through measurement in an oscillatıng U-tube digital density meter or modified Bingham pycnometer See ASTM methods D4052, D1480, and D1217

Dynamic viscosity ( $\eta$ ) in $\mathrm{mPa}$-s was generally determined by measuring the kınematıc viscosity and multiplyıng it by the density at the same temperature $[\eta-v \cdot p]$

Where appropriate, the kınematic viscosity dynamic viscosity, or density at certain temperatures was determined through regression of all measured data using industry standard equations These equations include the linear or quadratic viscosity/density-temperature equation denved from the ASTM viscosity-temperature charts for petroleum products as well as the NBS viscosity-temperature equation for petroleum products See ASTM method D341 and NBS equation

Traceability. All data are traceable to intrinsic standards and National Institute of Standards and Technology (NIST) calibration or calculated by ASTM or NIST methods KInematic viscosity values are traceable to the viscosity of water Temperature measurements were conducted with SPRTs that have NIST traceable fixed-point calibrations A complete traceability statement is available for purchase from CANNON Instrument Company

Measurement Uncertainty: CANNON Instrument Company has determined and reported the measurement uncertainty of its laboratory capabilities The expanded uncertainties of the laboratory measurements summanzed at the $95 \%$ confidence interval are as follows

Kinematic Viscosity $\left(-40^{\circ} \mathrm{C}\right.$ to $\left.+150^{\circ} \mathrm{C}\right)$

\begin{tabular}{|c|c|c|c|}
\hline \multirow{2}{*}{$\begin{array}{l}\text { Range of Kinematic Viscosity } \\
\left(\mathrm{mm}^{2} / \mathrm{s}\right)\end{array}$} & \multicolumn{3}{|c|}{ Expanded Uncertainty $(\%)$ at Temperatures: } \\
\hline & $<15^{\circ} \mathrm{C}$ & 15 to $45^{\circ} \mathrm{C}$ & $>45^{\circ} \mathrm{C}$ \\
\hline$<10$ & 021 & 016 & 021 \\
\hline $10-100$ & 026 & 022 & 026 \\
\hline $100-1000$ & 032 & 029 & 032 \\
\hline $1000-10,000$ & 047 & 038 & 038 \\
\hline $10000-100000$ & 053 & 044 & 048 \\
\hline
\end{tabular}

Density $\left(-56^{\circ} \mathrm{C}\right.$ to $\left.+150^{\circ} \mathrm{C}\right)$

\begin{tabular}{|c|c|}
\hline $\begin{array}{c}\text { Range of Density } \\
\left(\mathrm{g} / \mathrm{cm}^{3}\right)\end{array}$ & $\begin{array}{c}\text { Expanded Uncertainty" } \\
\left(\mathbf{k g} / \mathrm{m}^{3}\right)\end{array}$ \\
\hline $07-12$ & 005 \\
\hline * An expanded uncertainty $U$ is determined by multiplying the combined standard uncertainty $u_{c}$ by a coverage factor $k U=k u_{c}$ where $k=2$
\end{tabular}

See NIST Technical Note 1297, 1994 edition Guidelines for Evaluating and Expressing the Uncertainty of NIST Measurement Results

\begin{tabular}{|c|ll|}
\hline $\begin{array}{c}\text { CANNON Instrument Company } \\
2139 \text { High Tech Road }\end{array}$ & Laboratory Technical Director & D B Trowbridge Ph D \\
State College PA 16803 USA & Deputy Laboratory Technical Director & JT Mastropierro \\
$8143538000 \cdot 800676-6232 \cdot$ FAX $814353-8007$ & Director of Quality Assurance & M T Zubler \\
\hline
\end{tabular}

'Consult www cannoninstrument com for additional information

Page 2 of 2 


\section{References}

[1] Lakes, R. S., "Viscoelastic Measurement Techniques," Review of Scientific Instruments, vol. 75, No. 4, Apr, 2004.

[2] Ono, Y., and Jen, C. K., "Ultrasonic Sensor, Method and System for Measuring Shear Wave Properties and Temperature of Viscoelastic Fluids," Proc. 16th World Conference on Nondestructive Testing, Paper No. WP15, pp. 1-8, 2004.

[3] Ono, Y., Jen, C. K., and Kobayashi, M., "High Temperature Integrated Ultrasonic Shear and Longitudinal Wave Probes," Review of Scientific Instruments, vol. 78, No. 2, 2007.

[4] Cheeke, J. D. N., Fundamentals and Applications of Ultrasonic Wave, USA: CRC Press LLC, 2002.

[5] Sarvazyan, A., Skovoroda, A., and Emelianov, S., "Biophysical Bases of Elasticity Imaging,” Acoustical Imaging, vol. 21, pp. 223-240, 1995.

[6] Halliday, Resnick, and Walker, Fundamentals of Physic. 5th edition, New York: Wiley, ch.17, 1997.

[7] Reeder, T. M., and Winslow, D. K., "Characteristics of Microwave Acoustic Transducers for Volume Wave Excitation," IEEE Transactions on Microwave Theory and Techniques, vol. MTT-17, No. 11, pp. 927-941, Nov, 1969.

[8] Callens, D., Bruneel, C., and Assaad, J., "Matching Ultrasonic Transducer Using Two Matching Layers Where One of Them is Glue," NDT\&E International, vol. 37 pp. 591-596, 2004. 
[9] Sheen, S. H., Chien, H. T., and Raptis, A. C., "Measurement of Shear Impedances of Viscoelastic Fluids," IEEE Ultrasonics Symposium, pp. 453-457, 1996.

[10] Kulmyrzaev, A., McClements, D. J., "High Frequency Dynamic Shear Rheology of Honey," Journal of Food Engineering, vol. 45, pp. 219-224, 2000.

[11] Gosling, R., "Medical Imaging with Ultrasound: Some Basic Physics," Physics Education, vol. 24, 1989, pp. 215-221.

[12] Buiochi, F., Franco, E. E., Higuti, R. T., and Adamowski, J. C., "Viscosity Measuring Cell Using Ultrasonic Wave Mode Conversion," Ferroelectrics, vol. 333, pp. 139-149, 2006.

[13] Meyers and Chawla. Mechanical Behavior of Materials, USA: Prentice Hall, 1999.

[14] Viswanath, D. S., Ghosh, T. K., Prasad, D. H. L., Dutt, N. V. K., and Rani, K. Y., Viscosity of Liquids: Theory, Estimation, Experiment, and Data, Dordrecht: Springer, ch.1-2, 2007.

[15] Darby, R., Chemical Engineering Fluid Mechanics, 2nd edition, USA: CRC Press, ch.3, Jan, 2001.

[16] Madsen, E. L., Sathoff, H. J., and Zagzebski, J. A., "Ultrasonic Shear Wave Properties of Soft Tissues and Tissue-Like Materials," Journal of Acoustical Society of America, vol. 74, No. 5, pp. 1346-1355, 1983.

[17] Andreev, V. G., and Burlakova, T. A., "Measurement of Shear Elasticity and Viscosity of Rubberlike Materials," Acoustical Physics, vol. 53 No. 1, pp. 44-47, 2007.

[18] Kobayashi, K., Akashi, N., Kushibiki, J., and Dunn, F., "Measurement Method and System for Determining Acoustic Shear Wave Properties of Liquids by the Shear Reflectance Method Using a Network Analyzer," IM-96-89, 1996. 
[19] Dixon, S., and Lanyon, B., "Phase Change Measurement of Ultrasonic Shear Waves on Reflection from a Curing Epoxy System," Journal of Physics D: Applied Physics, vol. 38, pp. 4115-4125, 2005.

[20] Mason, W. P., Baker, W. O., McSkimin, H. J., and Heiss, J. H., "Measurement of shear elasticity and viscosity of liquids at ultrasonic frequencies," Physical Review, vol. 75, pp. 936-946, 1949.

[21] Desilets, C. S., Fraser, J. D., and Kino, G. S., "The Design of Efficient BroadBand Piezoelectric Transducers," IEEE Transactions on Sonics and Ultrasonics, vol. SU-25, No. 3, pp. 115-125, Nov, 1978.

[22] Sridhar, M., Liu, J., and Insana, M. F., "Elasticity Imaging of Polymeric Media," Journal of Biomechanical Engineering, vol. 129, pp. 259-272, Apr, 2007.

[23] Vappou, J., Maleke, C., and Konofagou, E. E., "Quantitative Viscoelastic Parameters Measured by Harmonic Motion Imaging," Physics in Medicine and Biology, vol. 54, pp. 3579-3594, 2009.

[24] Greenwood, M. S., and Bamberger, J. A., "Measurement of Viscosity and Shear Wave Velocity of a Liquid or Slurry for On-line Process Control," Ultrasonics, vol. 39, pp. 623-630, 2002.

[25] Catheline, S., Gennisson, J. L., Delon, G., Fink, M., Sinkus, R., Abouelkaram, S., and Culioli, J., "Measurement of Viscoelastic Properties of Homogeneous Soft Solid Using Transient Elastography: An Inverse Problem Approach," Acoustical Society of America, vol. 116, No. 6, pp. 3734-3741, Dec, 2004.

[26] Eskandari, H., Salcudean, S., and Rohling, R., "Viscoelastic Parameter Estimation Based on Spectral Analysis," IEEE Transactions on Ultrasonics, Ferroelectrics, and Frequency Control, vol. 55, No. 7, pp. 1611-1625, Jul, 2008.

[27] Baghani, A., Eskandari, H., Salcudean, S., and Rohling, R., "Measurement of Viscoelastic Properties of Tissue-Mimicking Material Using Longitudinal Wave 
Excitation," IEEE Transactions on Ultrasonics, Ferroelectrics, and Frequency Control, vol. 56, No. 7, pp. 1405-1418, Jul, 2009.

[28] Szabo, T. L., and Wu, J., "A Model for Longitudinal and Shear Wave Propagation in Viscoelastic Media," Acoustical Society of America, vol. 107, No. 5, pp. 2437-2446, May, 2000.

[29] Sinkus, R., Bercoff, J., Tanter, M., Gennisson, J., Khoury, C. E., Servois, V., Tardivon, A., and Fink, M., "Nonlinear Viscoelastic Properties of Tissue Assessed by Ultrasound," IEEE Transactions on Ultrasonics, Ferroelectrics, and Frequency Control, vol. 53, No. 11, pp. 2009-2018, 2006.

[30] Vives, A.A., Piezoelectric Transducers and Applications, New York: Springer, ch.17, 2008, pp. 444-449.

[31] Buiochi, F., Adamowski, J. C., and Furukawa, C. M., "Measurement of Viscosity Using Wave Mode Conversion," IEEE Ultrasonics Symposium, pp. 1196-1198, 1998.

[32] Franco, E. E., Adamowski, J. C., Higuti, R. T., and Buiochi, F., "Viscosity Measurement of Newtonian Liquids Using the Complex Reflection Coefficient," IEEE Transactions on Ultrasonics, Ferroelectrics, and Frequency Control, vol. 55, pp. 2247-2253, 2008.

[33] Franco, E. E., Adamowski, J. C., Higuti, R. T., and Buiochi F., "Ultrasonic Viscosity Measurement Using the Shear-Wave Reflection Coefficient with a Novel Signal Processing Technique," IEEE Transactions on Ultrasonics, Ferroelectrics, and Frequency Control, vol. 57, No. 5, pp. 1133-1139, May, 2010.

[34] Yang, X., and Church, C. C., "A simple Viscoelastic Model for Soft Tissues in the Frequency Range 6-20 MHz," IEEE Transactions on Ultrasonics, Ferroelectrics, and Frequency Control, vol. 53, No. 8, pp. 1404-1411, 2006.

[35] Roylance, D., Engineering Viscoelasticity, USA: MIT, October 24, 2001. 
[36] Shah, V., and Balasubramaniam, K., "Effect of Viscosity on Ultrasound Wave Reflection from a Solid/Liquid Interface," Ultrasonics, vol. 34, pp. 817-824, 1996.

[37] Goll, J. H., "The Design of Broad-Band Fluid-Loaded Ultrasonic Transducers," IEEE Transactions on Sonics and Ultrasonics, vol. SU-26, No. 6, pp. 385-393, Nov, 1979.

[38] Christman, D. R., "Dynamic Properties of Poly (Methylmethacrylate) (PMMA) (Plexiglas)," National Technical Information Service, 1972.

[39] Balasubramaniam, K., Shah, V. V., Costley, R. D., Boudreaux, G., and Singh, J.P., "High Temperature Ultrasonic Sensor for the Simultaneous Measurement of Viscosity and Temperature of Melts," Review of Scientific Instruments, vol. 70, No. 12, Dec, 1999.

[40] Crandall, Dahl, and Lardner, An Introduction to the Mechanics of Solids, USA: McGraw-Hill, 1959.

[41] Kimura, K., Yoneya, K., and Ohigashi, H., "A Wide-Band Polymer Ultrasonic Transducer Using Acoustic Impedance Matching Technique," Japanese Journal of Applied Physics, vol. 27, No. 4, pp. 547-551, Apr, 1988.

[42] Marechal, P., Levassort, Holc, F., Tran-Huu-Hue J. L., Kosec, M., and Lethiecq, M., "High-Frequency Transducers Based on Integrated Piezoelectric Thick Films for Medical Imaging," IEEE Transactions on Ultrasonics, Ferroelectrics, and Frequency Control, vol. 53 , No. 8, pp. 1524-1533, Aug, 2006.

[43] Jen, C. K., and Kobayashi, M., "Integrated and Flexible Piezoelectric Ultrasonic Transducers," IEEE Ultrasonics Symposium, pp. 1119-1127, 2006.

[44] Kobayashi, M., and Jen, C. K., "Flexible Ultrasonic Transducers," IEEE Transactions on Ultrasonics, Ferroelectrics, and Frequency Control, vol. 53, No. 8, pp. 1478-1486, Aug, 2008. 
[45] Kimura, K., and Ohigashi, H., "Analysis of Impulse Response Characteristics of Polymer Ultrasonic Transducers," Japanese Journal of Applied Physics, vol. 27, No. 4, pp. 540-546, Apr, 1988. 